\title{
Caracterización de nuevos aislados de Drechslera tritici-repentis y su efecto sobre el comportamiento de cultivares de trigo
}

Tesis presentada para optar al título de Magister Scientiae de la Facultad de Ciencias Agrarias y Forestales. Universidad Nacional de La Plata

Autor: Ing. Agr. Fernando Ariel Jecke

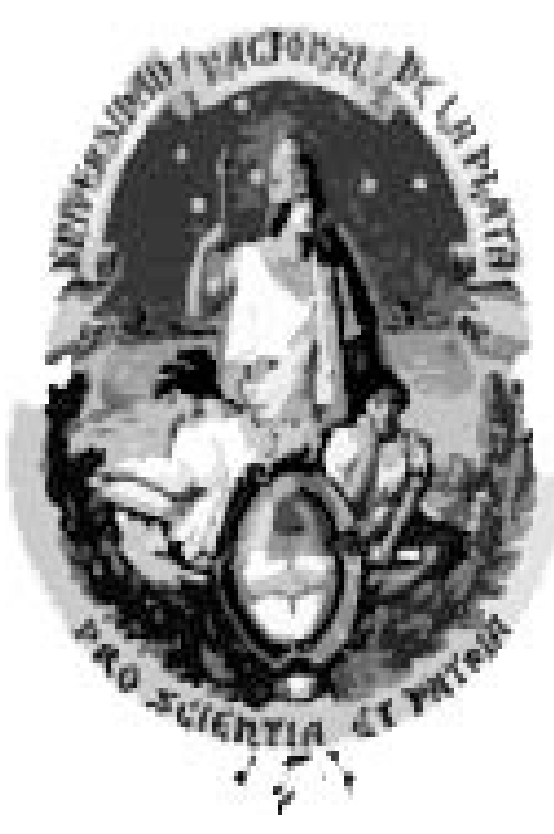

\section{UNIVERSIDAD \\ NACIONAL DE LA PLATA}

Facultad de Ciencias Agrarias y Forestales 
DIRECTORA: Ing. Agr. (MSc., PhD.) María Rosa Simón.

CODIRECTORA: Ing. Agr. (Dra.) Analía Edith Perelló.

TRIBUNAL EVALUADOR:

Lic. (Dr.) Saparrat Mario Carlos Nazareno

Ing. Agr. (Dr.) Antonio Juan Ivancovich

Ing. Agr. (Dra.) Rivera Marta Carolina

FECHA DE DEFENSA DE LA TESIS: 


\section{Agradecimientos:}

Al Ing. Agr. M. Sc. Ignacio Terrile, por su apoyo y colaboración para la realización de esta Tesis.

A la Dra. María Rosa Simón, por su ayuda, enseñanza y apoyo para encarar y llevar a cabo el proyecto.

A la Dra. Analía Edith Perelló, por su colaboración, enseñanza y apoyo para encarar y llevar a cabo el proyecto.

A mi mujer Mónica Viviana Martino, por su colaboración en la toma de datos a campo.

\section{Publicaciones derivadas de la tesis:}

Jecke, F. A., M. R. Simón, M. V. Moreno \& A. E. Perelló. 2014. Razas de Drechslera tritici-repentis y comportamiento de cultivares de trigo frente al patógeno. Seminario Internacional de Trigo en La Estanzuela. Un valioso legado para el futuro 27 al 29 de agosto de 2014, La Estanzuela, Uruguay. pp. 55.

Simón, M.R., M.V. Moreno, F. Jecke, M.C. Fleitas, M. Schierenbeck \& A.E. Perelló. 2014. Avances en resistencia genética a mancha amarilla en trigo en Argentina Seminario International de Trigo en La Estanzuela. Un valioso legado para el futuro 27 al 29 de agosto de 2014, La Estanzuela, Uruguay. Conferencia (trabajo completo). 
INDICE DE TABLAS..........................................................

INDICE DE FIGURAS ........................................................

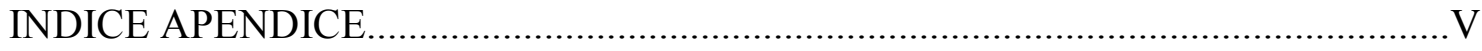

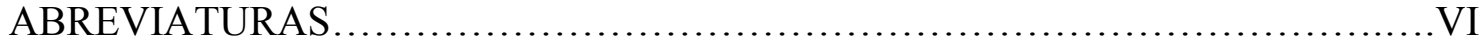

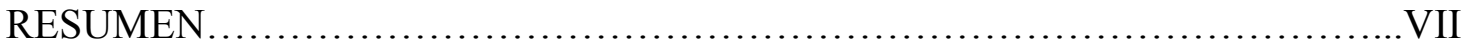

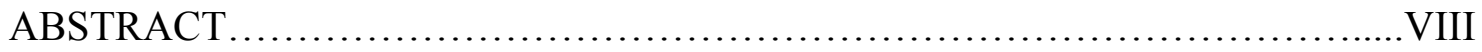

CAPITULO 1: INTRODUCCIÓN..............................................

1.1 Trigo...............................................................

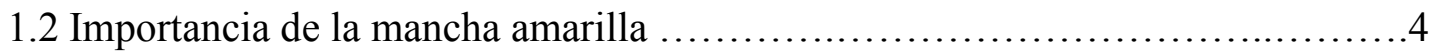

$1.3 \mathrm{El}$ agente causal.................................................... 5

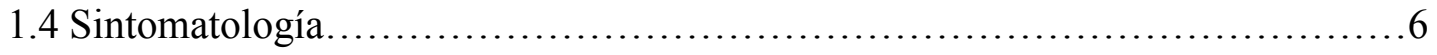

1.5 Ciclo del agente causal de la mancha amarilla...............................6

1.6 Variación Patogénica................................................... 8

1.7 Resistencia Genética................................................... 11

1.8 Hipótesis........................................................ 14

1.9 Objetivos....................................................... 14

CAPITULO 2: MATERIALES Y METODOS................................... 15

2.1 Aislados fúngicos.................................................... 15

2.2 Producción de Inóculo.................................................16

2.3 Caracterización del tipo de reacción en líneas diferenciales de trigo..............17

2.4 Análisis molecular de genes que codifican toxinas en los aislados..............18

2.4.1 Extracción de ADN.................................................. 18

2.4.2 Análisis de los genes Tox $A$ y Tox B por PCR............................. 18

2.5 Caracterización de cultivares argentinos de trigo al estado de plántula frente a la presencia/actividad de los aislados seleccionados de $D$. tritici-repentis en invernáculo..............................................................

2.6 Caracterización de cultivares argentinos de trigo al estado de planta adulta frente a la presencia/actividad de los aislados seleccionados de $D$. tritici-repentis bajo condiciones a campo......................................................21

2.7 Análisis Estadístico..................................................23

CAPITULO 3: RESULTADOS .............................................. 24

3.1 Caracterización del tipo de reacción en líneas diferenciales de trigo............24

3.2 Análisis molecular de genes que codifican toxinas en los aislados estudiados...26 
3.3 Caracterización de cultivares argentinos de trigo al estado de plántula frente a la presencia/actividad de los aislados seleccionados de $D$. tritici-repentis en invernáculo............................................................. 27

3.4 Caracterización de cultivares argentinos de trigo al estado de planta adulta frente a la presencia/actividad de los aislados seleccionados de $\mathrm{D}$. tritici-repentis bajo condiciones a campo..................................................... 31

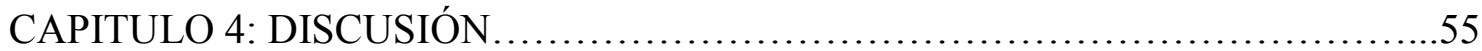

4.1 Caracterización del tipo de reacción en líneas diferenciales de trigo.............55

4.2 Análisis molecular de genes que codifican toxinas en los aislados estudiados...55

4.3 Caracterización de cultivares argentinos de trigo al estado de plántula frente a la presencia/actividad de los aislados seleccionados de $D$. tritici-repentis en invernáculo............................................................57

4.4 Caracterización de cultivares argentinos de trigo al estado de planta adulta frente a la presencia/actividad de los aislados seleccionados de $D$. tritici-repentis bajo condiciones a campo....................................................57

CAPITULO 5: CONCLUSIONES GENERALES $\ldots \ldots \ldots \ldots \ldots \ldots \ldots \ldots \ldots \ldots \ldots \ldots \ldots \ldots$

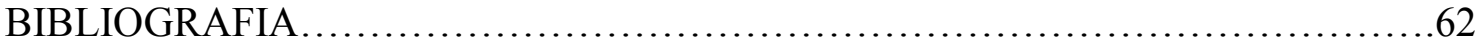

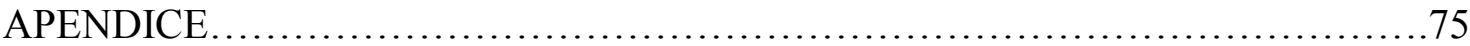




\section{INDICE DE TABLAS}

Tabla 1.1.1. Producción promedio de trigo de los principales 20 países productores (Promedio del periodo 1993-2013) ...................................................2

Tabla 1.1.2. Exportación promedio de trigo de los principales 20 países exportadores (Promedio del período 1991-2011). ..............................................

Tabla 1.1.3. Producción de trigo de Argentina. (Promedio del período 2009-

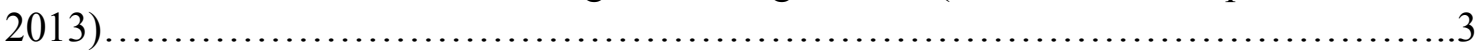

Tabla 1.1.4. Exportación de trigo de Argentina. (Promedio del periodo 20082012).................................................................... 3

Tabla 1.1.5. Superficie cosechada promedio en los últimos 10 años de los principales cultivos en Argentina. ........................................ 3 Tabla 1.1.6. Producción promedio en los últimos 10 años de los principales cultivos en Argentina....................................... Tabla 1.1.7 Estructura de razas de D. tritici-repentis de acuerdo a Andrie et al. (2007)

Tabla 3.1.1. Tipo de reacción de 9 líneas diferenciales de trigo frente a 3 aislados de $D$. tritici-repentis.

Tabla 3.3.1. Cuadrados medios de la severidad y el tipo de reacción (en estado de plántula) en un ensayo de trigo inoculado individualmente con aislados seleccionados de $D$. tritici-repentis en 31 cultivares de trigo.

Tabla 3.3.2. Medias de severidad en un ensayo de trigo inoculado individualmente con aislados seleccionados de $D$. tritici-repentis en 31 cultivares de trigo, evaluadas 14 días posteriores a la inoculación.

Tabla 3.3.3. Medias del tipo de reacción en un ensayo de trigo inoculado individualmente con aislados de $D$. tritici-repentis en 31 cultivares de trigo, evaluadas 14 días posteriores a la inoculación. .29

Tabla 3.4.1. Cuadrados medios de la severidad en tres momentos de evaluación (EC 37, EC 75 y EC 82) en un ensayo de trigo inoculado individualmente con tres aislados de $D$. tritici-repentis, en dos localidades y en 31 cultivares de trigo........................ 31

Tabla 3.4.2. Medias de severidad en un ensayo de trigo inoculado individualmente con aislados seleccionados de $D$. tritici-repentis, en dos localidades y 31 cultivares de trigo, evaluadas en el estadio EC 37.

Tabla 3.4.3. Medias de severidad en un ensayo de trigo inoculado individualmente con aislados seleccionados de $D$. tritici-repentis, en dos localidades y 31 cultivares de trigo,

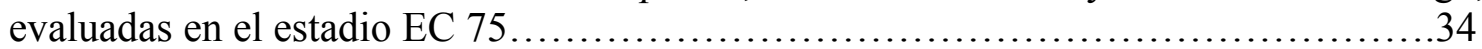
Tabla 3.4.4 Medias de severidad en un ensayo de trigo inoculado individualmente con aislados seleccionados de $D$. tritici-repentis, en dos localidades y 31 cultivares de trigo, evaluadas en el estadio EC $82 . .$.

Tabla 3.4.5. Cuadrados medios del tipo de reacción en tres momentos de evaluación (EC 37, EC 75 y EC 82) en un ensayo de trigo inoculado individualmente con tres aislados de $D$. tritici-repentis, en dos localidades y en 31 cultivares de trigo. 
Tabla 3.4.6. Medias del tipo de reacción en un ensayo de trigo inoculado individualmente con aislados seleccionados de D. tritici-repentis, en dos localidades y

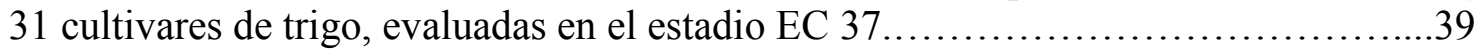
Tabla 3.4.7. Medias del tipo de reacción en un ensayo de trigo inoculado individualmente con aislados seleccionados de $D$. tritici-repentis, en dos localidades y

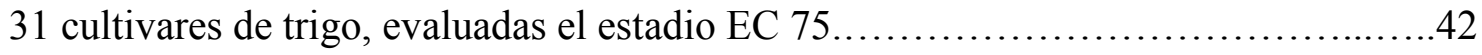

Tabla 3.4.8. Medias del tipo de reacción en un ensayo de trigo inoculado individualmente con aislados seleccionados de $D$. tritici-repentis, en dos localidades y 31 cultivares de trigo, evaluadas en el estadio EC $82 \ldots \ldots \ldots \ldots \ldots \ldots \ldots \ldots \ldots \ldots . \ldots \ldots 4$

Tabla 3.4.9. Cuadrados medios del ABCPE en un ensayo de trigo inoculado individualmente con aislados seleccionados de $D$. tritici-repentis, en dos localidades y en 31 cultivares de trigo ................................................... 47

Tabla 3.4.10. Medias del ABCPE en un ensayo de trigo inoculado individualmente con aislados seleccionados de $D$. tritici-repentis, en dos localidades y 31 cultivares de trigo.

Tabla 3.4.11. Clasificación de cultivares de trigo según valores de área bajo la curva de progreso de la enfermedad en un ensayo inoculado individualmente con tres aislados de D. tritici-repentis, en dos localidades y en 31 cultivares de trigo. .53 


\section{INDICE DE FIGURAS}

Figura 1.5.1. Ciclo del agente causal de la mancha amarilla, causado por D. triticirepentis........................................................................ 8 Figura 2.1.1. Aislado axénico de D. tritici-repentis procedente de la localidad de Los

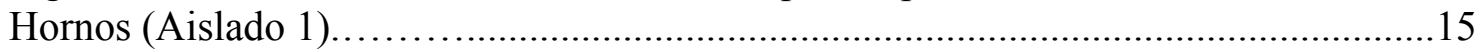
Figura 2.1.2. Aislado axénico de $D$. tritici-repentis procedente de la localidad de 25 de Mayo (Aislado 2)...................................................... 15 Figura 2.1.3. Aislado axénico de D. tritici-repentis procedente de la localidad de Gualeguaychu (Aislado 3) .............................................. 16

Figura 2.3.1. Temperatura $\left({ }^{\circ} \mathrm{C}\right)$ y Humedad relativa $(\%)$ registradas en un ensayo de trigo inoculado individualmente con 3 aislados de $D$. tritici-repentis, en invernáculo sobre 9 líneas de trigo.................................................... 17 Figura 2.3.2. Figura 2.3.2. Ensayo de trigo inoculado individualmente con aislados seleccionados de $D$. tritici-repentis, en invernáculo sobre 9 líneas diferenciales de trigo............................................................ 18 Figura 2.5.1. Escala de 1-5 propuesta por Lamari \& Bernier (1989a)..............20 Figura 2.5.2. Ensayo de trigo inoculado individualmente al estado de plántula con aislados seleccionados de D. tritici-repentis, en invernáculo sobre 31 cultivares de trigo. .21

Figura 2.6.1. Ensayo de trigo inoculado individualmente con aislados seleccionados de D. tritici-repentis, en la localidad de Los Hornos sobre 31 cultivares de trigo...........22 Figura 2.6.2. Ensayo de trigo inoculado individualmente con aislados seleccionados de D. tritici-repentis, en la localidad de Pergamino sobre 31 cultivares de trigo.. 22

Figura 3.1.1. Reacción de Clorosis, Necrosis y Necrosis + Clorosis respectivamente, en un ensayo de trigo inoculado individualmente con aislados seleccionados de $D$. tritici-repentis sobre 9 líneas diferenciales de trigo...........................25 Figura 3.2.1. Estimación de tamaños de fragmentos amplificados de $\mathrm{ADN}$ en comparación con controles positivos de los cebadores TOX A TA51F/TA52R, TOX B TB71F/TB58R, TOX B1 TB71F/TB60R y TOX $b$ TB71F/TB6R de 3 aislados de $D$. tritici-repentis........................................................... 26 Figura 3.4.1. Síntomas observados en un ensayo de trigo inoculado individualmente con aislados seleccionados de D. tritici-repentis, en dos localidades y 31 cultivares de

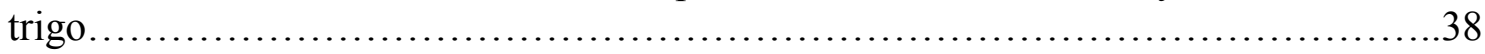
Figura 3.4.2. Tipos de reacción observados en un ensayo de trigo inoculado individualmente con aislados seleccionados de D. tritici-repentis, en dos localidades y en 31 cultivares de trigo

Figura 3.4.3. Medias del ABCPE en un ensayo de trigo inoculado con el aislado 1 de $D$. tritici-repentis, en la localidad de Los Hornos sobre 31 cultivares de trigo.............50 Figura 3.4.4. Medias del ABCPE en un ensayo de trigo inoculado con el aislado 2 de $D$. tritici-repentis, en la localidad de Los Hornos sobre 31 cultivares de trigo..............50 Figura 3.4.5. Medias del ABCPE en un ensayo de trigo inoculado con el aislado 3 de $D$. tritici-repentis, en la localidad de Los Hornos sobre 31 cultivares de trigo.............51 Figura 3.4.6. Medias del ABCPE en un ensayo de trigo inoculado con el aislado 1 de $D$. tritici-repentis, en la localidad de Pergamino sobre 31 cultivares de trigo..............51 Figura 3.4.7. Medias del ABCPE en un ensayo de trigo inoculado con el aislado 2 de $D$. tritici-repentis, en la localidad de Pergamino sobre 31 cultivares de trigo..............52 
Figura 3.4.8. Medias del ABCPE en un ensayo de trigo inoculado con el aislado 3 de $D$. tritici-repentis, en la localidad de Pergamino sobre 31 cultivares de trigo......... 


\section{INDICE APENDICE}

Tabla 6.1.1. Medias de severidad de tres aislados de D. tritici-repentis en un ensayo de trigo, en 31 cultivares al estado de plántula.......................................74 Tabla 6.1.2. Medias del tipo de reacción de tres aislados de D. tritici-repentis en un ensayo de trigo, en 31 cultivares al estado de plántula. ............................74 Tabla 6.1.3. Medias de severidad de tres aislados de D. tritici-repentis en un ensayo de trigo en dos localidades y 31 cultivares de trigo, evaluadas en el estadio EC $37 \ldots \ldots . .74$ Tabla 6.1.4. Medias de severidad de dos localidades en un ensayo de trigo inoculado con tres aislados de $D$. tritici-repentis, en 31 cultivares, evaluadas en el estadio EC

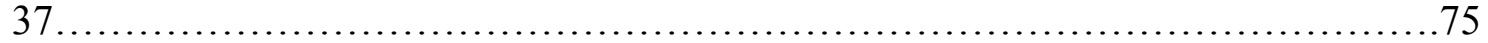

Tabla 6.1.5. Medias de severidad de tres aislados de D. tritici-repentis en un ensayo de trigo en dos localidades y 31 cultivares de trigo, evaluadas en el estadio EC $75 \ldots \ldots \ldots 75$ Tabla 6.1.6. Medias de severidad de dos localidades en un ensayo de trigo inoculado con tres aislados de $D$. tritici-repentis, en 31 cultivares, evaluadas en el estadio EC

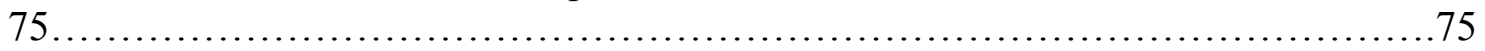

Tabla 6.1.7. Medias de severidad de tres aislados de D. tritici-repentis en un ensayo de trigo en dos localidades y 31 cultivares de trigo, evaluadas en el estadio EC $82 \ldots \ldots \ldots 76$ Tabla 6.1.8. Medias de severidad de dos localidades en un ensayo de trigo inoculado con tres aislados de D. tritici-repentis, en 31 cultivares, evaluadas en el estadio EC

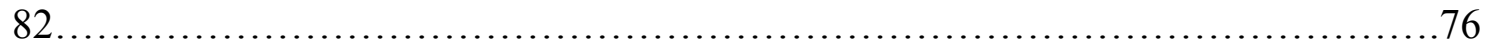

Tabla 6.1.9. Medias del tipo de reacción de tres aislados de D. tritici-repentis en un ensayo de trigo en dos localidades y 31 cultivares de trigo, evaluadas en el estadio EC

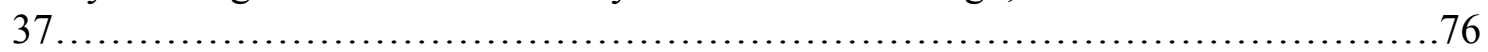

Tabla 6.1.10. Medias del tipo de reacción de dos localidades en un ensayo de trigo inoculado con tres aislados de $D$. tritici-repentis, en 31 cultivares, evaluadas en el

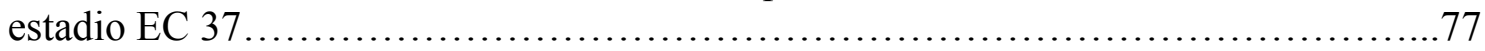
Tabla 6.1.11. Medias del tipo de reacción de tres aislados de D. tritici-repentis en un ensayo de trigo en dos localidades y 31 cultivares de trigo, evaluadas en el estadio EC

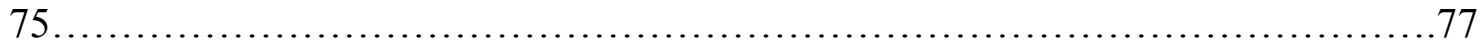

Tabla 6.1.12. Medias del tipo de reacción de dos localidades en un ensayo de trigo inoculado con tres aislados de $D$. tritici-repentis, en 31 cultivares, evaluadas en el

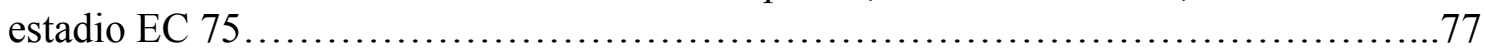
Tabla 6.1.13. Medias del tipo de reacción de tres aislados de D. tritici-repentis en un ensayo de trigo en dos localidades y 31 cultivares de trigo, evaluadas en el estadio EC 82. .78

Tabla 6.1.14. Medias del tipo de reacción de dos localidades en un ensayo de trigo inoculado con tres aislados de $D$. tritici-repentis, en 31 cultivares, evaluadas en el

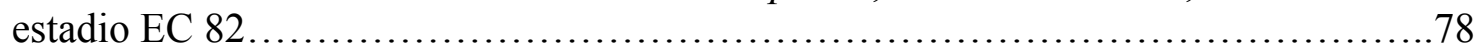

Tabla 6.1.15. Medias del ABCPE de tres aislados de D. tritici-repentis en un ensayo de trigo en dos localidades y 31 cultivares de trigo.................................. 78 Tabla 6.1.16. Medias del ABCPE de dos localidades en un ensayo de trigo inoculado con tres aislados de $D$. tritici-repentis, en 31 cultivares. .79 


\section{ABREVIATURAS}

A: Aislado

A1: Aislado 1

A2: Aislado 2

A3: Aislado 3

ABCPE: Área bajo la curva de progreso de la enfermedad

ADN: Ácido desoxirribonucleico

C: Cultivar

CIDEFI: Centro de Investigaciones de Fitopatología

CIMMYT : Centro Internacional de Mejoramiento de Maíz y Trigo

$\mathrm{Cl}$ : Clorosis

$\mathrm{Co}_{3} \mathrm{Ca}$ : Carbonato de calcio

CONICET: Consejo Nacional de Investigaciones Científicas y Técnicas

CTAB: Bromuro de cetil trimetil amonio

dNTP: Desoxirribonucleótidos trifosfato

EC: Estados de crecimiento de la escala de Zadoks et al., 1974

EDTA: Acido etildiaminotetraacético

EEUU: Estados Unidos de América

FAO: Organización de las Naciones Unidas para la Alimentación y la Agricultura

G.L.: Grados de Libertad

h: Horas

$\mathrm{HCl}$ : Ácido clorhídrico

$\mathrm{KCl}$ : Cloruro de Potasio

L: Localidad

LSD: Mínima diferencia significativa

$\mathrm{MgCl}_{2}$ : Cloruro de magnesio

MR: Moderadamente Resistente

MS: Moderadamente Susceptible

$\mathrm{N}$ : Necrosis

PCR: Reacción en cadena de la polimerasa

r: Coeficiente de correlación

R: Resistente

S: Susceptible

ToxA: Toxina A

ToxB: Toxina B

ToxC: Toxina $\mathrm{C}$

UV: Ultra violeta 


\section{RESUMEN}

Actualmente, se conocen en el mundo ocho razas de Drechslera tritici-repentis (Died) (teleomorfo Pyrenophora tritici-repentis, Died) determinadas sobre líneas diferenciales de trigo; sin embargo muchos investigadores sugieren la presencia de nuevas razas de este patógeno. La aparición de nuevas razas del hongo puede traer consigo la pérdida de resistencia genética en variedades comerciales de trigo. A pesar de ello, hay muy pocos trabajos donde se haya caracterizado el comportamiento de cultivares comerciales de trigo frente a diferentes aislados de $D$. tritici-repentis caracterizados fenotípica y molecularmente. El objetivo de este trabajo fue caracterizar tres aislados de D. triticirepentis y analizar el comportamiento de variedades comerciales argentinas de trigo en plántula en invernáculo y en planta adulta a campo, frente a los mismos. Se evaluó el tipo de reacción en líneas diferenciales de trigo en invernáculo y se realizó el análisis molecular de los genes que codifican la producción de toxinas. El ensayo con variedades comerciales llevado a cabo en invernáculo se realizó en la Universidad Nacional de La Plata, Partido de La Plata, con un diseño de parcela dividida donde la parcela principal fue el aislado y la sub-parcela el cultivar; mientras que los ensayos en planta adulta a campo se realizaron en la Estación Experimental Julio Hirschhorn dependiente de la Universidad Nacional de La Plata, Partido de Los Hornos y en la Estación Experimental Agropecuaria Pergamino del Instituto Nacional de Tecnología Agropecuaria en el partido de Pergamino, con un diseño de parcela dividida donde la parcela principal fue la localidad, la sub-parcela el aislado y la sub-sub-parcela el cultivar. Se inoculó en el estadio de 3 hojas en invernáculo y en principios de encañamiento y hoja bandera desplegada para la evaluación a campo con una concentración de 3000 conidios $/ \mathrm{ml}$. Se evaluó el tipo de reacción, usando la escala de 1-5 propuesta por Lamari \& Bernier (1989a), y la severidad a los 14 días después de la inoculación en plántula y en tres momentos (EC 37, EC 75 y EC 82) para el ensayo en planta adulta a campo. Los aislados mostraron diferencias en la reacción en líneas diferenciales y en el análisis molecular de genes que codifican toxinas. El aislado 1 (cepa $\mathrm{LH})$ se caracterizó por la presencia del gen $T O X b$; el aislado 2 (cepa 25M035) por la presencia de los genes homólogos TOX B, TOX B1 y TOX b y el aislado 3 (cepa G327) por poseer el gen TOX $A$ y $T O X B 1$. En plántula los cultivares que, en promedio, presentaron menor severidad fueron Baguette 601, Buck SY 300, Buck SY 110, Don Mario Lenox, Baguette 17, Buck AGP Fast, Nogal, BioInta 1001, ProInta Puntal y SY100 y según tipo de reacción Baguette 601, Buck SY 300, Klein Tauro, Buck SY 110, Buck SY 100, BioInta 1001, Klein Proteo, Klein Volcán, Don Mario Lenox y ACA 320. En planta adulta los que presentaron menor severidad fueron Baguette 601, Buck SY 110, Buck SY 300, Don Mario Lenox, Nogal, Baguette 17, ProInta Puntal, Buck AGP Fast y Buck SY 100 y en cuanto al tipo de reacción fueron Baguette 601, Buck SY 110, Buck SY 300, Baguette 17, Buck SY 100, ProInta Puntal, Buck AGP Fast, Nogal y BioInta 1001. A partir de estos resultados se puede sugerir que los aislados eran diferentes entre sí y que no se correspondieron con las razas conocidas. En los ensayos en plántula en invernáculo y en planta adulta a campo se encontraron algunos cultivares con aceptables niveles de resistencia parcial. 


\section{ABSTRACT}

Currently, there are eight known races of Drechslera tritici-repentis (Died) (teleomorfo Pyrenophora tritici-repentis, Died) around the world, determined on differential wheat lines; nevertheless, many researchers suggest the presence of new races of the pathogen. The emergence of new races of the fungus can lead to the loss of genetic resistance in commercial wheat cultivars. However, there are very few studies where the behavior of commercial wheat cultivars was analyzed against different strains of $D$. tritici-repentis characterized phenotypic and molecularly. The aim of this study was to characterize three isolates of $D$. tritici-repentis and analyze the behavior of Argentine wheat commercial cultivars in seedlings, in greenhouse, and in the adult plant in the field. To characterize the isolates, reaction type on differential lines, in greenhouse, was evaluated and molecular analysis of genes encoding toxin production was performed. Those isolates were used to test 31 commercial cultivars in greenhouse at seedling stage at the National University of La Plata. A split-plot design was used, where the main plot were the isolates and the subplot were the cultivars; In addition field trials were conducted in adult plants at the Experimental Station J. Hirschhorn dependent of the National University of La Plata and the Agricultural Experiment Station Pergamino dependent of the National Institute of Agricultural Technology with a split-plot design where the main plot was the location, subplot were the isolates and sub-sub-plot were the cultivars. Inoculum was applied at the third leaf stage in the greenhouse and at early stem elongation and flag leaf stage for adult stage evaluations in the field with a concentration of 3000 conidia / $\mathrm{ml}$. The reaction type was estimated by using the scale of 1 to 5 given by Lamari \& Bernier (1989a), and the severity was visually scored at 14 days after inoculation in seedling stage and at three adult stages (EC 37, EC 75 and EC 82). The isolates showed differences in reaction on the differential lines and by the molecular analysis of the genes that determine toxin production. The isolated 1 (strain $\mathrm{LH}$ ) was characterized by the presence of the gene $T O X b$; isolated 2 (strain 25M035) by the presence of homologous TOX B, TOX BI and TOX $b$ genes and isolated 3 (strain G327) by having the TOX A and TOX B1 gene. In seedling Baguette 601, Buck SY 300, Buck SY 110, Don Mario Lenox, Baguette 17, Buck AGP Fast, Sursem Nogal, BioInta 1001, ProInta Puntal and Buck SY 100 showed the lowest severity values, whereas Baguette 601, Buck SY 300, Klein Tauro, Buck SY 110, Buck SY 100, BioInta 1001, Klein Proteo, Klein Volcán, Don Mario Lenox and ACA 320 showed the lowest values according to the type of reaction. In adult stage those cultivar with the lowest severity values were Baguette 601, Buck SY 110, Buck SY 300, Don Mario Lenox, Sursem Nogal, Baguette 17, ProInta Puntal, Buck AGP Fast and Buck SY 100 and those with the lowest type of reaction were Baguette 601, Buck SY 110, Buck SY 300, Baguette 17, Buck SY 100, ProInta Puntal, Buck AGP Fast, Sursem Nogal and BioInta 1001. From these results it can be said that the isolates were different and that did not correspond to known races. In seedling tests in greenhouse, and adult plants in the field, there were some cultivars with acceptable levels of partial resistance. 


\section{CAPITULO 1:}

\section{INTRODUCCIÓN}

\subsection{Trigo}

El trigo es considerado actualmente uno de los principales cultivos a escala mundial. Es una de las especies vegetales más consumidas del mundo junto con el arroz, el maíz y la papa y es la principal fuente de hidratos de carbono del mundo occidental. Alrededor del $75 \%$ de la producción mundial es consumida por el hombre, constituyendo el $20 \%$ de las calorías que requiere la población mundial, y es la materia prima para casi el $40 \%$ de los alimentos del mundo (Wiese, 1987; Rajaram, 2001).

La producción mundial pronosticada de cereales para al año 2014 se ubica en alrededor de 2458 millones de toneladas mientras que la producción mundial de trigo pronosticada para el mismo año se ubica en alrededor de los 702 millones de toneladas representando el $28 \%$ de la producción de cereales (Perspectivas alimentarias FAO, 2014).

En las Tablas 1.1 .1 y 1.1 .2 se indican los principales 20 países productores y exportadores de trigo respectivamente, en base al promedio de su producción y exportación de los últimos 20 años. 
Tabla 1.1.1. Producción promedio de trigo de los principales 20 países productores (Promedio del periodo 1993-2013).

\begin{tabular}{|l|c|}
\hline País & $\begin{array}{c}\text { Promedio } \\
\text { Producción (t) }\end{array}$ \\
\hline China & 106968221 \\
\hline India & 74026795 \\
\hline EEUU & 59430392 \\
\hline Rusia & 43302383 \\
\hline Francia & 36075119 \\
\hline Canadá & 25183700 \\
\hline Alemania & 21765226 \\
\hline Australia & 20739048 \\
\hline Pakistán & 20337050 \\
\hline Turquía & 19600450 \\
\hline Ucrania & 16745490 \\
\hline Reino Unido & 14626550 \\
\hline Argentina & $\mathbf{1 3 1 5 1 9 6 9}$ \\
\hline Irán & 12036424 \\
\hline Kazajstán & 11549318 \\
\hline Polonia & 8832028 \\
\hline Italia & 7452228 \\
\hline Egipto & 7089214 \\
\hline Rumania & 5735496 \\
\hline España & 5687900 \\
\hline
\end{tabular}

Fuente: División estadística de la FAO. 2014.
Tabla 1.1.2. Exportación promedio de trigo de los principales 20 países exportadores (Promedio del período 1991-2011).

\begin{tabular}{|l|c|}
\hline País & $\begin{array}{c}\text { Promedio } \\
\text { Exportación (t) }\end{array}$ \\
\hline EEUU & 28786396 \\
\hline Canadá & 17232536 \\
\hline Francia & 16297402 \\
\hline Australia & 13611628 \\
\hline Argentina & $\mathbf{7 9 2 7 3 3 0}$ \\
\hline Rusia & 5917106 \\
\hline Alemania & 5359116 \\
\hline Kazajstán & 3531992 \\
\hline Ucrania & 3361031 \\
\hline Reino Unido & 2941167 \\
\hline Hungría & 1313508 \\
\hline Dinamarca & 931281 \\
\hline Bulgaria & 839604 \\
\hline India & 821674 \\
\hline Bélgica & 773091 \\
\hline Bélgica & 746258 \\
\hline Rumania & 707481 \\
\hline Turquía & 706207 \\
\hline Rep. Checa & 673208 \\
\hline Austria & 514993 \\
\hline
\end{tabular}

Fuente: División estadística de la FAO. 2014.

Argentina ocupa el puesto $\mathrm{N}^{\circ} 13$ en cuanto a producción mundial de trigo y constituye el quinto exportador a nivel mundial si se consideran los últimos 20 años (División estadística de la FAO, 2014), aunque la producción y la exportación han disminuido durante los últimos 5 años en nuestro país (Tabla 1.1.3 y 1.1.4). 
Tabla 1.1.3. Producción de trigo de Argentina (Promedio del periodo 2009-2013).

\begin{tabular}{|l|c|}
\hline Período & Producción (t) \\
\hline $2009 / 10$ & 9023188 \\
\hline $2010 / 11$ & 15875651 \\
\hline $2011 / 12$ & 14500517 \\
\hline $2012 / 13$ & 8024995 \\
\hline $2013 / 14$ & 9188339 \\
\hline Promedio & 11322528 \\
\hline
\end{tabular}

Fuente: Sistema Integrado de Información Agropecuaria. 2014.
Tabla 1.1.4. Exportación de trigo de Argentina (Promedio del periodo 2008-2012).

\begin{tabular}{|l|c|}
\hline Período & Exportación (t) \\
\hline $2008 / 09$ & 5375003 \\
\hline $2009 / 10$ & 3791944 \\
\hline $2010 / 11$ & 7732582 \\
\hline $2011 / 12$ & 11402510 \\
\hline $2012 / 13$ & 3061550 \\
\hline Promedio & 6272717 \\
\hline
\end{tabular}

Fuente: Dirección de Mercados Agrícolas. 2014.

En nuestro país, el trigo, constituye el segundo cultivo extensivo con mayor superficie cosechada luego del cultivo de soja (Tabla 1.1.5) y el tercer cultivo de mayor producción a nivel país (Tabla 1.1.6). La producción se concentra principalmente en las provincias de Buenos Aires, Santa Fe, Córdoba, Entre Ríos y La Pampa y el promedio de rendimiento (periodo 2009-2013) a nivel país se encuentra en $2961 \mathrm{~kg} / \mathrm{ha}$ (Sistema Integrado de Información Agropecuaria, 2014).

Tabla 1.1.5. Superficie cosechada promedio en los últimos 10 años de los principales cultivos en Argentina.

\begin{tabular}{|l|c|}
\hline Cultivo & $\begin{array}{c}\text { Superficie } \\
\text { Cosechada (Ha) }\end{array}$ \\
\hline Soja & 16650539 \\
\hline Trigo & $\mathbf{4 6 4 8 5 2 4}$ \\
\hline Maíz & 3139391 \\
\hline Girasol & 1873566 \\
\hline Cebada & 677974 \\
\hline Sorgo & 677752 \\
\hline Algodón & 386930 \\
\hline
\end{tabular}

Fuente: Sistema Integrado de Información Agropecuaria. 2014.

Tabla 1.1.6. Producción promedio en los últimos 10 años de los principales cultivos en Argentina.

\begin{tabular}{|l|c|}
\hline Cultivo & Producción (t) \\
\hline Soja & 42609566 \\
\hline Maíz & 20656443 \\
\hline Trigo & $\mathbf{1 2 6 3 7 0 0 7}$ \\
\hline Girasol & 3238744 \\
\hline Sorgo & 3091666 \\
\hline Cebada & 2306839 \\
\hline Arroz & 1326213 \\
\hline
\end{tabular}

Fuente: Sistema Integrado de Información Agropecuaria. 2014.

El cultivo de trigo es afectado por varias enfermedades fúngicas entre las que se encuentran: la septoriosis ó mancha de la hoja (Septoria tritici Roberge in Desmaz. f. asexual; Mycosphaerella graminicola (Fuckel) J. Schröt, in Cohn f. sexual), mancha amarilla (Drechslera tritici-repentis (Died.) Shoemaker f. asexual; Pyrenophora triticirepentis (Died.) Drechs. f. sexual), roya amarilla (Puccinia striiformis West), roya anaranjada o de la hoja (Puccinia triticina Eriks), roya negra o del tallo (Puccinia graminis $f$. sp. tritici Pers), fusariosis (Fusarium graminearum Schwabe f. asexual; 
Gibberella zeae (Schwein.) Petch. f. sexual), caries o carbón hediondo (Tilletia caries (DC.) Tul. \& C. Tul. y T. foetida (Wallr.) Liro.), carbón volador del trigo (Ustilago tritici (Pers.) Rostr.; U. nuda (J.L.Jensen) Kellerm. \& Swingle.), oidio (Oidium moniloides (Nees) Link f. asexual Blumeria graminis tritici (DC) Speer am. f. sexual) y pietín (Gaeumannomyces graminis (Sacc.) Arx. \& Oliv. var. tritici Walker) (Annone, 2004), aunque existe un complejo de enfermedades emergentes como la mancha de la hoja, causada por Ascochita (Ascochita hordei var. europea Punith), mancha de la hoja, causada por Phoma (Phoma sorghina (Sacc.) Boerama et al.), Rayado causado por Cephalosporium (Cephalosporium graminis Nis. e Ika.), tizón de la hoja (Alternaria triticina Prasada \& Amp f; Prahbu) y el complejo de especies de manchado del grano (Alternaria infectoria (Fuckel) M. Barr. \& Amp) (Perelló, 2007).

En nuestro país las principales micosis que afectan al cultivo de trigo son la roya de la hoja, mancha amarilla, fusariosis de espiga, septoriosis o mancha de la hoja y pietín (Annone, 2006). El nivel de pérdida de rendimiento en el cultivo de trigo para América del Sur oscila entre el 20-30 \% dependiendo del genotipo, características del patógeno y de las condiciones ambientales (Carmona, 2003). En el caso de roya de la hoja se han registrado pérdidas del 20 al $50 \%$ (Annone, 2006b; Galich et al., 1986). Para la fusariosis de la espiga, las pérdidas pueden ser desde casi imperceptibles a cuantiosas, habiéndose llegado a estimar mermas de rendimiento del orden del $50 \%$ (Annone \& Frutos, 1988; Galich, 2002; Kohli et al., 1996). A estas pérdidas deben sumarse la presencia de micotoxinas y la modificación de algunos parámetros que afectan la calidad comercial e industrial (Dalcero et al., 1997; Tombetta et al., 1994). Simón et al. (2002) han encontrado reducciones de rendimiento para mancha de la hoja del 16 al $45 \%$; mientras que Annone et al. (1991) han encontrado reducciones del 38 al $60 \%$ para la misma enfermedad. Para el caso de pietín se han registrado pérdidas de rendimiento del $33 \%$ en manchones moderados y del $79 \%$ en severos (Fernández \& Corro Molas, 2001).

\subsection{Importancia de la mancha amarilla}

La mancha amarilla fue observada por primera vez en trigo a fines de la década del 20 en Japón (Hosford, 1981). A partir de ese momento fue determinada en varios lugares del mundo, aunque casi siempre como una enfermedad de poca importancia hasta principios del 50, cuando ocasionó una epifitia severa en Kenia causando pérdidas del orden del $75 \%$ (Gilchrist et al., 1984). A comienzos de la década del 70 adquirió relevancia en regiones productoras de trigo del norte y centro de los EEUU, Australia, Nepal, México (Gilchrist et al., 1984), India, oeste de Canadá y Brasil (Hosford, 1981).

En EEUU, Sharp et al. (1976) observaron que bajo condiciones de severo ataque de esta enfermedad el peso de mil granos de un grupo de cultivares se redujo en un 9-20 \%. En el mismo país Hosford \& Busch (1974) informaron pérdidas del 12,9 \%. En Australia, Rees et al. (1982) calcularon que el efecto de esta enfermedad sobre los rendimientos de un cultivar susceptible fueron del orden del $50 \%$. Los trabajos más detallados sobre cuantificación de pérdidas debidas a esta enfermedad, fueron realizados 
en Australia (Rees \& Platz, 1983). Los autores reportaron pérdidas de 13 a $48 \%$, siendo éstas, función de la severidad (\% de área foliar necrosada). La fórmula encontrada fue $\mathrm{P}=0,26 \mathrm{X}$, donde $\mathrm{P}$ representa el porcentaje de pérdidas en el rendimiento de los granos de la espiga del tallo principal y X la severidad media de las últimas hojas en el estado de grano lechoso (Rees et al., 1981). Existen antecedentes que indican que Drechslera tritici-repentis una vez introducido en una determinada área triguera, donde existen otros hongos causantes de manchas foliares como $S$. nodorum y $S$. tritici, se convierte en el patógeno dominante a lo largo de los años (Wright \& Sutton, 1990).

En los últimos años, la presencia de esta enfermedad ha comenzado a observarse en varios países de Sudamérica como Argentina, Brasil, Paraguay, Chile y Uruguay. El nivel de pérdidas ocasionados por la mancha amarilla en lotes de producción, a principios de la década del 90, en Paraguay y Argentina habría fluctuado entre el 20 y el $70 \%$ (Kohli et al., 1992).

En nuestro país las primeras citas son de mediados de la década del 80 y corresponden al área centro-norte de la región triguera (Annone, 1985). Annone et al. (1994) observaron pérdidas del $20 \%$, en el norte de la Provincia de Buenos Aires, a través de la comparación entre tratamientos testigos severamente afectados (70\% de severidad) y tratamientos protegidos con un fungicida sistémico (20\% de severidad). Otros trabajos han registrado pérdidas del 6 al 13,5\% (Galich \& Galich, 1994) y del 8 al $32 \%$ (Annone et al., 2001). En los últimos años la mancha amarilla ha ganado predominancia entre las enfermedades foliares del trigo en las áreas productoras de nuestro país (Carmona et al., 1999; Moreno \& Perelló, 2010).

\subsection{El agente causal}

Pyrenophora tritici-repentis, forma sexual del agente causal de la mancha amarilla de la hoja del trigo, es un patógeno facultativo del phylum Ascomycota, Clase Loculoascomycetes, cuyo anamorfo (fase asexual) corresponde a Drechslera triticirepentis.

La forma asexual (D. tritici-repentis), imperfecta o anamorfo del parásito se desarrolla principalmente sobre las lesiones foliares originadas a partir de las infecciones primarias vía ascosporas y constituye el medio a través del cual la enfermedad se dispersa a tejidos no afectados de la misma planta y de plantas vecinas (Annone, 1995). Las esporas asexuales o conidios son cilíndricos, multicelulares (7 a 10 células), alargados (70-200 $\mu \mathrm{m} \times 12-18 \mu \mathrm{m})$ de aspecto cristalino bajo microscopio. Estas esporas tienen células basales con forma de "cabeza de serpiente" y pueden germinar a través de cualquiera de sus células (Annone et al., 1994; Gilchrist et al., 1984; Wiese, 1987; Zillinsky, 1984).

La forma sexual ( $P$. tritici-repentis) o perfecta constituye una de las más importantes formas de perpetuación del hongo de un año a otro y es el principal reservorio de inóculo para establecer las primeras infecciones en el campo. Puede observarse en residuos de trigo y corresponde a estructuras muy pequeñas (300 a 1200 
$\mu \mathrm{m})$, visibles a ojo desnudo, y denominadas pseudotecios. Estos cuerpos fructíferos presentes en la paja de trigo y dispuestos al azar son erumpentes, de color castaño oscuro y tienen forma de volcán con abundantes setas en su parte apical donde se pueden diferenciar eventualmente también esporas de origen asexual (conidios) (Annone et al., 1994; Gilchrist et al., 1984; Wiese, 1987; Zillinsky, 1984). En el interior de los pseudotecios se diferencian los ascos de forma alargada dentro de los cuales se forman las ascosporas (esporas de origen sexual) que son la principal fuente de inóculo primario. Las ascosporas son ovales con 2-3 septas transversales, 1-2 longitudinales y dimensiones en el siguiente rango: $33-112 \mu \mathrm{m} \times 15-44 \mu \mathrm{m}$ (Gilchrist et al., 1984).

\subsection{Sintomatología}

Los síntomas más comunes de esta enfermedad se observan sobre hojas y vainas y aparecen después de la emergencia del trigo cuando se produce la expansión de la plúmula. Sobre cultivares susceptibles se observan en las hojas características lesiones ovales en forma de ojo. Luego éstas se alargan y se rodean de un halo clorótico con una pequeña mancha marrón más oscura en el sitio de infección. Las áreas cloróticas tienden a elongarse y coalescer sobre hojas altamente infectadas. El desarrollo de los síntomas sigue un patrón vertical con efecto "escalera" (desde hojas inferiores a superiores). El borde o halo amarillento es atribuido a la producción de toxinas específicas del agente causal (Lamari \& Bernier, 1989a). En cultivares parcialmente resistentes el tamaño de la lesión es menor y la clorosis y/o necrosis pueden estar ausentes (Lamari \& Bernier, 1989a; 1989b). Lamari \& Bernier (1989a) identificaron dos tipos de síntomas producidos por el patógeno: manchas necróticas y clorosis. D. tritici-repentis puede también infectar a las semillas durante el periodo de llenados de granos (Schilder \& Bergstrom, 1994). Este desorden provoca un oscurecimiento o manchado rosado porque la semilla infectada se torna rosada (Rees \& Platz, 1979).

\subsection{Ciclo del agente causal de la mancha amarilla}

Las principales fuentes de inóculo son las semillas, los restos culturales del trigo y otros hospedantes secundarios o alternativos. Es a través de la semilla que el patógeno es transportado a largas distancias e introducido en lugares donde no existía. El patógeno se aloja en el pericarpio como micelio y la transmisión a la plántula no es sistémica (Schilder \& Bergstrom, 1994).

Muchos investigadores consideran a los restos culturales del trigo como la principal fuente de inóculo (Rees \& Platz, 1980). El tipo de inóculo presente en los restos culturales es la forma perfecta o sexual. Bajo condiciones de labranza conservacionista (rastrojo en superficie) la aparición de esta enfermedad ocurre más tempranamente en el ciclo del cultivo y con mayores niveles de severidad en comparación con labranza convencional (Kohli et al., 1992; Mehta \& Gaudencio, 1991). 
Dentro del género Drechslera, D. tritici-repentis es la especie que posee el mayor rango de hospedantes. Ha sido reportado naturalmente en unas 25 especies, además del trigo. Estas sirven como hospedantes secundarios o alternativos y entre las mismas puede citarse a: Agropyron sp., Alopecurus arundinaceus, Andropogon gerardi, Avena fatua, A. sativa, Bromus inermis, Dactilys glomerata, Echinochloa sp., Elymus innovatus, Lolium perenne, Phalaris arundinaceae, Poa sp. y Secale cereale (Ali \& Francl, 2002b; Hosford, 1971, Krupinsky, 1992). Las ascosporas (generadas en los restos culturales) y los conidios (generados junto a las ascosporas, en lesiones de plantas de trigo guacho y en hospedantes secundarios) alcanzan las hojas con tejido sano por medio del viento principalmente.

Una vez depositados en la superficie de los órganos verdes, necesitan de agua libre para iniciar el proceso de germinación (Mihtra, 1934). El proceso de infección se inicia con la germinación del conidio o ascospora, seguido por el alargamiento del tubo germinativo y la formación del apresorio. Una vez producida la necrosis en las células de la parte central de la mancha, el patógeno empieza a esporular. En consecuencia la cantidad de inóculo producida aumenta en función del incremento del área infectada (ciclos secundarios de la enfermedad). Este hongo puede crecer en un rango considerablemente amplio de condiciones ambientales con temperaturas de 10 a $30{ }^{\circ} \mathrm{C} \mathrm{y}$ periodos de 6 a 48 h de alta humedad relativa (Wiese, 1987). 


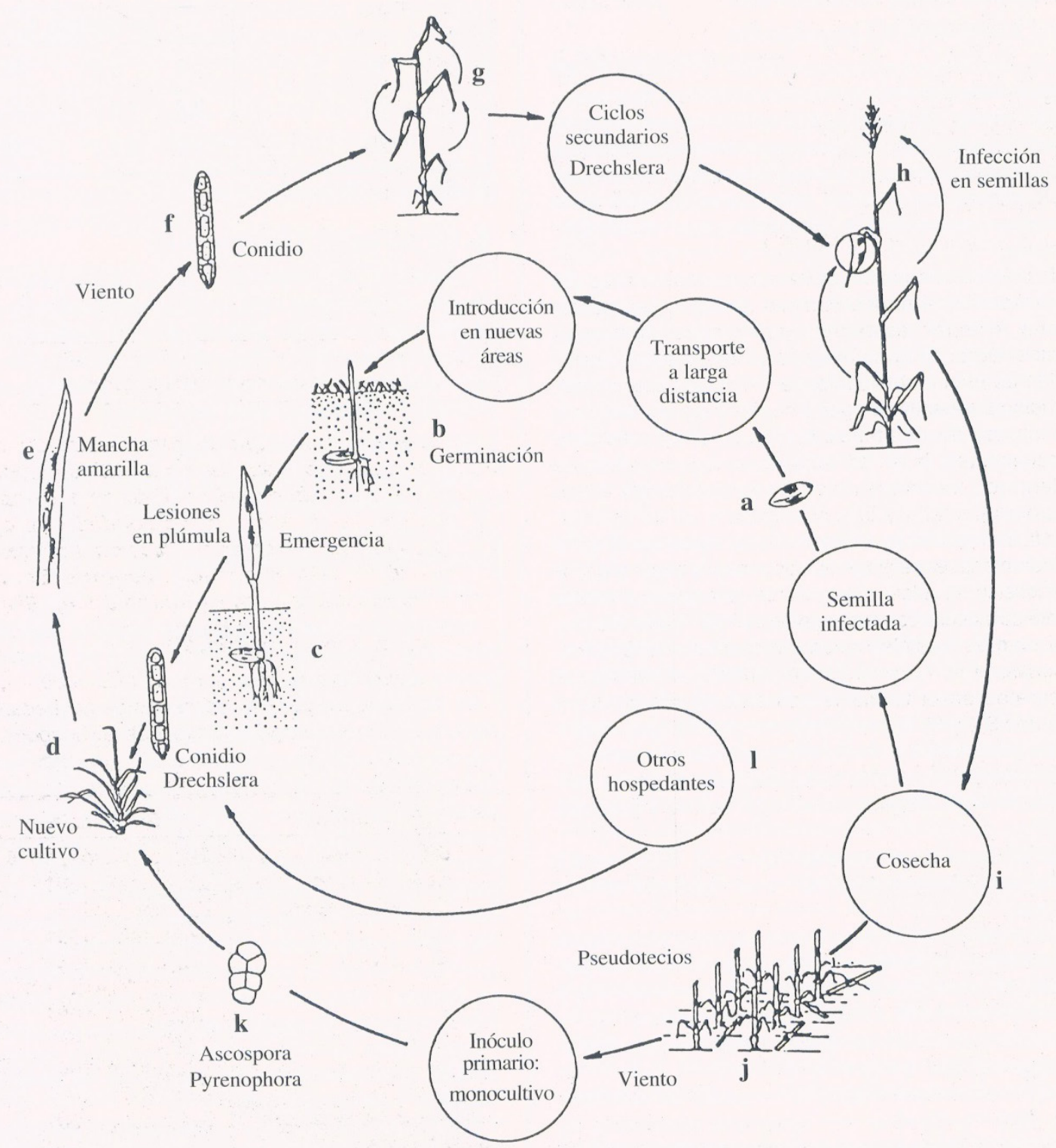

Figura 1.5.1. Ciclo del agente causal de la mancha amarilla, causado por $D$. tritici-repentis. Fuente: Reis \& Carmona (1996).

\subsection{Variación Patogénica}

La capacidad de un patógeno para producir enfermedad puede ser evaluada como patogenicidad o virulencia. El primer término es un atributo general de la especie mientras que virulencia es un atributo de un aislado particular de la especie en relación con un hospedante particular (Day, 1960). Según Vanderplank. (1963; 1978) la presencia de interacciones significativas entre aislados y cultivares es indicativa de diferencias en la especificidad o virulencia de los aislados. La ausencia de dicha interacción indica que no hay especificidad.

Varios trabajos muestran diferencias de virulencia entre aislados de D. triticirepentis. Hosford (1971) observó diferencias en los síntomas del hongo sobre cultivares 
de trigo producidas por diferentes aislados del mismo. Misra \& Singh (1972) también reportaron diferencias en la virulencia de tres aislados del hongo frente a 50 cultivares de trigo. Similares resultados fueron encontrados por Gilchrist et al. (1984) cuando evaluaron diferentes aislados obtenidos de México sobre el cultivar Morocco. Luz \& Hosford (1980) agruparon los aislados de D. tritici-repentis, obtenidos desde diferentes áreas de las grandes llanuras de América del Norte, en 12 razas de acuerdo a su comportamiento frente a 6 cultivares de trigo. Hunger \& Brown (1987) encontraron que nueve aislados provenientes de Oklahoma y Texas presentaban diferencias de virulencia sobre el cultivar TAM 101. Krupinsky (1987) determinó diferencias en el tamaño de la lesión y el porcentaje de severidad entre aislados de este patógeno obtenidos de Bromus inermis.

Actualmente, se conocen en el mundo unas 8 razas de $D$. tritici-repentis determinadas sobre líneas diferenciales de trigo (Ali \& Francl, 2001a; 2001b; Lamari \& Bernier, 1989a; 1989b; Lamari \& Gilbert, 1998; Lamari et al., 1995; 1998; 2003; 2005) (Tabla 1.1.7).

Tabla 1.1.7 Estructura de razas de D. tritici-repentis de acuerdo a Andrie et al. (2007).

\begin{tabular}{|c|c|c|c|c|c|c|}
\hline & \multicolumn{6}{|c|}{ Líneas diferenciales de Trigo } \\
\hline $\begin{array}{c}\text { Razas } \\
\text { del } \\
\text { hongo }\end{array}$ & Glenlea & Katepwa & $6 \mathrm{~B} 662$ & $6 B 365$ & $\begin{array}{l}\text { Sala- } \\
\text { mouni }\end{array}$ & M3 \\
\hline 1 & $\mathrm{~N}(\mathrm{Tox} A)$ & $\mathrm{N}(\operatorname{Tox} \mathrm{A})$ & $\mathrm{R}$ & $\begin{array}{c}\mathrm{Cl} \\
(\operatorname{Tox} C)\end{array}$ & $\mathrm{R}$ & $\mathrm{R}$ \\
\hline 2 & $\mathrm{~N}($ ToxA) & $\mathrm{N}($ ToxA) & $\mathrm{R}$ & $\mathrm{R}$ & $\mathrm{R}$ & $\mathrm{R}$ \\
\hline 3 & $\mathrm{R}$ & $\mathrm{R}$ & $\mathrm{R}$ & $\begin{array}{c}\mathrm{Cl} \\
(\text { ToxC) }\end{array}$ & $\mathrm{R}$ & $\mathrm{R}$ \\
\hline 4 & $\mathrm{R}$ & $\mathrm{R}$ & $\mathrm{R}$ & $\mathrm{R}$ & $\mathrm{R}$ & $\mathrm{R}$ \\
\hline 5 & $\mathrm{R}$ & $\begin{array}{c}\mathrm{Cl} \\
\text { (ToxB) }\end{array}$ & $\begin{array}{c}\mathrm{Cl} \\
(\text { ToxB) }\end{array}$ & $\mathrm{R}$ & $\mathrm{R}$ & $\mathrm{R}$ \\
\hline 6 & $\mathrm{R}$ & $\begin{array}{c}\mathrm{Cl} \\
\text { (ToxB) }\end{array}$ & $\begin{array}{c}\mathrm{Cl} \\
(\text { ToxB) }\end{array}$ & $\begin{array}{c}\mathrm{Cl} \\
(\text { ToxC) }\end{array}$ & $\mathrm{R}$ & $\mathrm{R}$ \\
\hline 7 & $\mathrm{~N}(\operatorname{Tox} \mathrm{A})$ & $\begin{array}{c}\mathrm{N} \mathrm{Cl} \\
(\mathrm{ToxA}) \\
(\mathrm{ToxB})\end{array}$ & $\begin{array}{c}\mathrm{Cl} \\
\text { (ToxB) }\end{array}$ & $\mathrm{R}$ & $\mathrm{R}$ & $\mathrm{R}$ \\
\hline 8 & $\mathrm{~N}(\mathrm{Tox} A)$ & $\begin{array}{c}\mathrm{N} \mathrm{Cl} \\
(\mathrm{ToxA}) \\
(\mathrm{ToxB})\end{array}$ & $\begin{array}{c}\mathrm{Cl} \\
\text { (ToxB) }\end{array}$ & $\begin{array}{c}\mathrm{Cl} \\
(\text { ToxC) }\end{array}$ & $\mathrm{R}$ & $\mathrm{R}$ \\
\hline
\end{tabular}

Referencias: $\mathrm{N}=$ Necrosis; $\mathrm{Cl}=$ Clorosis; $\mathrm{R}=$ Resistente. Tox $\mathrm{A}=$ Presencia de toxina $\mathrm{A}$; $\mathrm{ToxB}=$ Presencia de toxina $\mathrm{B}$; ToxC $=$ Presencia de toxina $\mathrm{C}$.

Inicialmente los aislados de este patógeno eran clasificados en 4 patotipos de acuerdo a su capacidad de producir necrosis o clorosis en las líneas diferenciales Glenlea, Salamouni y 6B-365 (Lamari \& Bernier, 1989b). El patotipo 1 causaba clorosis y necrosis, el 2 causaba necrosis pero no clorosis, el 3 causaba clorosis pero no necrosis 
y el 4 era no-patogénica y no producía ningún síntoma. Posteriormente se encontraron aislados del Norte de África que causaban clorosis en la linea 6B-662 previamente considerados resistentes a la clorosis. Por razones prácticas los patotipos del 1 al 4 fueron renombrados como raza 1 al 4 y fue introducida la raza 5 (Lamari et al., 1995). Luego Strelkov et al. (2002) encontraron aislados provenientes de Argelia que poseían los patrones de virulencia de la raza 3 y 5 y se designó a éstos como raza 6 . Aislados pertenecientes a la raza 7 y 8 fueron encontrados por Lamari et al. (2003) en Azerbaïdjan, Siria y Turquía. El primero poseía los patrones de virulencia de la raza 2 y 5 combinados en un solo aislado; mientras que el segundo poseía los patrones de virulencia de la raza 2, 3 y 5 . Este sistema tiene tres líneas diferenciales de trigo que son Glenlea, 6B365 y 6B662; los cuales tienen tres locus independientes que permiten detectar la presencia de aislados de las razas 2, 3 y 5 respectivamente (Gamba et al., 1998). Con este último trabajo se completa el número teórico máximo de razas que pueden ser diferenciadas por estos tres locus $\left(2^{3}=8\right)$ asumiendo una relación uno a uno. A pesar de esto, recientemente se han identificado dos razas más (tentativamente llamadas razas 9 y 10) provenientes de América del Sur, con un patrón de virulencia distinto al de América del Norte, lo que indicaría que la población de este patógeno es diversa en esta región (Ali \& Francl, 2002a; 2002b). En este trabajo se tomará en cuenta la estructura de razas propuesta por Andrie et al. (2007), basada en diferentes estudios (Lamari et al., 1995; 2003; Strelkov et al., 2002), y que se basa en las reacciones sobre las líneas Glenlea, Katepwa, 6B365, 6B662, Salamouni y M3 (Tabla 1.1.7).

La determinación de razas basada solamente en la caracterización fenotípica puede traer algunos errores. Por ello Andrie et al. (2007) propusieron minimizarlos, añadiendo a la caracterización fenotípica, la confirmación molecular a través de la determinación de la ausencia o presencia de genes asociados a la presencia de síntomas de necrosis y clorosis.

El gen Tox $A$ es responsable de la producción de la toxina ToxA y debería estar presente en las razas 1, 2, 7 y 8 . Esta toxina es una proteína de bajo peso molecular y es responsable de los típicos síntomas de necrosis en trigo (Ballance et al., 1989; Ciuffetti et al., 1997; Zhang et al., 1997). El gen Tox B es responsable de la producción de la toxina ToxB y debería estar presente en las razas 5, 6, 7 y 8. Esta toxina es una proteína de bajo peso molecular (Strelkov et al., 1999) y es responsable de los síntomas de clorosis en líneas susceptibles (Ciuffetti et al., 1998). La misma está codificada por múltiples copias del gen Tox B (Martínez et al., 2001; 2004; Strelkov et al., 2006) y debido a ello se han encontrado distintos genes homólogos Tox $B$ en aislados de la raza 3 (Strelkov \& Lamari, 2003; Strelkov et al., 2006) y raza 4 (de Wolf et al., 1998; Strelkov et al., 2006) aunque éstos no producían la toxina ToxB (Ciuffetti et al., 2003; Strelkov \& Lamari, 2003) o eran patogénicos en las líneas de trigo susceptibles a esta toxina (Lamari \& Bernier, 1989a). Se han hallado aislados de D. tritici-repentis que portan el gen Tox B pero sin la producción de ToxB (Andrie et al., 2007; Lamari et al., 1995; Martínez et al., 2004; Strelkov et al., 2006). El gen responsable de la producción de la toxina ToxC aún no está caracterizado y debería estar presente en las razas 1, 3, 6 y 8. Esta toxina también produce clorosis pero en diferentes líneas que la ToxB. La 
misma aún no está bien caracterizada y estudios genéticos sugieren que juega un importante rol en los factores de patogenicidad de D. tritici-repentis (Gamba \& Lamari, 1998; Gamba et al., 1998; Lamari \& Bernier, 1991; Moreno et al., 2014).

A pesar de que la caracterización genotípica ayudaría a corroborar la identificación de un determinado aislado en una raza en particular, en base a la caracterización fenotípica, varios trabajos encuentran discrepancias entre ambas. Andrie et al. (2007), Ali et al. (2010) y Lepoint et al. (2010) han encontrado aislados donde los patrones fenotípicos no coinciden con los análisis genéticos y proponen que estos deben estar produciendo otros tipos de toxinas. Estos resultados coinciden con los de otros investigadores quienes sugieren la presencia de nuevas razas de D. tritici-repentis además de las ocho conocidas mundialmente (Ali \& Francl, 2002a; 2002b; Ali et al., 2002; Ciuffetti et al., 2003; Manning et al., 2002; Meinhardt et al., 2003).

Diferentes trabajos han estudiado la variabilidad de este patógeno a nivel cultural, patogénico, bioquímico y molecular, utilizando diferentes técnicas, $\mathrm{y}$ han encontrado gran variabilidad entre los aislados del mismo a nivel genético y patogénico (Ali et al., 2010; Andrie et al., 2007; de Wolf et al., 1998; Diaz de Ackermann, 1987; Friesen et al., 2005; Gilchrist et al., 1984; Hosford, 1971; Hunger \& Brown, 1987; Leisová et al., 2008; Lepoint et al., 2010; Mehta et al., 2004; Moreno, 2007; Moreno et al., 2008; Pujol Vieira dos Santos et al., 2002). Varios métodos moleculares se han usado para analizar la diversidad de este patógeno a nivel genético como RAPD (random amplified polymorphic DNA), AFLP (amplified fragments length polymorphism), ERIC (enterobacterial intergenic consensus), REP (repetitive extragenic palindromic), SSRs (simple sequence repeats) y ISSR (inter simple sequence repeats) (Mehta et al., 2004; Moreno et al., 2008; 2012; Pujol Vieira dos Santos et al., 2002). Estos trabajos muestran que existe una alta variabilidad intraespecífica entre aislados de $D$. tritici-repentis y que no es posible establecer un agrupamiento genético por patotipos o por región geográfica (Friesen et al., 2005; Moreno et al., 2008; Pujol Vieira dos Santos et al., 2002). Por lo que estos resultados sugieren que la población de este patógeno es compleja en sus características.

En nuestro país la situación es similar y se ha encontrado gran variabilidad entre diferentes aislados de $D$. tritici-repentis a nivel cultural, patogénico, enzimático y molecular (Moreno, 2007; Moreno et al., 2008; 2011; Perelló et al., 2012). Moreno et al. (2014) también han encontrado discrepancias entre la caracterización fenotípica y genotípica de diferentes aislados tomados de diversos puntos del país. Estos resultados sugieren que la estructura poblacional del patógeno no está bien determinada tampoco en Argentina.

\subsection{Resistencia Genética}

La pérdida de resistencia genética en variedades comerciales de trigo debido a la aparición de nuevos patotipos del hongo ha sido bien documentada (Araya \& Cárdenas, 1999; Young \& Kelly, 1997). Es importante conocer la existencia de razas del patógeno y la relación de éstas con su hospedante para poder detectar genes de resistencia y 
obtener cultivares con resistencia durable (Ali \& Francl, 2002b). D. tritici-repentis produce la fase sexual de su ciclo en rastrojos de trigo, bajo condiciones de campo en nuestro país, lo que aumenta las posibilidades de recombinación sexual y ello podría explicar el gran nivel de variabilidad patogénica del hongo. Esto ayudaría a que ciertos patotipos que están en baja frecuencia rápidamente puedan convertirse en predominantes si los cultivares susceptibles se utilizan cada vez más.

El hecho de que hayan ocurrido epifitias de mancha amarilla en las grandes zonas productoras de trigo a nivel mundial y la alta variabilidad de la población de este patógeno hacen necesario incorporar y ampliar la base de la resistencia genética actual en los cultivares de alto rendimiento. El mejoramiento para la resistencia a $D$. triticirepentis es más eficaz a través de la identificación, caracterización e incorporación de nuevas fuentes de resistencia, eficaces frente a varias razas del patógeno, en cultivares de alto potencial. El uso de materiales con buen comportamiento frente a la enfermedad, en combinación con la rotación de cultivos, es la forma más económica y amigable con el medio ambiente para controlar las pérdidas causadas por ésta (Singh et al., 2010; Strelkov \& Lamari, 2003).

Una parte importante de la resistencia disponible frente a $D$. tritici-repentis es de tipo parcial o incompleta (Rees \& Platz, 1992) caracterizada por la ausencia de inmunidad frente a la enfermedad. Esto quiere decir que aquéllos materiales de buen comportamiento tendrán una menor intensidad de lesiones que aquéllos que son altamente susceptibles.

La escasa disponibilidad de resistencia fue puntualizada por Rees \& Platz. (1992) quienes reportaron que sólo unos pocos materiales, entre más de 60 evaluados, demostraron poseer resistencia detectable frente a esta enfermedad. Los mismos autores no han encontrado reacción de inmunidad en 1400 materiales de trigo evaluados; aunque se han hallado varios niveles de resistencia en variedades de hábito primaveral o invernal y sobre todo en aquellas de origen brasilero (Rees \& Platz, 1990). Kohli et al. (1992) también informaron la escasez de altos niveles de resistencia en cultivares y líneas avanzadas de trigo en el Cono Sur. Gilchrist (1992) ha encontrado materiales con buen nivel de resistencia en líneas de trigo Chinas, Mejicanas y Brasileras y en la progenie de un cruzamiento interespecífico con Agropyrum curvifolium. Altos niveles de resistencia han sido encontrados en trigo pan y trigo sintético por otros investigadores (Tadesse et al., 2006a; 2006b; Riede et al., 1996) y también en trigos de distinto nivel de ploidia, aunque ningún genotipo fue hallado inmune (Lamari \& Bernier, 1989a; Singh et al., 2006). Se han detectado buenos niveles de resistencia en especies silvestres relacionadas con el trigo especialmente en T. monococum (AA), Aegilops tauschii (DD), T. dicoccoides (AABB), T. dicoccum (AABB). T. turgidum (AABB), T. persicum (CCUU), T. timopheevii (AAGG), T. spelta (AABBDD) y $T$. zukhovskii (AAAAGG) (Lamari \& Bernier, 1989a; Singh et al., 2006; Zhang \& Jin, 1998). Similares observaciones fueron halladas por Alam \& Gustafson (1988) en Ae. speltoides (SS), Ae. triaristata (UUMM), Ae cylindrica (CCDD), y Ae ovata (UUMM). Materiales con resistencia también han sido identificados en especies 
derivadas del trigo como Ae. tauschii (DD), Leymus racemosus (NsNsXmXm), Elymus rectisetus (StStYYWW), Thinopyrum elongatum (EE), Th. junceum (EEEEEE), Th. Ponticum (EEEEEEEEEE), Th. Intermedium (EEEEStSt o JJEEStSt), Dasypyrum villosa (VV), Avena sativa (AACCDD), y Secale cereale (RR) (Oliver et al., 2008). En una reciente evaluación de 126 materiales entre los que había trigos duros, rojos primaverales y líneas de las grandes planicies de Norte América se ha encontrado altos niveles de resistencia frente a varias razas de $D$. tritici-repentis y sus toxinas en 10 de estos materiales (Singh et al., 2006).

En nuestro país la situación es similar donde la mayoría de los cultivares comerciales son susceptibles a altamente susceptibles bajo condiciones naturales de alta presión de la enfermedad (Annone, 1998). En base a observaciones realizadas durante los años 1994, 1995 y 1996 el mismo autor presentó una lista de variedades comerciales con algún grado de resistencia frente a la enfermedad entre las que se encuentran Buck Charrua, Buck Guarani, Cooperación Calquin, Cooperacion Maipun, Don Ernesto INTA, Klein Cacique, Klein Centauro, Klein Estrella, ProINTA Federal, ProINTA Guazu y ProINTA Real. También señaló que el rango de 1-30 \% de severidad de mancha amarilla en hoja bandera parece el adecuado para caracterizar al material como moderadamente resistente. En un trabajo más reciente, llevado a cabo en tres localidades y durante los años 2003 y 2004, Annone \& García (2005) caracterizaron 34 variedades comerciales de trigo frente a $D$. tritici-repentis, en condiciones naturales de campo, y encontraron que Buck Aguara, Klein Proteo, Relmo Tijereta, Buck Arriero y ProINTA Gaucho se manifestaron como las de mejor comportamiento. Galich \& Galich (1994) analizaron el comportamiento de cultivares de trigo de distinto ciclo frente a $D$. tritici-repentis en el sur de Córdoba y Santa Fe observando que sólo un grupo limitado se comportó como moderadamente susceptible y el resto como susceptible. Además de éstos, varios trabajos han caracterizado cultivares comerciales de trigo frente a la enfermedad en condiciones naturales de campo. Sin embargo hay muy pocos trabajos donde se haya caracterizado el comportamiento de cultivares comerciales de trigo frente a distintos aislados del patógeno caracterizados molecularmente (Moreno et al., 2008).

Considerando estos antecedentes y que existen algunos aislados que parecen corresponder a diferentes razas del patógeno se plantean las siguientes hipótesis: 


\subsection{Hipótesis}

- Los aislados seleccionados son diferentes entre sí en base a su caracterización por el tipo de reacción sobre líneas diferenciales y por el análisis molecular de genes que codifican toxinas específicas.

- Existen interacciones específicas entre los aislados del patógeno y los cultivares argentinos de trigo.

- Es posible detectar resistencia frente a varios aislados del patógeno en cultivares argentinos de trigo.

\subsection{Objetivos}

- Caracterizar tres aislados de D. tritici-repentis, tomados de distintas regiones del país, a través del tipo de reacción en líneas diferenciales de trigo y a través del análisis molecular de los genes que codifican la producción de toxinas específicas del hongo.

- Analizar la respuesta a la infección de 31 cultivares comerciales argentinas de trigo, entre las que se encuentran algunas que muestran moderada resistencia a campo y los cultivares más sembrados, frente a tres aislados, previamente caracterizados, de D. tritici-repentis al estado de plántula en invernáculo, y en planta adulta a campo. 


\section{CAPITULO 2:}

\section{MATERIALES Y METODOS}

\subsection{Aislados fúngicos}

Se caracterizaron tres aislados monospóricos del patógeno $D$. tritici-repentis. Los mismos fueron aportados por la Dra. Analía Perelló del Centro de Investigaciones de Fitopatología (CIDEFI), Facultad de Ciencias Agrarias y Forestales, Universidad Nacional de La Plata y del Consejo Nacional de Investigaciones Científicas y Técnicas (CONICET). Los tres aislados se seleccionaron en base a haber demostrado un comportamiento diferencial en algunos cultivares en ensayos previamente realizados (Perelló com. pers.). Su procedencia es:

- Aislado 1 (cepa LH) procedente de la localidad Los Hornos (Fig. 2.1.1.).

- Aislado 2 (cepa 25M035) procedente de la localidad de 25 de Mayo (Fig. 2.1.2.).

- Aislado 3 (G327) procedente de la localidad de Gualeguaychu (Fig. 2.1.3.).

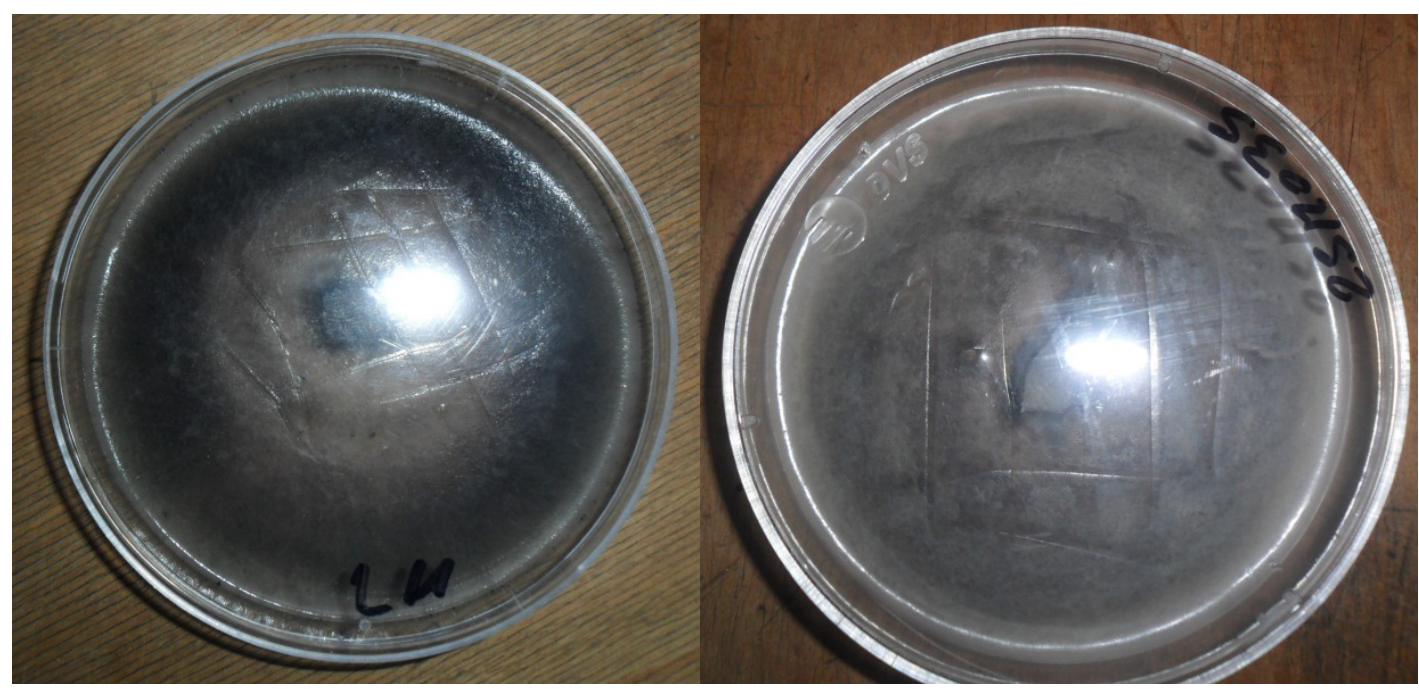

Figura 2.1.1. Aislado axénico de $D$. Figura 2.1.2. Aislado axénico de $D$. tritici-repentis procedente de la tritici-repentis procedente de la localidad de Los Hornos (Aislado 1). $\quad$ localidad de 25 de Mayo (Aislado 2). 


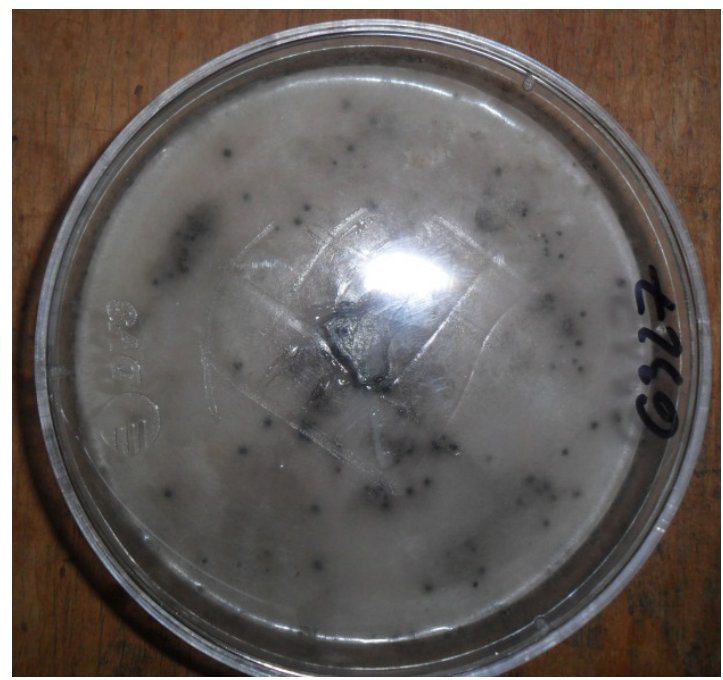

Figura 2.1.3. Aislado axénico de $D$. tritici-repentis procedente de la localidad de Gualeguaychu (Aislado 3).

\subsection{Producción de Inóculo}

A partir de una caja de Petri conteniendo un cultivo axénico de cada aislado de D. tritici-repentis, la cual fue considerada como el inóculo de partida, se obtuvieron, con la ayuda de un sacabocado previamente flameado, discos de $6 \mathrm{~mm}$ de diámetro del margen en activo crecimiento. Estos se sembraron individualmente en el centro de cajas de Petri conteniendo el medio agar simil V8 (2 grs. de caldo vegetal deshidratado comercial Knorr +20 grs. Agar +3 grs. $\mathrm{Co} 3 \mathrm{Ca}+$ agua destilada $1 \mathrm{~L} .+250 \mathrm{mg}$. Cloranfenicol), a través del método de siembra en un punto, colocando el mismo en el centro de la caja (Evans et al., 1993). Se sembró 10 cajas de Petri para $10 \mathrm{~m}^{2} \mathrm{de}$ superficie a inocular a nivel de campo.

Las cajas de Petri inoculadas se incubaron a $21{ }^{\circ} \mathrm{C} \pm 2{ }^{\circ} \mathrm{C}$ con ciclos de alternancia de $12 \mathrm{~h}$ de luz y $12 \mathrm{~h}$ de oscuridad (3500 lux emitida por tubos de luz negra con un adicional de luz cercana al UV de $365 \mathrm{~nm}$; Raymond \& Bockus, 1982). Transcurrido 6 días de incubación, se procedió a realizar un raspado superficial de la colonia con la ayuda de un portaobjeto previamente flameado, para favorecer la esporulación, seguido de un shock de $24 \mathrm{~h}$ luz y posteriormente $24 \mathrm{~h}$ de oscuridad.

Los conidios y/o micelio se cosecharon agregando $5 \mathrm{ml}$ de agua destilada estéril sobre la caja de Petri. Posteriormente esta suspensión se transfirió a un vaso aforado. Esta operación se repitió dos veces por caja de Petri. La suspensión resultante se filtró y licuó en procesadora.

La concentración de conidios en la suspensión se ajustó a $3 \times 10^{3}$ conidios $/ \mathrm{ml}$, siendo estimada a través del recuento en cámara de Neubauer e incluyendo el agregado de 3 gotas de Tween 20 el cual se utilizó como surfactante (Ali et al., 1990; Ali \& Francl, 2001a; Gamba \& Lamari, 1998, Gamba et al., 1998; Lamari et al., 1995; 1998; Luz \& Hosford, 1980; Schilder \& Bergstrom, 1990). 


\subsection{Caracterización del tipo de reacción en líneas diferenciales de trigo:}

Se utilizaron las líneas diferenciales propuestas por Andrie et al. (2007) y Ali et al. (2010) el cual posee las líneas Glenlea, Katepwa, 6B365, 6B662, Salamouni y M3. A estas se le sumaron las líneas diferenciales Coulter, Erik y 4B-160 utilizadas en otros trabajos de investigación (Benslimane et al., 2011; Lamari et al., 2003). Las semillas fueron proporcionadas por el Dr. Pawan Kumar Singh del Centro Internacional de Mejoramiento de Maíz y Trigo (CIMMYT).

El ensayo se realizó con un diseño factorial, siendo los factores las líneas y los aislados, con seis repeticiones. Se sembraron siete semillas de cada línea por aislado por repetición en macetas de plástico de $12 \mathrm{~cm}$ de diámetro y $15 \mathrm{~cm}$ de profundidad. Éstas se mantuvieron en invernáculo con condiciones de temperatura y humedad registradas en la Figura 2.3.1.

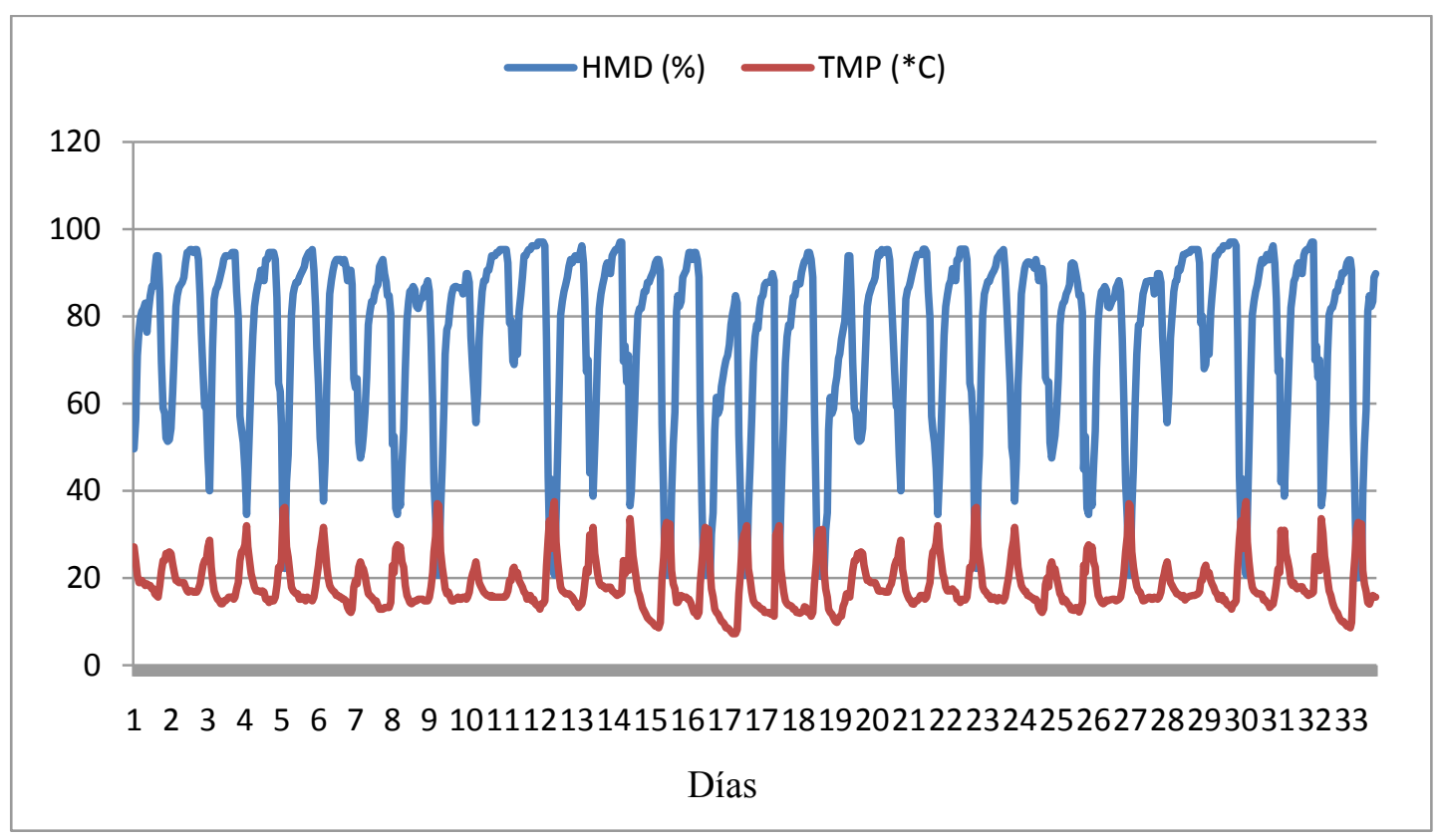

Figura 2.3.1. Temperatura $\left({ }^{\circ} \mathrm{C}\right)$ y Humedad relativa $(\%)$ registradas en un ensayo de trigo inoculado individualmente con 3 aislados de D. tritici-repentis, en invernáculo sobre 9 líneas de trigo.

Cuando las plantas poseían 3 hojas desplegadas, se procedió a realizar la inoculación de cada aislado a través de un pulverizador manual hasta chorreo completo de la planta ( $25 \mathrm{ml}$ por maceta aproximadamente). Luego de la inoculación se cubrieron con una bolsa de plástico que contenía en su interior un recipiente con agua para asegurar una alta humedad por $48 \mathrm{~h}$ y así favorecer la infección. A los 10 y 14 días de la inoculación se evaluaron en base al tipo de reacción en cada línea $(\mathrm{N}=\mathrm{Necrosis} ; \mathrm{Cl}=$ Clorosis; $\mathrm{N} \mathrm{Cl}=$ Necrosis + Clorosis; $\mathrm{R}=$ Resistente) para así poder determinar el patrón de virulencia de cada aislado. 


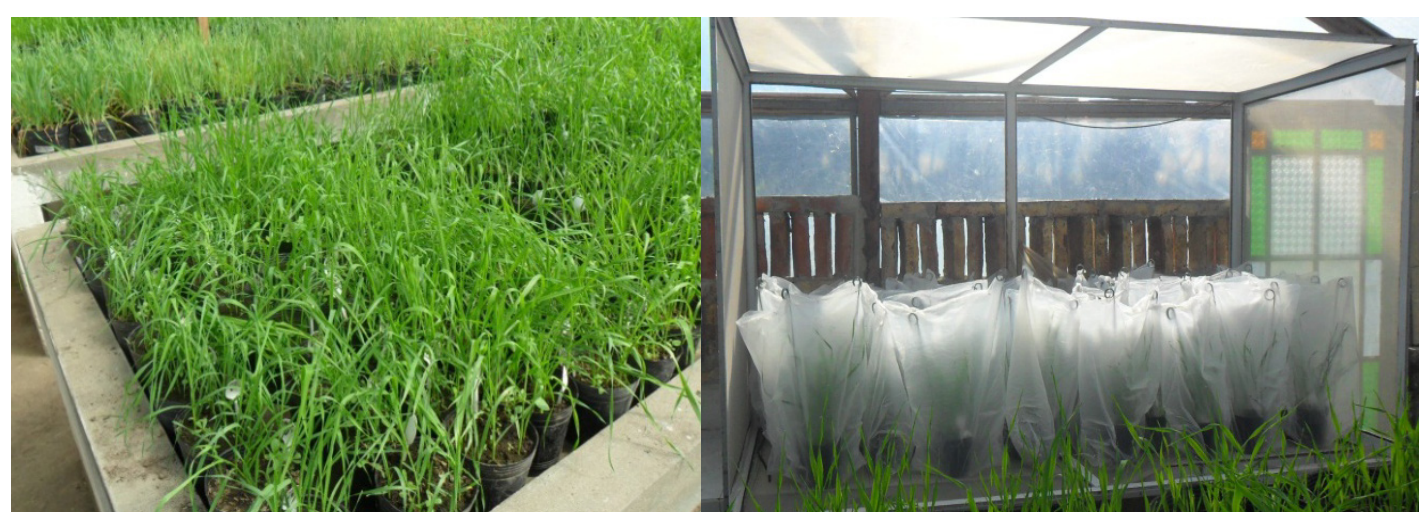

Figura 2.3.2. Ensayo de trigo inoculado individualmente con aislados seleccionados de $D$. tritici-repentis, en invernáculo sobre 9 líneas diferenciales de trigo.

\subsection{Análisis molecular de genes que codifican toxinas en los aislados:}

\subsubsection{Extracción de ADN}

Los aislados se cultivaron en agar-simil V8. Para cada aislado, se utilizó material proveniente de cultivos de 7 días de crecimiento y se rasparon, cuidadosamente, la superficie de los mismos con un bisturí para luego transferirlo a un Eppendorf de 1,5 ml. Se mezcló con $400 \mu \mathrm{l}$ de CTAB (bromuro de cetil trimetil amonio) + buffer de extracción $(100 \mathrm{mM}$ Tris-HCl pH $8.0+20$ mM EDTA pH $8.0+1.4 \mathrm{M} \mathrm{NaCl}+0,2 \%$ $(\mathrm{w} / \mathrm{v}) \beta$ mercapto ethanol) $+100 \mu \mathrm{l}$ de CTAB $10 \%$. Se extrajo el ADN por calentamiento de la suspensión a $60{ }^{\circ} \mathrm{C}$ por $30 \mathrm{~min}$. Luego, se añadió un volumen de una mezcla de cloroformo: alcohol isoamílico $(24: 1 \mathrm{v} / \mathrm{v})$, y los tubos se agitaron y centrifugaron a $10000 \mathrm{~g}$ durante $5 \mathrm{~min}$. La fase acuosa, que contenía el ADN, se transfirió a un nuevo tubo y se precipitó durante toda la noche mediante la adición de isopropanol. El ADN se sedimentó por centrifugación a $10000 \mathrm{xg}$ durante $10 \mathrm{~min}$; se lavó con $10 \mathrm{mM}$ de acetato de amonio en etanol al $75 \%$ (10000 xg, $10 \mathrm{~min})$ y luego con etanol al $70 \%$ (10000 xg, $10 \mathrm{~min}$ ) (Murray \& Thompson, 1980; Wagner et al., 1987). Posteriormente, el sedimento de ADN se secó y se disolvió en $80 \mu 1$ de TE (10 $\mathrm{mM}$ Tris-HCl pH 8.0 + 1 mM EDTA pH 8.0). La concentración de ADN se estimó por comparación con un marcador molecular de concentración conocida en electroforesis en gel de agarosa al $0,7 \%$.

\subsubsection{Análisis de los genes Tox $A$ y Tox $B$ por PCR}

Se seleccionaron los cebadores correspondientes a la región codificadora de los genes Tox A, Tox $B$ y tox $b$ determinados por Andrie et al. (2007). Los cebadores Tox $A$ (TA51F/TA52R) amplifican un fragmento de 600 pb sólo en las razas 1 y 2; mientras que las razas 3, 4 y 5 amplifican un fragmento de 250 pb específico para Tox $B$ utilizando el par de cebadores TB71F/TB6R. El cebador inverso TB60R emparejado con TB71F amplifica tanto al gen Tox $B 1$ específico de raza 5 y secuencias homólogas de Tox $B$ que son características de la raza 5, mientras que el cebador inverso TB58R es específico de tox $b$ en la raza 4. Las PCR se realizaron en un volumen final de $25 \mu 1$ que contenía 12 ng de ADN genómico, $10 \mathrm{X}$ de buffer de reacción $(2 \mathrm{mM}$ Tris- $\mathrm{HCl} \mathrm{pH} 8.0+$ $10 \mathrm{mM} \mathrm{KCl}+0,01 \mathrm{mM}$ EDTA $+1 \mathrm{mM}$ DTT $+50 \%$ glicerol $+0,5 \%$ Tween $20+0.5$ $\%$ Nonidet P40.), 0,7 $\mu \mathrm{M}$ de cebador, $200 \mu \mathrm{M}$ de cada dNTP (Promega Biotech. Corporation), 2,5 $\mathrm{mM}$ de $\mathrm{MgCl}_{2}$ y 1,25 unidades de Taq ADN polimerasa. Las 
amplificaciones de ADN se realizaron en un termociclador XP (Bioer Tecnología Co, Hangzhou, China) usando el siguiente protocolo de ciclos: una etapa de desnaturalización inicial de $95{ }^{\circ} \mathrm{C}$ durante $2 \mathrm{~min}$., seguido de 29 ciclos a $95{ }^{\circ} \mathrm{C}$ durante 30 seg., $50{ }^{\circ} \mathrm{C}$ durante 35 seg. (TA51F / TA52R y TB71F/TB58R) y $72{ }^{\circ} \mathrm{C}$ durante 45 seg. y un ciclo de extensión final a $72^{\circ} \mathrm{C}$ durante $2 \mathrm{~min}$. La temperatura de hibridación o "annealing" fue de $52{ }^{\circ} \mathrm{C}$ para los cebadoresTB71F/TB6Ry TB71F/TB60R. Cada reacción se realizó al menos dos veces. Los productos de PCR se sometieron a electroforesis en geles de agarosa de 1,5\% (peso/vol), que contenían $3 \mu \mathrm{l}^{-1}$ de GelRed (Biotium, Hayward, EE.UU.), a 80 voltios en solución buffer $5 \mathrm{X}$ de Tris-borato-EDTA durante $3 \mathrm{~h}$ a temperatura ambiente. Los fragmentos amplificados se visualizaron bajo luz UV. El tamaño de los fragmentos de ADN se estimó mediante la comparación de las bandas de ADN con controles positivos de aislados de razas de $D$. tritici-repentis que portan las diferentes toxinas. Las imágenes del gel se fotografiaron con un sistema digital DOC 6490 (Biodinámica SRL, Buenos Aires, Argentina).

2.5 Caracterización de cultivares argentinos de trigo al estado de plántula frente a la presencia/actividad de los aislados seleccionados de $D$. tritici-repentis en invernáculo.

Se seleccionaron 31 cultivares de trigo en base a cuatro criterios.

Grupo 1. Veinte cultivares comerciales de trigo en base a su buen comportamiento (moderada resistencia) a D. tritici-repentis a través de información obtenida de diversas fuentes (Alberione et al., 2011a; Alberione et al., 2011b; Alberione et al., 2012; Castro et al., 2010; Catalogo Semillas Buck Trigo 2012; Díaz de Ackermann, 2010; Pereyra \& Díaz, 2011; Pereyra \& Germán, 2012; Proyecto Regional Trigo: principales logros y avances / IICA - PROCISUR, 2010; Red de Ensayos Comparativos de Variedades de Trigo. Campaña 2012/13. Localidades: Marcos Juárez, Pergamino, Pla. INASE.; Resultados Experimentales de la Evaluación de Cultivares de Trigo, Cebada, Colza, Triticale y Trigo doble propósito de los tres últimos años. Período 2008-2009-2010. INIA). Estos son Sursem Nogal, Baguette Premium 11, Buck SY 300, Klein Capricornio, Don Mario Don Mario Lenox, Klein Proteo, Klein Tauro, BioInta 1001, Klein Castor, Buck $75^{\circ}$ Aniversario, Buck AGP Fast, Buck SY 110, ACA 901, Klein León, Klein Rayo, Baguette Premium 13, Baguette 701, Buck SY 100, ACA 320 y Klein Nutria.

Grupo 2. Cinco cultivares de trigo de mayor superficie sembrada en el país para poder conocer como es su comportamiento frente a la enfermedad. Estos datos se obtuvieron en base a informes personales de los criaderos Klein y Buck ya que no existen estadísticas oficiales respecto a este tema. Estos son Baguette 601, Baguette 9, Baguette 17, BioInta 3005 y Don Mario Cronox.

Grupo 3. Cuatro cultivares de trigo que han manifestado diferencias a campo y que constituyen progenitores de una población de mapeo. En caso de encontrar diferentes niveles de resistencia con estos aislados serían de utilidad para localizar marcadores para resistencia al patógeno. Estas son ProInta Puntal, Klein Volcán, Klein Dragón y Buck Brasil. 
Grupo 4. Dos cultivares muy susceptibles frente a $D$. tritici-repentis a fín de asegurar que la naturaleza patogénica de los aislados analizados. Estas son BioInta 2004 y Sursem 2330.

El ensayo se realizó con un diseño factorial con dos repeticiones, siendo los factores los cultivares y los aislados. Se sembraron siete semillas de cada línea por aislado por repetición en macetas de plástico de $12 \mathrm{~cm}$ de diámetro y $15 \mathrm{~cm}$ de profundidad. Estas se mantuvieron en invernáculo con similares condiciones de temperatura y humedad que las registradas para el ensayo del tipo de reacción en líneas diferenciales de trigo.

Cuando las plantas poseían 3 hojas desplegadas se procedió a realizar la inoculación de cada aislado a través de un pulverizador manual hasta chorreo completo de la planta. Luego de la inoculación se cubrieron con una bolsa de plástico que contenía en su interior un recipiente con agua para asegurar una alta humedad por $48 \mathrm{~h}$ y así favorecer la infección. A los 14 días se evaluó la segunda y tercer hoja de 5 plantas de cada macetas en base al tipo de reacción, usando la escala de 1-5 propuesta por Lamari \& Bernier (1989a) (Figura 2.5.1), y la severidad de la misma (porcentaje de área foliar afectada por la enfermedad).

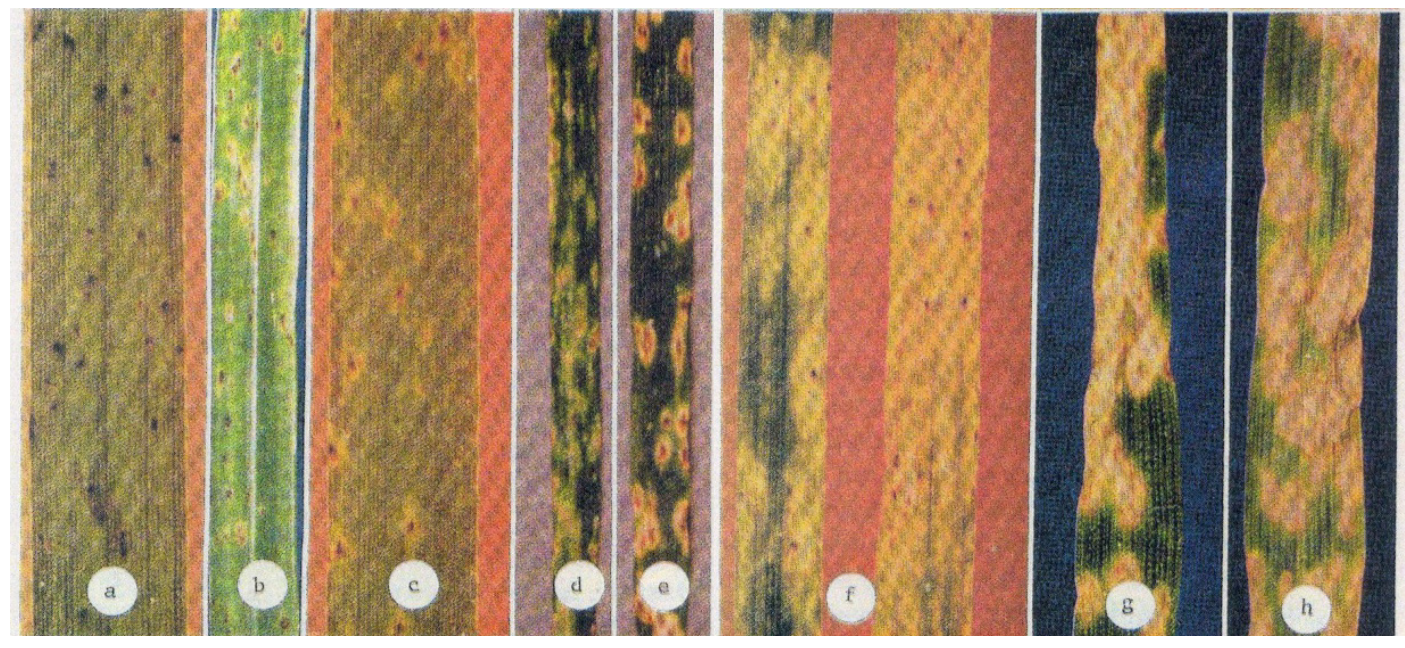

Figura 2.5.1. Escala de 1-5 propuesta por Lamari \& Bernier (1989a). Referencias: a. Lesión tipo 1 = Pequeños puntos negros o marrones sin halo clorótico o necrosis; b. Lesión tipo 2 = Pequeños puntos negros o marrones con muy poca clorosis o necrosis; c. Lesión tipo $3=$ Pequeños puntos negros o marrones completamente rodeados por halo clorótico o necrótico; d,e. Lesión tipo $4=$ Pequeños puntos negros o marrones completamente rodeados por halo clorótico o necrótico, algunas de las lesiones coalescen; f,g,h. Lesión tipo $5=$ Los pequeños puntos negros o marrones pueden o no ser distinguibles, la mayoría de las lesiones son zonas cloróticas o necróticas coalescentes. 


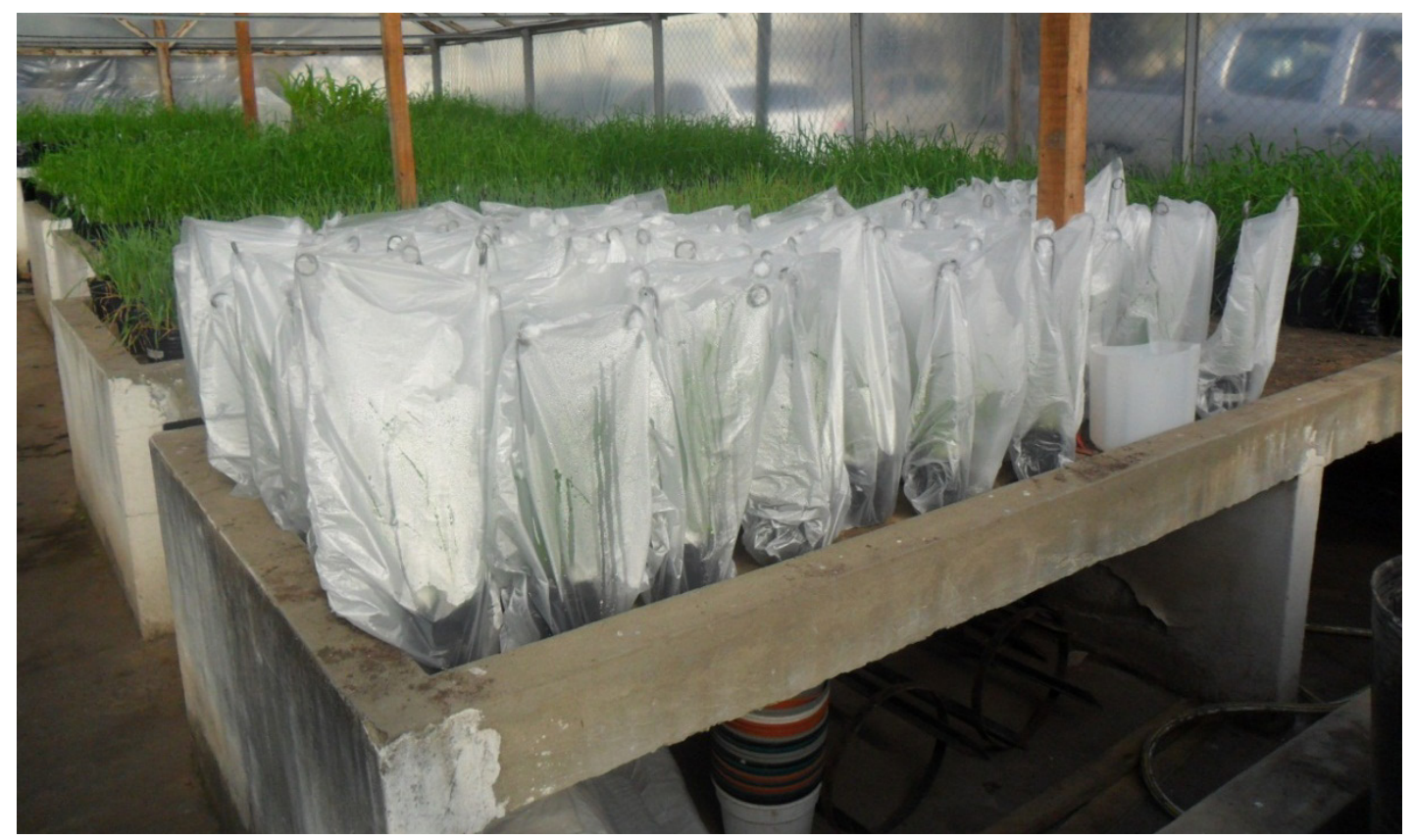

Figura 2.5.2. Ensayo de trigo inoculado individualmente al estado de plántula con aislados seleccionados de $D$. tritici-repentis, en invernáculo sobre 31 cultivares de trigo.

2.6 Caracterización de cultivares argentinos de trigo al estado de planta adulta frente a la presencia/actividad de los aislados seleccionados de $D$. tritici-repentis bajo condiciones a campo.

Se utilizaron los 31 cultivares seleccionados para realizar la evaluación en plántula. El ensayo se realizó en dos localidades en el mismo año para obtener dos ambientes con un diseño de parcela subdividida. Estas fueron la Estación Experimental Julio Hirschhorn dependiente de la Universidad Nacional de La Plata en Los Hornos, Partido de La Plata y la Estación Experimental Agropecuaria Pergamino, del Instituto Nacional de Tecnología Agropecuaria en el partido de Pergamino. La parcela principal fue la localidad, la sub-parcela el aislado y la sub-sub-parcela el cultivar.

De cada cultivar se sembraron 10 semillas a $2 \mathrm{~cm}$ entre sí y con una separación entre surcos de $20 \mathrm{~cm}$ por cada aislado y dos repeticiones en cada ambiente. Los aislados se separaron entre sí a una distancia mínima de $20 \mathrm{~m}$ y entre ellos se sembró avena para minimizar las posibilidades de contaminación de uno con otro. El suelo se laboreo previamente y las semillas se sembraron manualmente. Se fertilizó con una dosis de $50 \mathrm{~kg}$ de $\mathrm{P} / \mathrm{ha}$ y $100 \mathrm{~kg}$ de N/ha aplicados al voleo al momento de la siembra.

Se procedió a realizar dos inoculaciones durante el ciclo del cultivo, la primera coincidiendo con los estados de principios de encañazón (EC 31 a 32 de la escala de Zadoks et al., 1974) y la segunda comprendida entre la lígula de la hoja bandera visible hasta embuche hinchado (EC 39 a 45). Las inoculaciones se realizaron con aspersor manual con la concentración mencionada anteriormente y un volumen de $3 \mathrm{~L}$ por aislado. Para favorecer la infección se humedecieron las plantas con aspersor manual cada 2 horas durante los 3 días siguientes a la inoculación. 
Se realizaron tres evaluaciones de la enfermedad:

1. La primera, se realizó 15 días después de la primera inoculación (ya que en condiciones de campo la expresión de los síntomas es posterior a lo que sucede en condiciones controladas, en que se consideran 7 días) (EC 37).

2. La segunda, se realizó alrededor de 30-35 días después de la aparición de la hoja bandera (este rango se debe a la diferencia de ciclo de cada uno de los cultivares lo que dificulta tener una uniformidad de estados de crecimiento en un momento dado) (EC 75).

3. La tercera, se realizó 40-45 días después de la aparición de hoja bandera (EC 82).

Se evaluaron las hojas con superficie verde de 7 macollos principales de cada surco y en cada una de éstas se evaluó el tipo de reacción usando la escala de 1-5 propuesta por Lamari \& Bernier (1989a) y la severidad de la misma (porcentaje de área foliar afectada por la enfermedad).

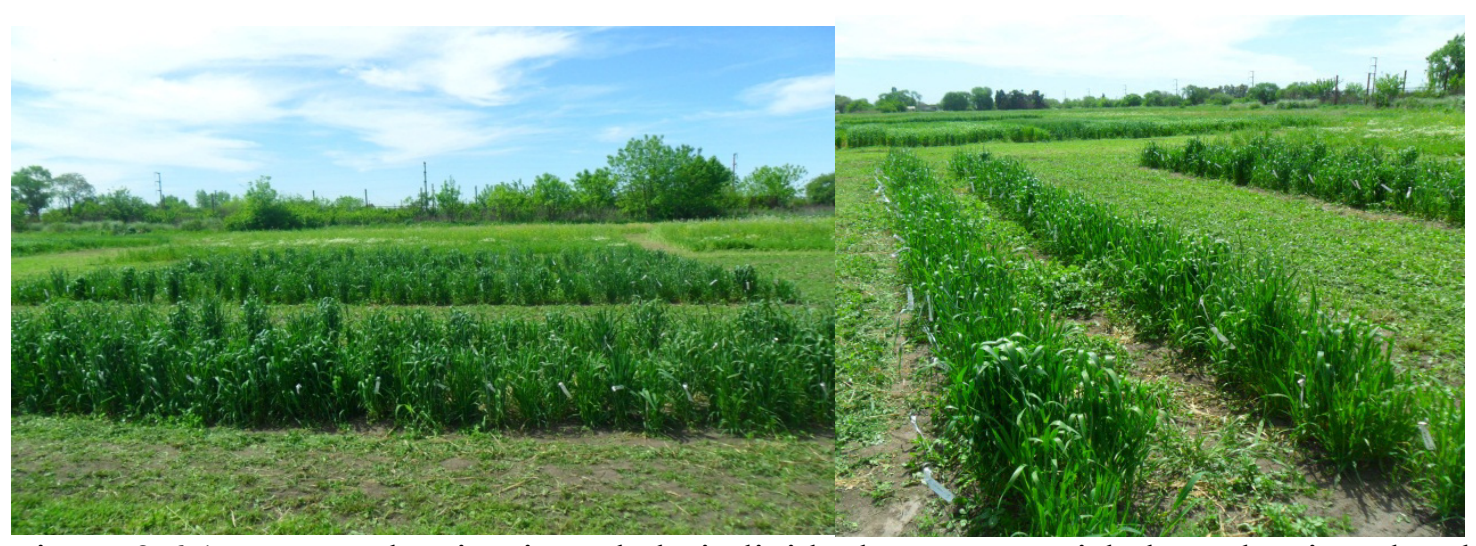

Figura 2.6.1. Ensayo de trigo inoculado individualmente con aislados seleccionados de D. tritici-repentis, en la localidad de Los Hornos sobre 31 cultivares de trigo.

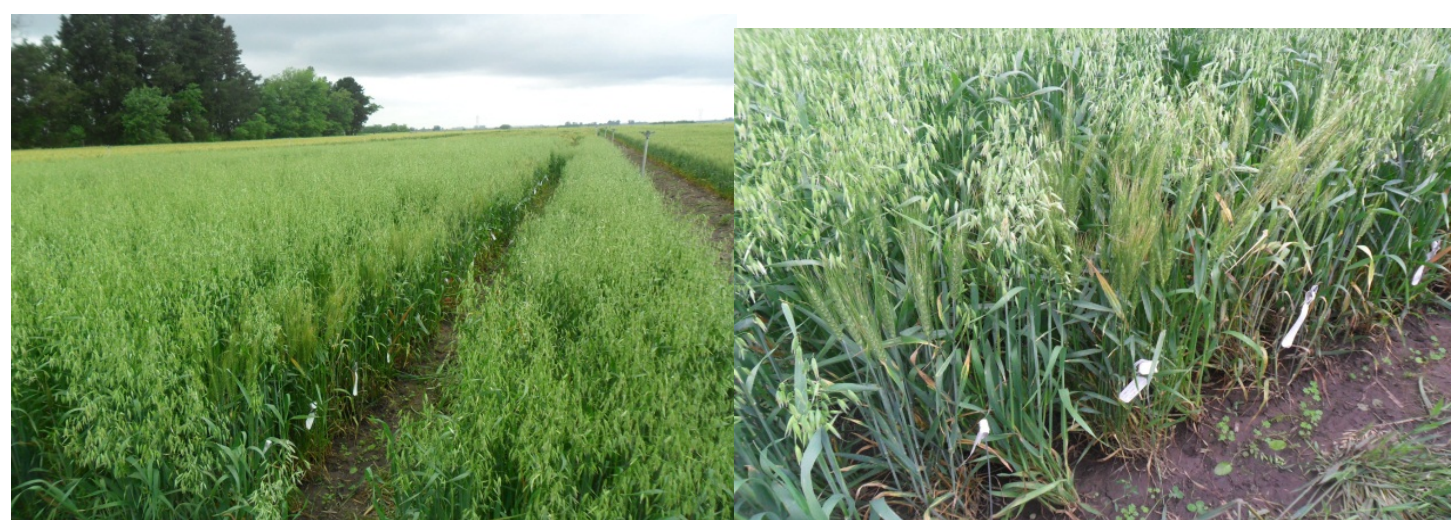

Figura 2.6.2. Ensayo de trigo inoculado individualmente con aislados seleccionados de D. tritici-repentis, en la localidad de Pergamino sobre 31 cultivares de trigo. 


\subsection{Análisis Estadístico}

La caracterización de los cultivares se analizó con el programa GENSTAT para parcelas sub-subdivididas. Para la caracterización en plántula se consideró al aislado como parcela principal y a los cultivares como sub-parcela. Se utilizaron los datos promedio de la segunda y tercer hoja. Para la caracterización a campo se consideró a la localidad como la parcela principal, el aislado como sub-parcela y los cultivares como sub-sub-parcela. Se utilizaron los datos promedio de las 4 hojas superiores en la primera y segunda evaluación y tres hojas superiores en la tercera. Las medias se compararon mediante el test LSD.

Se realizó una discriminación de los cultivares según los valores de área bajo la curva de progreso de la enfermedad (ABCPE) para cada localidad y aislado considerándose como resistentes a todos aquellos cultivares que son estadísticamente iguales al menor valor, susceptibles a los que son estadísticamente iguales al mayor valor y los que quedaron entre ambos valores se clasificaron como moderadamente resistentes si estaban en la mitad inferior de este rango o moderadamente susceptibles si estaban en la mitad superior. 


\section{CAPITULO 3:}

\section{RESULTADOS}

\subsection{Caracterización del tipo de reacción en líneas diferenciales de trigo.}

En la Tabla 3.1.1 se observa el tipo de reacción de las 9 líneas evaluadas, a los 14 días post-inoculación, frente a los 3 aislados de $D$. tritici-repentis.

Tabla 3.1.1. Tipo de reacción de 9 líneas diferenciales de trigo frente a 3 aislados de $D$. tritici-repentis.

\begin{tabular}{|c|c|c|c|c|c|c|c|c|c|}
\hline $\begin{array}{r}\stackrel{\mathscr{J}}{\mathrm{d}} \\
\text { Aislado } \\
\end{array}$ & 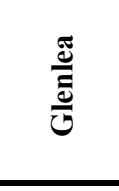 & 苟 & 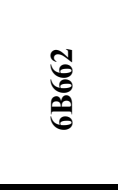 & 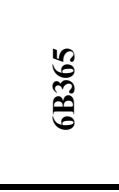 & 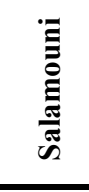 & $\stackrel{m}{z}$ & $\frac{8}{8}$ & 这 & 资 \\
\hline 1 & $\begin{array}{c}\mathrm{N} \mathrm{Cl} \\
\text { (ToxA) }\end{array}$ & $\mathrm{R}$ & $\mathrm{R}$ & $\begin{array}{c}\mathrm{Cl} \\
\text { (ToxC) }\end{array}$ & $\mathrm{NCl}$ & $\mathrm{R}$ & $\mathrm{N}$ & $\mathrm{N} \mathrm{Cl}$ & $\mathrm{R}$ \\
\hline 2 & $\mathrm{R}$ & $\mathrm{R}$ & $\mathrm{R}$ & $\begin{array}{c}\mathrm{Cl} \\
\text { (ToxC) }\end{array}$ & $\mathrm{NCl}$ & $\mathrm{R}$ & $\mathrm{N}$ & $\mathrm{N}$ & $\mathrm{R}$ \\
\hline 3 & $\begin{array}{c}\mathrm{N} \\
\text { (ToxA) }\end{array}$ & $\begin{array}{c}\mathrm{NCl} \\
\text { (ToxA) } \\
\text { (ToxB) }\end{array}$ & $\begin{array}{c}\mathrm{Cl} \\
\text { (ToxB) }\end{array}$ & $\begin{array}{c}\mathrm{Cl} \\
\text { (ToxC) }\end{array}$ & $\mathrm{N}$ & $\mathrm{R}$ & $\mathrm{N} \mathrm{Cl}$ & $\mathrm{Cl}$ & $\mathrm{R}$ \\
\hline
\end{tabular}

Referencias: $\mathrm{N}=$ Necrosis; $\mathrm{Cl}=$ Clorosis; $\mathrm{R}=$ Resistente. Tox $\mathrm{A}=$ Presencia de toxina $\mathrm{A}$; $\mathrm{ToxB}=$ Presencia de toxina $\mathrm{B}$; ToxC $=$ Presencia de toxina $\mathrm{C}$. Aislado 1 = cepa $\mathrm{LH}$; Aislado 2 = cepa 25M035; Aislado 3 = cepa G327.

El aislado 1 se caracterizó por presentar una reacción de necrosis y clorosis en las líneas Glenlea, Salamouni y Coulter, una reacción de clorosis en la línea 6B-365, una reacción de necrosis en 4B-160 y de resistencia en el resto. La reacción de necrosis en Glenlea sería indicativa de la presencia de la toxina A; mientras que la reacción de clorosis en 6B-365 sería indicativa de la presencia de la toxina C. Este aislado comparte algunos tipos de reacción característicos de la raza 1 excepto por la ausencia de necrosis en Katepwa y por la presencia de necrosis y clorosis en Salamouni.

El aislado 2 se caracterizó por una reacción de necrosis y clorosis en Salamouni, una reacción de clorosis en la línea 6B-365, una reacción de necrosis en 4B-160 y Coulter y una reacción de resistencia en el resto de las líneas. La reacción de clorosis en 6B-365 sería indicativa de la presencia de la toxina C. Este aislado comparte algunos tipos de reacción característicos de la raza 3 excepto por la presencia de necrosis y clorosis en Salamouni. 
El aislado 3 se caracterizó por una reacción de necrosis y clorosis en Katepwa y 4B-160, de clorosis en 6B-662, 6B-365 y Coulter, de necrosis en Glenlea y Salamouni y de resistencia en el resto de las líneas. La reacción de necrosis en Glenlea y Katepwa sería indicativa de la presencia de la toxina A; la de clorosis en 6B-662 y Katepwa indicaría la presencia de la toxina $\mathrm{B}$ y la reacción de clorosis en 6B-365 sería indicativa de la presencia de la toxina $\mathrm{C}$. Este aislado comparte algunos tipos de reacción característicos de la raza 8 excepto por la presencia de necrosis en Salamouni.

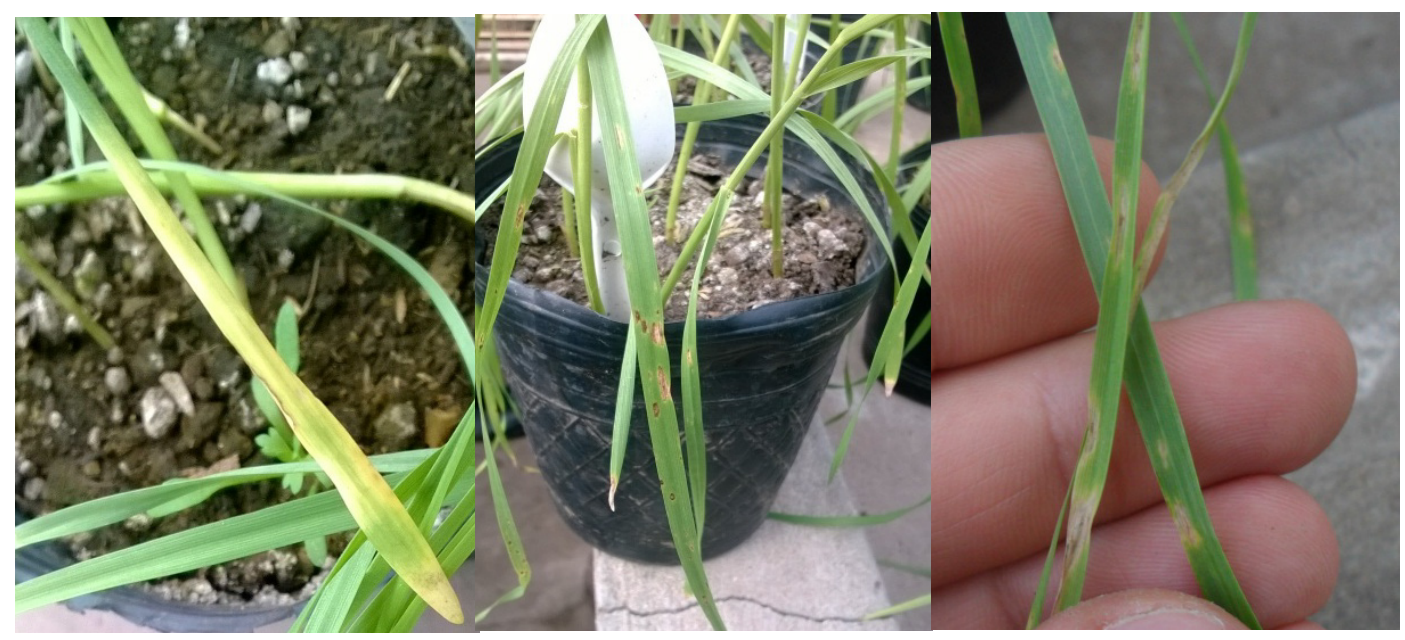

Figura 3.1.1. Reacción de Clorosis, Necrosis y Necrosis + Clorosis respectivamente, en un ensayo de trigo inoculado individualmente con aislados seleccionados de $D$. tritici-repentis sobre 9 líneas diferenciales de trigo. 


\subsection{Análisis molecular de genes que codifican toxinas en los aislados estudiados.}

En la Figura 3.2.1 puede observarse la amplificación de los fragmentos de ADN que indican la presencia de genes que codifican la toxina A (TOX A TA51F/TA52R) y genes homólogos que codifican para la producción de la toxina $\mathrm{B}$ (TOX $b$ TB71F/TB58R, TOX B1 TB71F/TB60R y TOX B TB71F/TB6R).

TOX A TA51F/TA52R

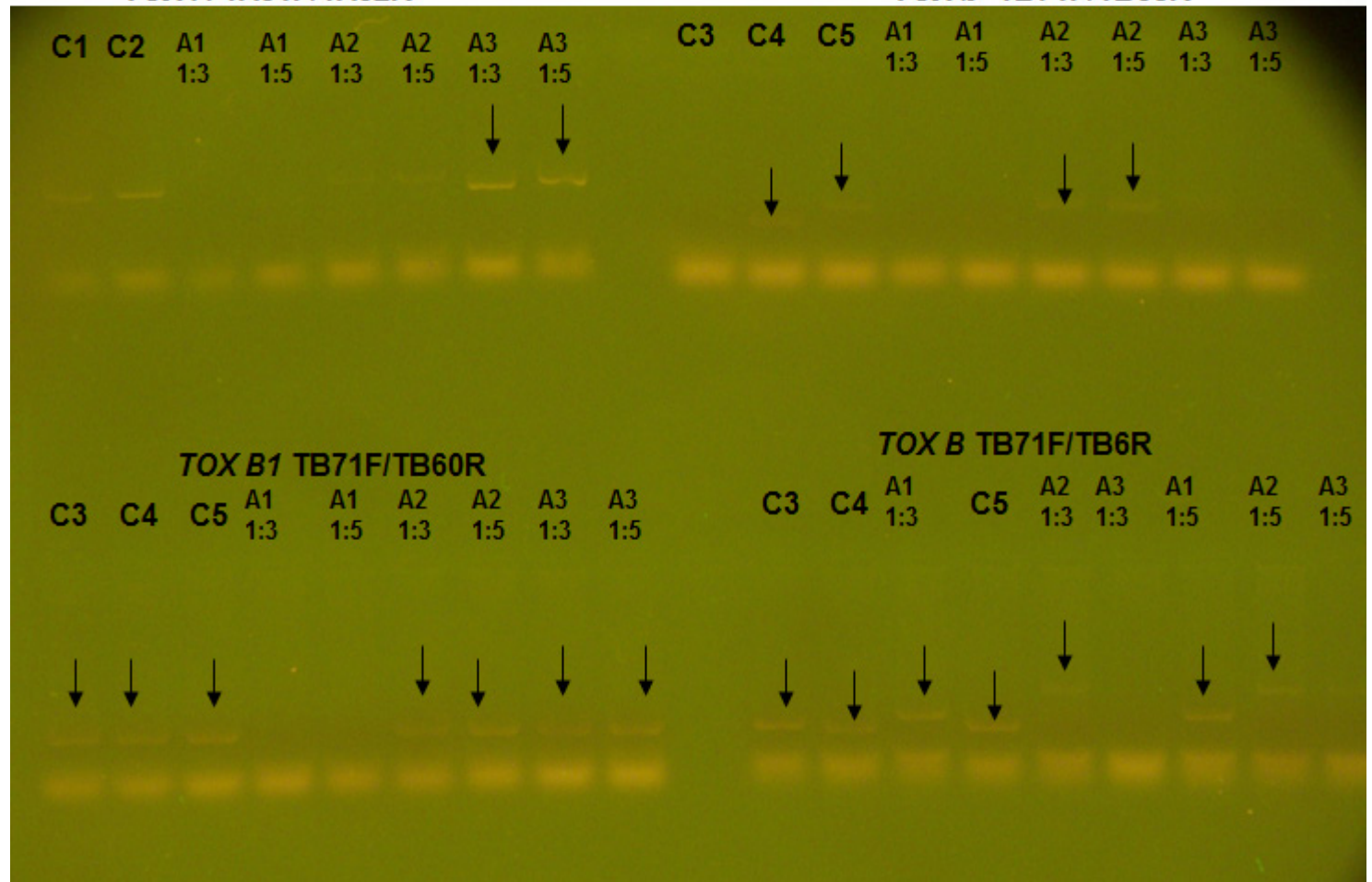

Figura 3.2.1. Estimación de tamaños de fragmentos amplificados de ADN en comparación con controles positivos de los cebadores TOX A TA51F/TA52R, TOX B TB71F/TB58R, TOX B1 TB71F/TB60R y TOX $b$ TB71F/TB6R de 3 aislados de $D$. tritici-repentis. Referencias. $\mathrm{C} 1, \mathrm{C} 2, \mathrm{C} 3, \mathrm{C} 4$ y $\mathrm{C} 5=$ Controles positivos de cada cebador. A1 = aislado 1 (cepa LH); A2 = aislado 2 (cepa 25M035) y A3 = aislado 3 (cepa G327). Flechas negras indican presencia de gen que codifica para la producción de la toxina correspondiente.

El aislado 1 se caracterizó por la presencia del gen $T O X B$; el 2 por la presencia de los genes homólogos $T O X B, T O X B 1$ y $T O X b$ y el aislado 3 por poseer el gen $T O X$ $A$ y $T O X B 1$. 
3.3 Caracterización de cultivares argentinos de trigo al estado de plántula frente a la presencia/actividad de los aislados seleccionados de $D$. tritici-repentis en invernáculo.

En la Tabla 3.3.1 se muestran los cuadrados medios y sus correspondientes probabilidades para la severidad y el tipo de reacción evaluadas 14 días posteriores a la inoculación.

Tabla 3.3.1. Cuadrados medios de la severidad y el tipo de reacción (en estado de plántula) en un ensayo de trigo inoculado individualmente con aislados seleccionados de $D$. tritici-repentis en 31 cultivares de trigo.

\begin{tabular}{|c|c|c|c|}
\hline $\begin{array}{c}\text { Fuente de } \\
\text { Variación }\end{array}$ & G.L. & $\begin{array}{c}\text { Evaluación Severidad } \\
\text {-Promedio de la } \mathbf{2}^{\mathbf{0}} \mathbf{~} \mathbf{3}^{\mathbf{0}} \text { hoja- }\end{array}$ & $\begin{array}{c}\text { Evaluación Tipo de Reacción } \\
\text {-Promedio de la } \mathbf{2}^{\mathbf{0}} \mathbf{~} \mathbf{3}^{\mathbf{0}} \text { hoja- }\end{array}$ \\
\hline Cultivar & 30 & $0,077(<0,001)^{*}$ & $0,002(<0,001)$ \\
\hline Error a & 30 & 0,002 & 0,000 \\
\hline Aislado & 2 & $0,027(<0,001)$ & $0,008(<0,001)$ \\
\hline $\mathbf{C} \times \mathbf{A}$ & 60 & $0,005(<0,001)$ & $0,000(<0,001)$ \\
\hline Error b & 62 & 0,000 & 0,000 \\
\hline
\end{tabular}

* Valor de $\mathrm{P}$ de acuerdo al test de F.

Se observaron diferencias estadísticamente significativas entre cultivares y aislados y en la interacción cultivar $\times$ aislado para la evaluación de severidad y tipo de reacción.

En la Tabla 3.3.2 se indican las medias de severidad, en estado de plántula, para los tres aislados y 31 cultivares de trigo.

Tabla 3.3.2. Medias de severidad en un ensayo de trigo inoculado individualmente con aislados seleccionados de $D$. tritici-repentis en 31 cultivares de trigo, evaluadas 14 días posteriores a la inoculación.

\begin{tabular}{|l|c|c|c|c|c|}
\hline \multicolumn{1}{|c|}{ Aislado } & \multicolumn{5}{|c|}{ Cultivar } \\
\hline & Sursem Nogal & $\begin{array}{c}\text { Baguette } \\
\text { Premium 11 }\end{array}$ & Buck SY 300 & $\begin{array}{c}\text { Klein } \\
\text { Capricornio }\end{array}$ & $\begin{array}{c}\text { Don Mario } \\
\text { Lenox }\end{array}$ \\
\hline 1 & $7,95 \mathrm{a}$ & $13,05 \mathrm{a}$ & $6,80 \mathrm{a}$ & $16,25 \mathrm{a}$ & $8,71 \mathrm{a}$ \\
\hline 2 & $10,66 \mathrm{a}$ & $14,13 \mathrm{a}$ & $5,06 \mathrm{a}$ & $15,40 \mathrm{a}$ & $9,02 \mathrm{a}$ \\
\hline 3 & $13,11 \mathrm{a}$ & $23,96 \mathrm{~b}$ & $7,06 \mathrm{a}$ & $17,53 \mathrm{a}$ & $9,61 \mathrm{a}$ \\
\hline Promedio & 10,57 & 17,05 & 6,31 & 16,39 & 9,11 \\
\hline & Klein Proteo & Klein Tauro & BioInta 1001 & Klein Castor & $\begin{array}{c}\text { Buck 75 } \\
\text { Aniversario }\end{array}$ \\
\hline 1 & $11,82 \mathrm{a}$ & $12,84 \mathrm{a}$ & $9,81 \mathrm{a}$ & $15,49 \mathrm{a}$ & $26,42 \mathrm{~b}$ \\
\hline 2 & $23,34 \mathrm{~b}$ & $13,72 \mathrm{a}$ & $12,83 \mathrm{a}$ & $25,64 \mathrm{~b}$ & $17,31 \mathrm{a}$ \\
\hline 3 & $14,23 \mathrm{a}$ & $22,17 \mathrm{~b}$ & $11,58 \mathrm{a}$ & $15,05 \mathrm{a}$ & $16,02 \mathrm{a}$ \\
\hline Promedio & 16,46 & 16,24 & 11,41 & 18,73 & 19,92 \\
\hline & Buck AGP Fast & Buck SY 110 & ACA 901 & Klein León & Klein Rayo \\
\hline 1 & $10,29 \mathrm{a}$ & $6,54 \mathrm{a}$ & $23,54 \mathrm{a}$ & $18,83 \mathrm{a}$ & $26,27 \mathrm{a}$ \\
\hline 2 & $9,720 \mathrm{a}$ & $7,22 \mathrm{a}$ & $21,36 \mathrm{a}$ & 24,10 ab & $35,28 \mathrm{~b}$ \\
\hline
\end{tabular}




\begin{tabular}{|c|c|c|c|c|c|}
\hline 3 & $11,62 \mathrm{a}$ & $5,42 \mathrm{a}$ & $20,61 \mathrm{a}$ & $26,48 \mathrm{~b}$ & $33,57 \mathrm{~b}$ \\
\hline Promedio & 10,54 & 6,39 & 21,84 & 23,14 & 31,71 \\
\hline & $\begin{array}{c}\text { Baguette } \\
\text { Premium } 13 \\
\end{array}$ & Baguette 701 & Buck SY 100 & $\overline{A C A 320}$ & Klein Nutria \\
\hline 1 & $16,22 \mathrm{a}$ & $38,49 \mathrm{a}$ & $15,59 \mathrm{a}$ & $23,99 \mathrm{a}$ & $18,82 \mathrm{a}$ \\
\hline 2 & $16,60 \mathrm{a}$ & $40,69 \mathrm{a}$ & $12,16 \mathrm{a}$ & $23,91 \mathrm{a}$ & $19,91 \mathrm{a}$ \\
\hline 3 & $17,60 \mathrm{a}$ & $39,41 \mathrm{a}$ & $17,30 \mathrm{a}$ & $30,20 \mathrm{~b}$ & $17,79 \mathrm{a}$ \\
\hline \multirow[t]{2}{*}{ Promedio } & 16,81 & 39,53 & 15,02 & 26,03 & 18,84 \\
\hline & Baguette 601 & Baguette 9 & Baguette 17 & BioInta 3005 & $\begin{array}{c}\text { Don Mario } \\
\text { Cronox }\end{array}$ \\
\hline 1 & $5,23 \mathrm{a}$ & $17,48 \mathrm{a}$ & $7,17 \mathrm{a}$ & $26,07 \mathrm{a}$ & $23,15 \mathrm{a}$ \\
\hline 2 & $4,58 \mathrm{a}$ & $29,29 \mathrm{~b}$ & $6,73 \mathrm{a}$ & $24,48 \mathrm{a}$ & $26,33 \mathrm{a}$ \\
\hline 3 & $4,93 \mathrm{a}$ & $12,87 \mathrm{a}$ & $16,58 \mathrm{~b}$ & $25,78 \mathrm{a}$ & $28,45 \mathrm{a}$ \\
\hline \multirow[t]{2}{*}{ Promedio } & 4,91 & 19,88 & 10,16 & 25,44 & 25,98 \\
\hline & ProInta Puntal & Klein Volcán & Klein Dragón & BioInta 2004 & Sursem 2330 \\
\hline 1 & $10,07 \mathrm{a}$ & $16,94 \mathrm{a}$ & $23,40 \mathrm{a}$ & $18,65 \mathrm{a}$ & $28,58 \mathrm{a}$ \\
\hline 2 & $9,88 \mathrm{a}$ & $17,25 \mathrm{a}$ & $22,66 \mathrm{a}$ & $20,40 \mathrm{a}$ & $36,42 b$ \\
\hline 3 & $14,34 \mathrm{a}$ & $15,99 \mathrm{a}$ & $37,58 \mathrm{~b}$ & $36,00 \mathrm{~b}$ & $41,32 \mathrm{~b}$ \\
\hline \multirow[t]{2}{*}{ Promedio } & 11,43 & 16,73 & 27,88 & 25,02 & 35,44 \\
\hline & Buck Brasil & & & & \\
\hline 1 & $30,39 \mathrm{~b}$ & & & & \\
\hline 2 & $21,71 \mathrm{a}$ & & & & \\
\hline 3 & $34,59 \mathrm{~b}$ & & & & \\
\hline Promedio & 28,90 & & & & \\
\hline
\end{tabular}

Referencias: Aislado 1 = cepa LH; Aislado 2 = cepa 25M035; Aislado 3 = cepa G327. Medias seguidas por la misma letra no difieren estadísticamente ( $\mathrm{P}=0,05, \mathrm{LSD}$ test). LSD cultivar $=4,20$

Los cultivares que presentaron mejor comportamiento fueron Baguette 601, Buck SY 300, Buck SY 110, Don Mario Lenox, Baguette 17, Buck AGP Fast, Sursem Nogal, BioInta 1001, ProInta Puntal y SY100. El aislado 3 presentó el mayor valor de severidad y se diferenció significativamente del aislado 2 y éste a su vez del 1 (Tabla 6.1.1 del apéndice). Buck $75^{\circ}$ Aniversario evidenció una mayor severidad con el aislado 1. Klein Proteo, Klein Castor y Baguette 9 tuvieron una mayor severidad con el aislado 2; mientras que Baguette Premium 11, Klein Tauro, Klein León, ACA 320, Baguette 17, Klein Dragón, BioInta 2004 presentaron una mayor severidad con el aislado 3. Klein Rayo y Sursem 2330 mostraron altos valores de severidad con el aislado 2 y 3 respecto del 1; mientras que Buck Brasil tuvo altos valores con el aislado 1 y 3 respecto al 2. 
En la Tabla 3.3.3 se encuentran las medias del tipo de reacción, en estado de plántula, para los tres aislados y 31 cultivares de trigo.

Tabla 3.3.3. Medias del tipo de reacción en un ensayo de trigo inoculado individualmente con aislados de $D$. tritici-repentis en 31 cultivares de trigo, evaluadas 14 días posteriores a la inoculación.

\begin{tabular}{|c|c|c|c|c|c|}
\hline Aislado & \multicolumn{5}{|c|}{ Cultivar } \\
\hline & Sursem Nogal & $\begin{array}{c}\text { Baguette } \\
\text { Premium } 11 \\
\end{array}$ & Buck SY 300 & $\begin{array}{c}\text { Klein } \\
\text { Capricornio } \\
\end{array}$ & $\begin{array}{c}\text { Don Mario } \\
\text { Lenox }\end{array}$ \\
\hline 1 & $1,57 \mathrm{ab}$ & $1,10 \mathrm{a}$ & $0,70 \mathrm{a}$ & $1,42 \mathrm{a}$ & $1,15 \mathrm{a}$ \\
\hline 2 & $1,35 \mathrm{a}$ & $1,62 \mathrm{a}$ & $1,07 \mathrm{ab}$ & $1,22 \mathrm{a}$ & $1,17 \mathrm{a}$ \\
\hline 3 & $1,92 \mathrm{~b}$ & $3,14 \mathrm{~b}$ & $1,37 \mathrm{~b}$ & $1,72 \mathrm{a}$ & $1,28 \mathrm{a}$ \\
\hline Promedio & 1,61 & 1,96 & 1,05 & 1,46 & 1,20 \\
\hline & Klein Proteo & Klein Tauro & BioInta 1001 & Klein Castor & $\begin{array}{c}\text { Buck } 75^{\circ} \\
\text { Aniversario }\end{array}$ \\
\hline 1 & $1,11 \mathrm{ab}$ & $0,85 \mathrm{a}$ & $1,20 \mathrm{a}$ & $1,63 \mathrm{a}$ & $1,56 \mathrm{a}$ \\
\hline 2 & $1,39 \mathrm{~b}$ & $0,88 \mathrm{a}$ & $0,98 \mathrm{a}$ & $1,34 \mathrm{a}$ & $1,15 \mathrm{a}$ \\
\hline 3 & $0,87 \mathrm{a}$ & $1,47 \mathrm{~b}$ & $1,16 \mathrm{a}$ & $1,43 \mathrm{a}$ & $1,38 \mathrm{a}$ \\
\hline Promedio & 1,13 & 1,07 & 1,12 & 1,47 & 1,36 \\
\hline & Buck AGP Fast & Buck SY 110 & ACA 901 & Klein León & Klein Rayo \\
\hline 1 & $0,95 \mathrm{a}$ & $0,95 \mathrm{a}$ & $1,30 \mathrm{a}$ & $1,34 \mathrm{a}$ & $1,57 \mathrm{a}$ \\
\hline 2 & $1,16 \mathrm{a}$ & $0,98 \mathrm{a}$ & $1,25 \mathrm{a}$ & $1,64 \mathrm{a}$ & $1,54 \mathrm{a}$ \\
\hline 3 & $2,15 b$ & $1,36 \mathrm{a}$ & $1,78 \mathrm{a}$ & $1,78 \mathrm{a}$ & $1,92 \mathrm{a}$ \\
\hline Promedio & 1,42 & 1,10 & 1,44 & 1,59 & 1,68 \\
\hline & $\begin{array}{c}\text { Baguette } \\
\text { Premium } 13 \\
\end{array}$ & Baguette 701 & Buck SY 100 & $\overline{A C A ~ 320}$ & Klein Nutria \\
\hline 1 & $1,29 \mathrm{a}$ & $2,59 \mathrm{a}$ & $1,08 \mathrm{a}$ & $0,95 \mathrm{a}$ & $1,26 \mathrm{a}$ \\
\hline 2 & $1,35 \mathrm{a}$ & $2,34 \mathrm{a}$ & $1,20 \mathrm{a}$ & $1,45 \mathrm{a}$ & $1,20 \mathrm{a}$ \\
\hline 3 & $1,10 \mathrm{a}$ & $2,83 \mathrm{a}$ & $1,04 \mathrm{a}$ & $1,32 \mathrm{a}$ & $1,61 \mathrm{a}$ \\
\hline Promedio & 1,25 & 2,59 & 1,11 & 1,24 & 1,36 \\
\hline & Baguette 601 & Baguette 9 & Baguette 17 & BioInta 3005 & $\begin{array}{c}\text { Don Mario } \\
\text { Cronox }\end{array}$ \\
\hline 1 & $0,85 \mathrm{a}$ & $1,24 \mathrm{a}$ & $1,13 \mathrm{a}$ & $1,68 \mathrm{a}$ & $1,09 \mathrm{a}$ \\
\hline 2 & $0,59 \mathrm{a}$ & $2,17 \mathrm{~b}$ & $1,42 \mathrm{ab}$ & $1,78 \mathrm{a}$ & $1,32 \mathrm{a}$ \\
\hline 3 & $0,80 \mathrm{a}$ & $1,20 \mathrm{a}$ & $1,90 \mathrm{~b}$ & $2,05 \mathrm{a}$ & $1,61 \mathrm{~b}$ \\
\hline Promedio & 0,75 & 1,54 & 1,49 & 1,84 & 1,34 \\
\hline & ProInta Puntal & Klein Volcán & Klein Dragón & BioInta 2004 & Sursem 2330 \\
\hline 1 & $1,30 \mathrm{a}$ & $0,89 \mathrm{a}$ & $1,52 \mathrm{a}$ & $0,85 \mathrm{a}$ & $1,11 \mathrm{a}$ \\
\hline 2 & $1,29 \mathrm{a}$ & $1,39 \mathrm{a}$ & $1,97 \mathrm{a}$ & $1,70 \mathrm{~b}$ & $1,25 \mathrm{a}$ \\
\hline 3 & $1,96 \mathrm{~b}$ & $1,23 \mathrm{a}$ & $3,36 \mathrm{~b}$ & $1,96 \mathrm{~b}$ & $2,00 \mathrm{~b}$ \\
\hline Promedio & 1,52 & 1,17 & 2,28 & 1,51 & 1,45 \\
\hline & Buck Brasil & & & & \\
\hline 1 & $1,87 \mathrm{~b}$ & & & & \\
\hline 2 & $1,31 \mathrm{a}$ & & & & \\
\hline 3 & $2,45 \mathrm{c}$ & & & & \\
\hline
\end{tabular}


\begin{tabular}{|l|c|l|l|}
\hline Promedio & 1,88 & & \\
\hline Referencias: Aislado 1 = cepa LH; Aislado 2 = cepa 25M035; Aislado 3 = cepa G327.
\end{tabular} Medias seguidas por la misma letra no difieren estadísticamente $(\mathrm{P}=0,05$, LSD test). LSD cultivar $=0,30$

Los cultivares que presentaron mejor comportamiento, para tipo de reacción, fueron Baguette 601, Buck SY 300, Klein Tauro, Buck SY 110, Buck SY 100, BioInta 1001, Klein Proteo, Klein Volcán, Don Mario Lenox y ACA 320. El aislado 3 presentó el mayor valor y se diferenció significativamente del aislado 2 y éste a su vez del 1 (Tabla 6.1.2 del apéndice). Klein Proteo y Baguette 9 tuvieron un aumento significativo del tipo de reacción con el aislado 2; mientras que Sursem Nogal, Baguette Premium 11, Buck SY 300, Klein Tauro, Buck AGP Fast, Baguette 17, Don Mario Cronox, ProInta Puntal, Klein Dragón y Sursem 2330 mostraron un aumento significativo con el aislado 3. BioInta 2004 evidenció altos valores con el aislado 2 y 3 respecto del 1 y Buck Brasil con el aislado 3 y 1 respecto al 2. 
3.4 Caracterización de cultivares argentinos de trigo al estado de planta adulta frente a la presencia/actividad de los aislados seleccionados de $D$. tritici-repentis bajo condiciones a campo

En la Tabla 3.4.1 se muestran los cuadrados medios y sus correspondientes probabilidades para la severidad en tres momentos de evaluación (EC 37, EC 75 y EC $82)$.

Tabla 3.4.1. Cuadrados medios de la severidad en tres momentos de evaluación (EC 37, EC 75 y EC 82) en un ensayo de trigo inoculado individualmente con tres aislados de $D$. tritici-repentis, en dos localidades y en 31 cultivares de trigo.

\begin{tabular}{|c|c|c|c|c|}
\hline $\begin{array}{c}\text { Fuente de } \\
\text { Variación }\end{array}$ & G.L. & $\begin{array}{c}\text { Estadio EC 37 } \\
- \text { Promedio de las 4 } \\
\text { hojas superiores- }\end{array}$ & $\begin{array}{c}\text { Estadio EC 75 } \\
\text { Promedio de las 4 hojas } \\
\text { superiores- }\end{array}$ & $\begin{array}{c}\text { Estadio EC 82 } \\
- \text { Promedio de las 3 } \\
\text { hojas superiores- }\end{array}$ \\
\hline Localidad & 1 & $0,038(0,170)^{*}$ & $1,039(0,08)$ & $8,147(0,035)$ \\
\hline Error a & 1 & 0,003 & 0,016 & 0,025 \\
\hline Aislado & 2 & $0,004(0,039)$ & $0,094(0,106)$ & $0,089(0,011)$ \\
\hline $\mathbf{L} \times \mathbf{A}$ & 2 & $0,006(0,021)$ & $0,026(0,405)$ & $0,009(0,293)$ \\
\hline Error b & 4 & 0,000 & 0,023 & 0,005 \\
\hline $\mathbf{C u l t i v a r}$ & 30 & $0,017(<0,001)$ & $0,197(<0,001)$ & $0,234(<0,001)$ \\
\hline $\mathbf{L} \times \mathbf{C}$ & 30 & $0,009(<0,001)$ & $0,056(<0,001)$ & $0,094(<0,001)$ \\
\hline $\mathbf{A} \times \mathbf{C}$ & 60 & $0,002(0,736)$ & $0,010(0,062)$ & $0,019(0,007)$ \\
\hline $\mathbf{L} \times \mathbf{A} \times \mathbf{C}$ & 60 & $0,002(0,789)$ & $0,013(0,003)$ & $0,020(0,003)$ \\
\hline Error c & 180 & 0,002 & 0,007 & 0,0117 \\
\hline
\end{tabular}

* Valor de $\mathrm{P}$ de acuerdo al test de F.

No se observaron diferencias significativas entre localidades en el estadio EC 37 y EC 75 pero si en el EC 82. Se observaron diferencias estadísticamente significativas entre aislados para el estadio EC 37 y EC 82, no siendo así para EC 75. Entre cultivares hubo diferencias estadísticamente significativas en los tres estadios. La triple interacción fue significativa para EC 75 y EC 82, no siendo así para EC 37.

En la Tabla 3.4.2 se indican las medias de severidad correspondientes al estadio EC 37 para los tres aislados, dos localidades y 31 cultivares de trigo. 
Tabla 3.4.2. Medias de severidad en un ensayo de trigo inoculado individualmente con aislados seleccionados de $D$. tritici-repentis, en dos localidades y 31 cultivares de trigo, evaluadas en el estadio EC 37.

\begin{tabular}{|c|c|c|c|c|c|c|}
\hline \multirow[t]{2}{*}{ Localidad } & \multirow[t]{2}{*}{ Aislado } & \multicolumn{5}{|c|}{ Cultivar } \\
\hline & & $\begin{array}{c}\text { Sursem } \\
\text { Nogal }\end{array}$ & $\begin{array}{c}\text { Baguette } \\
\text { Premium } 11\end{array}$ & Buck SY 300 & $\begin{array}{c}\text { Klein } \\
\text { Capricornio }\end{array}$ & $\begin{array}{c}\text { Don Mario } \\
\text { Lenox }\end{array}$ \\
\hline \multirow[t]{3}{*}{ Los Hornos } & 1 & $1,61 \mathrm{a}$ & $1,57 \mathrm{a}$ & $0,48 \mathrm{a}$ & $5,14 b$ & $0,00 \mathrm{a}$ \\
\hline & 2 & $0,19 \mathrm{a}$ & $1,69 \mathrm{a}$ & $1,04 \mathrm{a}$ & $1,71 \mathrm{a}$ & $0,20 \mathrm{a}$ \\
\hline & 3 & $0,43 \mathrm{a}$ & $0,26 \mathrm{a}$ & $0,14 \mathrm{a}$ & $4,23 \mathrm{~b}$ & $0,64 \mathrm{a}$ \\
\hline \multirow[t]{3}{*}{ Pergamino } & 1 & $1,18 \mathrm{a}$ & $0,84 \mathrm{a}$ & $1,77 \mathrm{a}$ & $2,39 \mathrm{a}$ & $1,00 \mathrm{a}$ \\
\hline & 2 & $0,77 \mathrm{a}$ & $0,62 \mathrm{a}$ & $0,84 \mathrm{a}$ & $1,38 \mathrm{a}$ & $0,00 \mathrm{a}$ \\
\hline & 3 & $0,52 \mathrm{a}$ & $0,59 \mathrm{a}$ & $0,76 \mathrm{a}$ & $0,99 \mathrm{a}$ & $1,62 \mathrm{a}$ \\
\hline \multirow[t]{2}{*}{ Promedio } & & 0,78 & 0,93 & 0,84 & 2,64 & 0,58 \\
\hline & & Klein Proteo & Klein Tauro & BioInta 1001 & Klein Castor & $\begin{array}{c}{\text { Buck } 75^{\circ}} \\
\text { Aniversario }\end{array}$ \\
\hline \multirow[t]{3}{*}{ Los Hornos } & 1 & $1,81 \mathrm{a}$ & $4,32 \mathrm{~b}$ & $0,45 \mathrm{a}$ & $0,68 \mathrm{a}$ & $0,88 \mathrm{a}$ \\
\hline & 2 & $1,87 \mathrm{a}$ & $1,40 \mathrm{a}$ & $0,30 \mathrm{a}$ & $0,65 \mathrm{a}$ & $0,90 \mathrm{a}$ \\
\hline & 3 & $0,50 \mathrm{a}$ & $0,65 \mathrm{a}$ & $0,13 \mathrm{a}$ & $0,13 \mathrm{a}$ & $0,25 \mathrm{a}$ \\
\hline \multirow[t]{3}{*}{ Pergamino } & 1 & $3,87 \mathrm{a}$ & $6,36 \mathrm{a}$ & $1,30 \mathrm{a}$ & $2,32 \mathrm{a}$ & $2,96 \mathrm{a}$ \\
\hline & 2 & $3,39 \mathrm{a}$ & $6,25 \mathrm{a}$ & $1,40 \mathrm{a}$ & $2,85 \mathrm{a}$ & $3,58 \mathrm{a}$ \\
\hline & 3 & $3,41 \mathrm{a}$ & $5,39 \mathrm{a}$ & $1,16 \mathrm{a}$ & $2,18 \mathrm{a}$ & $2,43 \mathrm{a}$ \\
\hline \multirow[t]{2}{*}{ Promedio } & & 2,48 & 4,06 & 0,79 & 1,47 & 1,83 \\
\hline & & $\begin{array}{c}\text { Buck AGP } \\
\text { Fast }\end{array}$ & Buck SY 110 & ACA 901 & Klein León & Klein Rayo \\
\hline \multirow[t]{3}{*}{ Los Hornos } & 1 & $0,29 \mathrm{a}$ & $0,55 \mathrm{a}$ & $0,48 \mathrm{a}$ & $0,34 \mathrm{a}$ & $0,91 \mathrm{a}$ \\
\hline & 2 & $0,30 \mathrm{a}$ & $0,61 \mathrm{a}$ & $0,43 \mathrm{a}$ & $0,68 \mathrm{a}$ & $0,43 \mathrm{a}$ \\
\hline & 3 & $0,29 \mathrm{a}$ & $0,48 \mathrm{a}$ & $0,38 \mathrm{a}$ & $0,64 \mathrm{a}$ & $0,27 \mathrm{a}$ \\
\hline \multirow[t]{3}{*}{ Pergamino } & 1 & $1,69 \mathrm{a}$ & $0,95 \mathrm{a}$ & $0,96 \mathrm{a}$ & $1,09 \mathrm{a}$ & $0,87 \mathrm{a}$ \\
\hline & 2 & $1,09 \mathrm{a}$ & $2,36 \mathrm{a}$ & $0,66 \mathrm{a}$ & $1,76 \mathrm{a}$ & $1,27 \mathrm{a}$ \\
\hline & 3 & $1,24 \mathrm{a}$ & $1,41 \mathrm{a}$ & $1,29 \mathrm{a}$ & $0,80 \mathrm{a}$ & $1,84 \mathrm{a}$ \\
\hline \multirow[t]{2}{*}{ Promedio } & & 0,82 & 1,06 & 0,70 & 0,89 & 0,93 \\
\hline & & $\begin{array}{c}\text { Baguette } \\
\text { Premium } 13 \\
\end{array}$ & Baguette 701 & Buck SY 100 & ACA 320 & Klein Nutria \\
\hline \multirow[t]{3}{*}{ Los Hornos } & 1 & $3,08 \mathrm{a}$ & $1,41 \mathrm{a}$ & $4,89 \mathrm{a}$ & $1,97 \mathrm{a}$ & $1,93 \mathrm{a}$ \\
\hline & 2 & $2,35 \mathrm{a}$ & $1,75 \mathrm{a}$ & $4,62 \mathrm{a}$ & $2,35 \mathrm{a}$ & $1,68 \mathrm{a}$ \\
\hline & 3 & $1,11 \mathrm{a}$ & $1,38 \mathrm{a}$ & $6,61 \mathrm{a}$ & $0,72 \mathrm{a}$ & $0,88 \mathrm{a}$ \\
\hline \multirow[t]{3}{*}{ Pergamino } & 1 & $2,30 \mathrm{a}$ & $0,62 \mathrm{a}$ & $0,96 \mathrm{a}$ & $0,79 \mathrm{a}$ & $3,71 \mathrm{a}$ \\
\hline & 2 & $1,27 \mathrm{a}$ & $1,34 \mathrm{a}$ & $2,14 \mathrm{a}$ & $1,16 \mathrm{a}$ & $3,87 \mathrm{a}$ \\
\hline & 3 & $2,86 \mathrm{a}$ & $0,50 \mathrm{a}$ & $1,75 \mathrm{a}$ & $2,89 \mathrm{a}$ & $3,62 \mathrm{a}$ \\
\hline \multirow[t]{2}{*}{ Promedio } & & 2,16 & 1,17 & 3,50 & 1,65 & 2,62 \\
\hline & & $\begin{array}{c}\text { Baguette } \\
601\end{array}$ & Baguette 9 & Baguette 17 & BioInta 3005 & $\begin{array}{c}\text { Don Mario } \\
\text { Cronox }\end{array}$ \\
\hline
\end{tabular}




\begin{tabular}{|c|c|c|c|c|c|c|}
\hline \multirow[t]{3}{*}{ Los Hornos } & 1 & $0,60 \mathrm{a}$ & $1,18 \mathrm{a}$ & $2,59 \mathrm{a}$ & $1,43 \mathrm{a}$ & $0,39 \mathrm{a}$ \\
\hline & 2 & $0,27 \mathrm{a}$ & $0,27 \mathrm{a}$ & $0,86 \mathrm{a}$ & $1,07 \mathrm{a}$ & $0,66 \mathrm{a}$ \\
\hline & 3 & $0,36 \mathrm{a}$ & $0,15 \mathrm{a}$ & $1,32 \mathrm{a}$ & $2,26 \mathrm{a}$ & $0,61 \mathrm{a}$ \\
\hline \multirow[t]{3}{*}{ Pergamino } & 1 & $1,11 \mathrm{a}$ & $1,09 \mathrm{a}$ & $0,77 \mathrm{a}$ & $0,95 \mathrm{a}$ & $1,57 \mathrm{a}$ \\
\hline & 2 & $1,23 \mathrm{a}$ & $0,88 \mathrm{a}$ & $0,96 \mathrm{a}$ & $0,75 \mathrm{a}$ & $1,25 \mathrm{a}$ \\
\hline & 3 & $0,75 \mathrm{a}$ & $0,80 \mathrm{a}$ & $0,46 \mathrm{a}$ & $0,43 \mathrm{a}$ & $3,75 \mathrm{a}$ \\
\hline \multirow[t]{2}{*}{ Promedio } & & 0,72 & 0,73 & 1,16 & 1,15 & 1,37 \\
\hline & & $\begin{array}{c}\text { ProInta } \\
\text { Puntal } \\
\end{array}$ & $\begin{array}{c}\text { Klein } \\
\text { Volcán } \\
\end{array}$ & $\begin{array}{c}\text { Klein } \\
\text { Dragón }\end{array}$ & BioInta 2004 & Sursem 2330 \\
\hline \multirow[t]{3}{*}{ Los Hornos } & 1 & $0,39 \mathrm{a}$ & $0,46 \mathrm{a}$ & $1,00 \mathrm{a}$ & $0,27 \mathrm{a}$ & $2,12 \mathrm{a}$ \\
\hline & 2 & $0,43 \mathrm{a}$ & $0,63 \mathrm{a}$ & $0,29 \mathrm{a}$ & $0,02 \mathrm{a}$ & $4,98 \mathrm{~b}$ \\
\hline & 3 & $0,23 \mathrm{a}$ & $0,95 \mathrm{a}$ & $0,63 \mathrm{a}$ & $0,36 \mathrm{a}$ & $5,40 \mathrm{~b}$ \\
\hline \multirow[t]{3}{*}{ Pergamino } & 1 & $0,52 \mathrm{a}$ & $0,33 \mathrm{a}$ & $1,55 \mathrm{a}$ & $0,45 \mathrm{a}$ & $0,79 \mathrm{a}$ \\
\hline & 2 & $0,36 \mathrm{a}$ & $0,64 \mathrm{a}$ & $2,04 \mathrm{a}$ & $1,52 \mathrm{a}$ & $2,27 \mathrm{a}$ \\
\hline & 3 & $0,12 \mathrm{a}$ & $1,27 \mathrm{a}$ & $3,07 \mathrm{a}$ & $0,34 \mathrm{a}$ & $0,45 \mathrm{a}$ \\
\hline \multirow[t]{2}{*}{ Promedio } & & 0,34 & 0,71 & 1,43 & 0,49 & 2,67 \\
\hline & & Buck Brasil & & & & \\
\hline \multirow[t]{3}{*}{ Los Hornos } & 1 & $9,83 \mathrm{c}$ & & & & \\
\hline & 2 & $6,67 \mathrm{~b}$ & & & & \\
\hline & 3 & $1,19 \mathrm{a}$ & & & & \\
\hline \multirow[t]{3}{*}{ Pergamino } & 1 & $2,51 \mathrm{a}$ & & & & \\
\hline & 2 & $4,01 \mathrm{a}$ & & & & \\
\hline & 3 & $3,68 \mathrm{a}$ & & & & \\
\hline Promedio & & 4,65 & & & & \\
\hline
\end{tabular}

Referencias: Aislado 1 = cepa LH; Aislado 2 = cepa 25M035; Aislado 3 = cepa G327. Medias seguidas por la misma letra no difieren estadísticamente ( $\mathrm{P}=0,05, \mathrm{LSD}$ test). LSD cultivar $=1,15$

En EC 37 se registraron bajos valores de severidad y hubo diferencias estadísticas significativas entre los cultivares. Los que tuvieron mejor comportamiento fueron ProInta Puntal, BioInta 2004, Don Mario Lenox, ACA 901, Klein Volcán, Baguette 601, Baguette 9, Sursem Nogal, BioInta 1001 y Buck AGP Fast. El aislado 1 se diferenció significativamente del aislado 3 causando un mayor nivel de severidad pero no se diferenció significativamente del 2 (Tabla 6.1.3 del apéndice). A pesar de no haber diferencias significativas entre localidades, Pergamino tuvo una mayor severidad que Los Hornos (Tabla 6.1.4 del apéndice). Hubo algunos cultivares que presentaron diferente severidad de acuerdo al aislado y la localidad, así el cultivar Klein Capricornio mostró una mayor severidad con los aislados 1 y 3 en la localidad de Los Hornos. La variedad Klein Tauro tuvo una mayor severidad con el aislado 1 en la misma localidad. La variedad Sursem 2330 evidenció una mayor severidad para los aislados 2 y 3 en Los 
Hornos; mientras que Buck Brasil también tuvo una mayor severidad para los aislados 1 y 2 en la misma localidad.

En la Tabla 3.4.3 se presentan las medias de severidad correspondientes al estadio EC 75 para los tres aislados, dos localidades y 31 cultivares de trigo.

Tabla 3.4.3. Medias de severidad en un ensayo de trigo inoculado individualmente con aislados seleccionados de $D$. tritici-repentis, en dos localidades y 31 cultivares de trigo, evaluadas en el estadio EC 75

\begin{tabular}{|c|c|c|c|c|c|c|}
\hline \multirow[t]{2}{*}{ Localidad } & \multirow[t]{2}{*}{ Aislado } & \multicolumn{5}{|c|}{ Cultivar } \\
\hline & & $\begin{array}{c}\begin{array}{c}\text { Sursem } \\
\text { Nogal }\end{array} \\
\end{array}$ & $\begin{array}{c}\text { Baguette } \\
\text { Premium 11 }\end{array}$ & Buck SY 300 & $\begin{array}{c}\text { Klein } \\
\text { Capricornio } \\
\end{array}$ & $\begin{array}{c}\text { Don Mario } \\
\text { Lenox } \\
\end{array}$ \\
\hline \multirow[t]{3}{*}{ Los Hornos } & 1 & $34,61 \mathrm{a}$ & $47,02 \mathrm{a}$ & $2,84 \mathrm{a}$ & $48,66 \mathrm{a}$ & $18,66 \mathrm{a}$ \\
\hline & 2 & $31,89 \mathrm{a}$ & $50,84 \mathrm{ab}$ & $16,25 \mathrm{a}$ & $45,11 \mathrm{a}$ & $8,45 \mathrm{a}$ \\
\hline & 3 & $31,86 \mathrm{a}$ & $64,11 b$ & $12,95 \mathrm{a}$ & $51,84 \mathrm{a}$ & $14,05 \mathrm{a}$ \\
\hline \multirow[t]{3}{*}{ Pergamino } & 1 & $28,11 \mathrm{a}$ & $60,43 \mathrm{a}$ & $26,39 \mathrm{a}$ & $60,57 \mathrm{a}$ & $22,16 \mathrm{a}$ \\
\hline & 2 & $19,71 \mathrm{a}$ & $73,88 \mathrm{a}$ & $28,88 \mathrm{a}$ & $60,07 \mathrm{a}$ & $29,59 \mathrm{a}$ \\
\hline & 3 & $17,43 \mathrm{a}$ & $61,91 \mathrm{a}$ & $24,02 \mathrm{a}$ & $55,22 \mathrm{a}$ & $32,75 \mathrm{a}$ \\
\hline \multirow[t]{2}{*}{ Promedio } & & 27,27 & 59,70 & 18,56 & 53,58 & 20,94 \\
\hline & & Klein Proteo & Klein Tauro & BioInta 1001 & Klein Castor & $\begin{array}{c}{\text { Buck } 75^{\circ}} \\
\text { Aniversario }\end{array}$ \\
\hline \multirow{3}{*}{ Los Hornos } & 1 & $19,55 \mathrm{a}$ & $32,95 \mathrm{ab}$ & $7,21 \mathrm{a}$ & $20,21 \mathrm{a}$ & $44,30 \mathrm{~b}$ \\
\hline & 2 & $36,51 \mathrm{~b}$ & $24,05 \mathrm{a}$ & $21,93 \mathrm{a}$ & $38,70 \mathrm{~b}$ & $30,20 \mathrm{ab}$ \\
\hline & 3 & $23,63 \mathrm{ab}$ & $42,02 \mathrm{~b}$ & $11,88 \mathrm{a}$ & $25,30 \mathrm{ab}$ & $18,48 \mathrm{a}$ \\
\hline \multirow[t]{3}{*}{ Pergamino } & 1 & $50,50 \mathrm{a}$ & $58,09 \mathrm{a}$ & $25,46 \mathrm{a}$ & $51,13 \mathrm{a}$ & $30,07 \mathrm{a}$ \\
\hline & 2 & $52,91 \mathrm{a}$ & $56,11 \mathrm{a}$ & $45,52 \mathrm{~b}$ & $39,38 \mathrm{a}$ & $45,57 \mathrm{a}$ \\
\hline & 3 & $54,25 \mathrm{a}$ & $55,02 \mathrm{a}$ & $20,66 \mathrm{a}$ & $49,30 \mathrm{a}$ & $33,55 \mathrm{a}$ \\
\hline \multirow[t]{2}{*}{ Promedio } & & 39,56 & 44,71 & 22,11 & 37,34 & 33,70 \\
\hline & & $\begin{array}{c}\text { Buck AGP } \\
\text { Fast } \\
\end{array}$ & Buck SY 110 & $\overline{\text { ACA } 901}$ & Klein León & Klein Rayo \\
\hline \multirow[t]{3}{*}{ Los Hornos } & 1 & $22,11 \mathrm{a}$ & $5,46 \mathrm{a}$ & $26,63 \mathrm{a}$ & $26,89 a$ & $33,04 \mathrm{a}$ \\
\hline & 2 & $20,91 \mathrm{a}$ & $11,30 \mathrm{a}$ & $36,36 \mathrm{a}$ & $31,25 \mathrm{a}$ & $42,51 \mathrm{a}$ \\
\hline & 3 & $8,18 \mathrm{a}$ & $9,13 \mathrm{a}$ & $30,16 \mathrm{a}$ & $23,48 \mathrm{a}$ & $37,46 \mathrm{a}$ \\
\hline \multirow[t]{3}{*}{ Pergamino } & 1 & $30,55 \mathrm{a}$ & $26,25 \mathrm{a}$ & $34,16 \mathrm{a}$ & $31,35 \mathrm{a}$ & $48,77 \mathrm{a}$ \\
\hline & 2 & $34,38 \mathrm{a}$ & $26,57 \mathrm{a}$ & $39,00 \mathrm{a}$ & $49,02 \mathrm{~b}$ & $46,95 \mathrm{a}$ \\
\hline & 3 & $30,55 \mathrm{a}$ & $22,13 \mathrm{a}$ & $46,66 \mathrm{a}$ & $38,80 \mathrm{ab}$ & $46,23 \mathrm{a}$ \\
\hline \multirow[t]{2}{*}{ Promedio } & & 24,45 & 16,81 & 35,50 & 33,47 & 42,49 \\
\hline & & $\begin{array}{c}\text { Baguette } \\
\text { Premium } 13 \\
\end{array}$ & Baguette 701 & Buck SY 100 & ACA 320 & Klein Nutria \\
\hline \multirow[t]{3}{*}{ Los Hornos } & 1 & $16,04 \mathrm{a}$ & $56,14 \mathrm{a}$ & $25,88 \mathrm{a}$ & $48,71 \mathrm{a}$ & $27,89 \mathrm{a}$ \\
\hline & 2 & $27,80 \mathrm{a}$ & $57,05 \mathrm{a}$ & $23,88 \mathrm{a}$ & $39,61 \mathrm{a}$ & $25,75 \mathrm{a}$ \\
\hline & 3 & $24,34 \mathrm{a}$ & $55,29 \mathrm{a}$ & $27,77 \mathrm{a}$ & $46,75 \mathrm{a}$ & $27,34 \mathrm{a}$ \\
\hline Pergamino & 1 & $31,04 \mathrm{a}$ & $16,05 \mathrm{a}$ & $37,52 \mathrm{a}$ & $50,54 \mathrm{a}$ & $49,39 \mathrm{a}$ \\
\hline
\end{tabular}




\begin{tabular}{|c|c|c|c|c|c|c|}
\hline & 2 & $34,95 \mathrm{a}$ & $14,04 \mathrm{a}$ & $31,09 \mathrm{a}$ & $64,45 \mathrm{ab}$ & $40,27 \mathrm{a}$ \\
\hline & 3 & $43,52 \mathrm{a}$ & $17,89 \mathrm{a}$ & $32,93 \mathrm{a}$ & $67,98 \mathrm{~b}$ & $48,63 \mathrm{a}$ \\
\hline \multirow[t]{2}{*}{ Promedio } & & 29,62 & 36,08 & 29,85 & 53,01 & 36,55 \\
\hline & & $\begin{array}{c}\text { Baguette } \\
601\end{array}$ & Baguette 9 & Baguette 17 & BioInta 3005 & $\begin{array}{c}\text { Don Mario } \\
\text { Cronox } \\
\end{array}$ \\
\hline \multirow[t]{3}{*}{ Los Hornos } & 1 & $4,68 \mathrm{a}$ & $26,48 \mathrm{a}$ & $17,93 \mathrm{a}$ & $43,02 \mathrm{a}$ & $25,25 \mathrm{a}$ \\
\hline & 2 & $6,04 \mathrm{a}$ & $49,61 \mathrm{~b}$ & $20,84 \mathrm{a}$ & $46,70 \mathrm{a}$ & $37,98 \mathrm{a}$ \\
\hline & 3 & $12,05 \mathrm{a}$ & $19,38 \mathrm{a}$ & $38,47 \mathrm{~b}$ & $39,13 \mathrm{a}$ & $39,07 \mathrm{a}$ \\
\hline \multirow{3}{*}{ Pergamino } & 1 & $16,79 \mathrm{a}$ & $26,45 \mathrm{a}$ & $21,89 \mathrm{a}$ & $49,61 \mathrm{a}$ & $29,18 \mathrm{a}$ \\
\hline & 2 & $17,75 \mathrm{a}$ & $52,36 \mathrm{~b}$ & $28,27 \mathrm{a}$ & $65,57 \mathrm{ab}$ & $38,43 \mathrm{a}$ \\
\hline & 3 & $20,45 \mathrm{a}$ & $37,34 \mathrm{ab}$ & $30,79 \mathrm{a}$ & $67,41 \mathrm{~b}$ & $44,05 \mathrm{a}$ \\
\hline \multirow[t]{2}{*}{ Promedio } & & 12,96 & 35,27 & 26,37 & 51,91 & 35,66 \\
\hline & & $\begin{array}{c}\text { ProInta } \\
\text { Puntal }\end{array}$ & $\begin{array}{c}\text { Klein } \\
\text { Volcán }\end{array}$ & $\begin{array}{c}\text { Klein } \\
\text { Dragón }\end{array}$ & BioInta 2004 & Sursem 2330 \\
\hline \multirow[t]{3}{*}{ Los Hornos } & 1 & $10,34 \mathrm{a}$ & $22,34 \mathrm{a}$ & $27,38 \mathrm{a}$ & $17,48 \mathrm{a}$ & $49,95 \mathrm{a}$ \\
\hline & 2 & $11,68 \mathrm{a}$ & $28,16 \mathrm{a}$ & $36,96 \mathrm{a}$ & $24,88 \mathrm{ab}$ & $49,57 \mathrm{a}$ \\
\hline & 3 & $36,88 \mathrm{~b}$ & $36,00 \mathrm{a}$ & $61,48 \mathrm{~b}$ & $37,39 \mathrm{~b}$ & $55,19 \mathrm{a}$ \\
\hline \multirow[t]{3}{*}{ Pergamino } & 1 & $30,45 \mathrm{a}$ & $23,57 \mathrm{a}$ & $40,89 \mathrm{a}$ & $30,41 \mathrm{a}$ & $47,16 \mathrm{a}$ \\
\hline & 2 & $40,25 \mathrm{a}$ & $39,73 \mathrm{~b}$ & $42,46 \mathrm{a}$ & $37,96 \mathrm{a}$ & $52,46 \mathrm{a}$ \\
\hline & 3 & $32,11 \mathrm{a}$ & $29,34 \mathrm{ab}$ & $31,61 \mathrm{a}$ & $32,25 \mathrm{a}$ & $45,61 \mathrm{a}$ \\
\hline \multirow[t]{2}{*}{ Promedio } & & 26,95 & 29,86 & 40,13 & 30,06 & 49,99 \\
\hline & & Buck Brasil & & & & \\
\hline \multirow[t]{3}{*}{ Los Hornos } & 1 & $43,08 \mathrm{~b}$ & & & & \\
\hline & 2 & $26,82 \mathrm{a}$ & & & & \\
\hline & 3 & $33,64 \mathrm{ab}$ & & & & \\
\hline \multirow[t]{3}{*}{ Pergamino } & 1 & $46,07 \mathrm{a}$ & & & & \\
\hline & 2 & $52,30 \mathrm{a}$ & & & & \\
\hline & 3 & $56,57 \mathrm{a}$ & & & & \\
\hline Promedio & & 43,08 & & & & \\
\hline
\end{tabular}

Referencias: Aislado 1 = cepa LH; Aislado 2 = cepa 25M035; Aislado 3 = cepa G327. Medias seguidas por la misma letra no difieren estadísticamente ( $\mathrm{P}=0,05$, LSD test). LSD cultivar $=6,31$

En EC 75 hubo diferencias significativas entre los cultivares, destacándose por su mejor comportamiento Baguette 601, Buck SY 110, Buck SY 300, Don Mario Lenox, BioInta 1001, Buck AGP Fast, Baguette 17, ProInta Puntal, Sursem Nogal, Baguette Premium 13, Buck SY 100 y Klein Volcán con valores de severidad promedio inferiores al $30 \%$ y con un comportamiento similar a lo registrado en plántula. Los aislados no se diferenciaron significativamente entre sí pero pudo observarse una tendencia de mayor severidad para el aislado 3, luego para el aislado 2 y por último el 1 (Tabla 6.1.5 del apéndice) teniendo un comportamiento similar que en las evaluaciones realizadas en plántula. Si bien no se observaron diferencias significativas entre 
localidades hubo un mayor nivel de severidad general para la localidad de Pergamino en comparación con Los Hornos (Tabla 6.1.6 del apéndice). Al igual que en EC 37 hubo un comportamiento diferencial de los cultivares con el aislado y la localidad, así Buck $75^{\circ}$ Aniversario y Buck Brasil tuvieron una mayor severidad con el aislado 1 en Los Hornos y este último obtuvo un valor similar en Pergamino. Klein Proteo y Klein Castor evidenciaron una mayor severidad con el aislado 2 en Los Hornos y este último obtuvo un valor similar en Pergamino. BioInta 1001, Klein León y Klein Volcán tuvieron una mayor severidad con el aislado 2 en Pergamino mientras que BioInta 1001 y Klein León evidenciaron el mayor nivel de severidad con el mismo aislado en Los Hornos. Baguette 9 tuvo una mayor severidad con el aislado 2 en ambos ambientes. Los cultivares Baguette Premium 11, Klein Tauro, ProInta Puntal, Klein Dragón, Baguette 17 y BioInta 2004 tuvieron una mayor severidad con el aislado 3 en Los Hornos y presentaron valores similares en Pergamino. ACA 320 y BioInta 3005 tuvieron una mayor severidad con el aislado 3 en Pergamino.

En la Tabla 3.4.4 se presentan las medias de severidad correspondientes al estadio EC 82 para los tres aislados, dos localidades y 31 cultivares de trigo.

Tabla 3.4.4 Medias de severidad en un ensayo de trigo inoculado individualmente con aislados seleccionados de $D$. tritici-repentis, en dos localidades y 31 cultivares de trigo, evaluadas en el estadio EC 82.

\begin{tabular}{|c|c|c|c|c|c|c|}
\hline \multirow[t]{2}{*}{ Localidad } & \multirow[t]{2}{*}{ Aislado } & \multicolumn{5}{|c|}{ Cultivar } \\
\hline & & $\begin{array}{c}\begin{array}{c}\text { Sursem } \\
\text { Nogal }\end{array} \\
\end{array}$ & $\begin{array}{c}\text { Baguette } \\
\text { Premium } 11 \\
\end{array}$ & Buck SY 300 & $\begin{array}{c}\text { Klein } \\
\text { Capricornio } \\
\end{array}$ & $\begin{array}{c}\text { Don Mario } \\
\text { Lenox } \\
\end{array}$ \\
\hline \multirow[t]{3}{*}{ Los Hornos } & 1 & $34,60 \mathrm{a}$ & $63,93 \mathrm{a}$ & $14,19 \mathrm{a}$ & $66,67 \mathrm{a}$ & $39,17 \mathrm{~b}$ \\
\hline & 2 & $33,93 \mathrm{a}$ & $63,24 \mathrm{a}$ & $30,43 \mathrm{a}$ & $66,31 \mathrm{a}$ & $21,12 \mathrm{a}$ \\
\hline & 3 & $46,88 \mathrm{a}$ & $82,26 \mathrm{~b}$ & $18,90 \mathrm{a}$ & $69,64 \mathrm{a}$ & $27,87 \mathrm{ab}$ \\
\hline \multirow[t]{3}{*}{ Pergamino } & 1 & $50,52 \mathrm{a}$ & $88,29 \mathrm{a}$ & $59,10 \mathrm{a}$ & $97,02 \mathrm{a}$ & $52,31 \mathrm{a}$ \\
\hline & 2 & $50,52 \mathrm{a}$ & $90,48 \mathrm{a}$ & $65,74 \mathrm{a}$ & $94,40 \mathrm{a}$ & $64,57 \mathrm{a}$ \\
\hline & 3 & $45,76 \mathrm{a}$ & $82,92 \mathrm{a}$ & $56,64 \mathrm{a}$ & $89,64 \mathrm{a}$ & $66,07 \mathrm{a}$ \\
\hline \multirow[t]{2}{*}{ Promedio } & & 43,70 & 78,52 & 40,83 & 80,61 & 45,19 \\
\hline & & Klein Proteo & Klein Tauro & BioInta 1001 & Klein Castor & $\begin{array}{c}\text { Buck } 7^{\circ} \\
\text { Aniversario } \\
\end{array}$ \\
\hline \multirow[t]{3}{*}{ Los Hornos } & 1 & $34,05 \mathrm{a}$ & $51,81 \mathrm{a}$ & $19,31 \mathrm{a}$ & $36,69 \mathrm{a}$ & $65,57 \mathrm{~b}$ \\
\hline & 2 & $47,60 \mathrm{a}$ & $40,10 \mathrm{a}$ & $34,67 \mathrm{a}$ & $59,33 \mathrm{~b}$ & $41,79 \mathrm{a}$ \\
\hline & 3 & $35,74 \mathrm{a}$ & $47,17 \mathrm{a}$ & $35,86 \mathrm{a}$ & $33,98 \mathrm{a}$ & $38,10 \mathrm{a}$ \\
\hline \multirow[t]{3}{*}{ Pergamino } & 1 & $82,98 \mathrm{a}$ & $87,26 \mathrm{a}$ & $86,07 \mathrm{a}$ & $89,88 \mathrm{a}$ & $63,93 \mathrm{a}$ \\
\hline & 2 & $81,55 \mathrm{a}$ & $83,93 \mathrm{a}$ & $80,95 \mathrm{a}$ & $76,23 \mathrm{a}$ & $64,88 \mathrm{a}$ \\
\hline & 3 & $92,14 \mathrm{a}$ & $87,00 \mathrm{a}$ & $85,24 \mathrm{a}$ & $87,38 \mathrm{a}$ & $69,05 \mathrm{a}$ \\
\hline \multirow[t]{2}{*}{ Promedio } & & 62,34 & 66,21 & 57,02 & 63,92 & 57,22 \\
\hline & & $\begin{array}{c}\text { Buck AGP } \\
\text { Fast } \\
\end{array}$ & Buck SY 110 & $\overline{\text { ACA 901 }}$ & Klein León & Klein Rayo \\
\hline Los Hornos & 1 & $23,33 \mathrm{a}$ & $15,21 \mathrm{a}$ & $51,64 \mathrm{a}$ & $39,40 \mathrm{a}$ & $58,74 \mathrm{a}$ \\
\hline
\end{tabular}




\begin{tabular}{|c|c|c|c|c|c|c|}
\hline & 2 & $50,74 \mathrm{~b}$ & $18,79 \mathrm{a}$ & $61,05 \mathrm{a}$ & $44,88 \mathrm{a}$ & $70,36 \mathrm{a}$ \\
\hline & 3 & $37,48 \mathrm{ab}$ & $19,00 \mathrm{a}$ & $49,86 \mathrm{a}$ & $40,40 \mathrm{a}$ & $61,12 \mathrm{a}$ \\
\hline \multirow[t]{3}{*}{ Pergamino } & 1 & $60,36 \mathrm{a}$ & $53,74 \mathrm{a}$ & $75,71 \mathrm{a}$ & $65,48 \mathrm{a}$ & $89,38 \mathrm{a}$ \\
\hline & 2 & $82,86 \mathrm{~b}$ & $65,40 \mathrm{a}$ & $79,05 \mathrm{a}$ & $85,60 \mathrm{~b}$ & $87,98 \mathrm{a}$ \\
\hline & 3 & $82,26 \mathrm{~b}$ & $65,83 \mathrm{a}$ & $86,43 \mathrm{a}$ & $75,00 \mathrm{ab}$ & $95,71 \mathrm{a}$ \\
\hline \multirow[t]{2}{*}{ Promedio } & & 56,17 & 39,66 & 67,29 & 58,46 & 77,22 \\
\hline & & $\begin{array}{c}\text { Baguette } \\
\text { Premium 13 }\end{array}$ & Baguette 701 & Buck SY 100 & $\overline{\text { ACA } 320}$ & Klein Nutria \\
\hline \multirow[t]{3}{*}{ Los Hornos } & 1 & $43,60 \mathrm{a}$ & $82,90 \mathrm{a}$ & $52,29 \mathrm{a}$ & $71,90 \mathrm{~b}$ & $40,55 \mathrm{a}$ \\
\hline & 2 & $49,60 \mathrm{a}$ & $75,83 \mathrm{a}$ & $35,21 \mathrm{a}$ & $52,95 \mathrm{a}$ & $33,90 \mathrm{a}$ \\
\hline & 3 & $53,45 \mathrm{a}$ & $76,31 \mathrm{a}$ & $52,38 \mathrm{a}$ & $50,67 \mathrm{a}$ & $40,19 \mathrm{a}$ \\
\hline \multirow[t]{3}{*}{ Pergamino } & 1 & $72,52 \mathrm{a}$ & $50,21 \mathrm{a}$ & $64,55 \mathrm{a}$ & $79,76 \mathrm{a}$ & $81,67 \mathrm{a}$ \\
\hline & 2 & $72,14 \mathrm{a}$ & $48,45 \mathrm{a}$ & 59,16 a & $84,29 \mathrm{a}$ & $80,83 \mathrm{a}$ \\
\hline & 3 & $76,90 \mathrm{a}$ & $45,40 \mathrm{a}$ & $60,00 \mathrm{a}$ & $96,07 \mathrm{a}$ & $89,52 \mathrm{a}$ \\
\hline \multirow[t]{2}{*}{ Promedio } & & 61,37 & 63,18 & 53,93 & 72,61 & 61,11 \\
\hline & & $\begin{array}{c}\text { Baguette } \\
601\end{array}$ & Baguette 9 & Baguette 17 & BioInta 3005 & $\begin{array}{c}\text { Don Mario } \\
\text { Cronox }\end{array}$ \\
\hline \multirow[t]{3}{*}{ Los Hornos } & 1 & $15,55 \mathrm{a}$ & $39,29 \mathrm{a}$ & $36,43 \mathrm{a}$ & $64,64 \mathrm{a}$ & $43,57 \mathrm{a}$ \\
\hline & 2 & $12,57 \mathrm{a}$ & $53,60 \mathrm{a}$ & $49,81 \mathrm{a}$ & $65,12 \mathrm{a}$ & $57,79 \mathrm{ab}$ \\
\hline & 3 & $15,67 \mathrm{a}$ & $47,40 \mathrm{a}$ & $46,69 \mathrm{a}$ & $55,12 \mathrm{a}$ & $68,98 \mathrm{~b}$ \\
\hline \multirow[t]{3}{*}{ Pergamino } & 1 & $34,98 \mathrm{a}$ & $66,43 \mathrm{a}$ & $51,26 \mathrm{a}$ & $79,52 \mathrm{a}$ & $72,38 \mathrm{a}$ \\
\hline & 2 & $48,19 \mathrm{a}$ & $84,52 \mathrm{a}$ & $55,29 \mathrm{a}$ & $91,19 \mathrm{a}$ & $79,64 \mathrm{a}$ \\
\hline & 3 & $37,95 \mathrm{a}$ & $70,48 \mathrm{a}$ & $61,07 \mathrm{a}$ & $91,79 \mathrm{a}$ & $88,33 \mathrm{a}$ \\
\hline \multirow[t]{2}{*}{ Promedio } & & 27,49 & 60,29 & 50,09 & 74,56 & 68,45 \\
\hline & & $\begin{array}{c}\text { ProInta } \\
\text { Puntal } \\
\end{array}$ & $\begin{array}{c}\text { Klein } \\
\text { Volcán } \\
\end{array}$ & $\begin{array}{c}\text { Klein } \\
\text { Dragón }\end{array}$ & BioInta 2004 & Sursem 2330 \\
\hline \multirow[t]{3}{*}{ Los Hornos } & 1 & $21,36 \mathrm{a}$ & $52,50 \mathrm{ab}$ & $55,81 \mathrm{a}$ & $30,71 \mathrm{a}$ & $62,62 \mathrm{a}$ \\
\hline & 2 & $25,26 \mathrm{a}$ & $43,74 \mathrm{a}$ & $61,67 \mathrm{a}$ & $47,79 \mathrm{ab}$ & $73,21 \mathrm{a}$ \\
\hline & 3 & $56,18 \mathrm{~b}$ & $69,29 \mathrm{~b}$ & $84,35 \mathrm{~b}$ & $56,02 \mathrm{~b}$ & $76,50 \mathrm{a}$ \\
\hline \multirow[t]{3}{*}{ Pergamino } & 1 & $61,60 \mathrm{a}$ & $53,33 \mathrm{a}$ & $78,10 \mathrm{a}$ & $70,71 \mathrm{a}$ & $68,93 \mathrm{a}$ \\
\hline & 2 & $75,00 \mathrm{a}$ & $70,60 \mathrm{a}$ & $82,98 \mathrm{a}$ & $76,19 \mathrm{a}$ & $76,31 \mathrm{a}$ \\
\hline & 3 & $67,26 \mathrm{a}$ & $70,71 \mathrm{a}$ & $86,19 \mathrm{a}$ & $77,62 \mathrm{a}$ & $80,48 \mathrm{a}$ \\
\hline \multirow[t]{2}{*}{ Promedio } & & 51,11 & 60,03 & 74,85 & 59,84 & 73,01 \\
\hline & & Buck Brasil & & & & \\
\hline \multirow[t]{3}{*}{ Los Hornos } & 1 & $72,78 \mathrm{~b}$ & & & & \\
\hline & 2 & $33,71 \mathrm{a}$ & & & & \\
\hline & 3 & $15,67 \mathrm{a}$ & & & & \\
\hline \multirow[t]{3}{*}{ Pergamino } & 1 & $79,64 \mathrm{a}$ & & & & \\
\hline & 2 & $71,90 \mathrm{a}$ & & & & \\
\hline & 3 & $77,62 \mathrm{a}$ & & & & \\
\hline
\end{tabular}


\begin{tabular}{l|l|c|l|l|l|}
\hline Promedio & & 58,55 & & & \\
Referencias: Aislado 1 = cepa LH; Aislado 2 = cepa 25M035; Aislado 3 = cepa G327.
\end{tabular} Medias seguidas por la misma letra no difieren estadísticamente ( $\mathrm{P}=0,05$, LSD test). LSD cultivar $=7,58$

En EC 82 hubo diferencias significativas entre los cultivares destacándose por su mejor comportamiento a Baguette 601, Buck SY 110, Buck SY 300, Sursem Nogal, Don Mario Lenox, Baguette 17, ProInta Puntal, Buck SY 100, Buck AGP Fast, BioInta 1001, Buck $75^{\circ}$ Aniversario y Klein León. El aislado 3 se diferenció significativamente del aislado 2 y éste a su vez se diferenció significativamente del 1 teniendo un comportamiento similar que en la anterior evaluación (Tabla 6.1.7 del apéndice). La localidad Pergamino se diferenció significativamente de Los Hornos con una mayor severidad general (Tabla 6.1.8 del apéndice). Buck 75 Aniversario, Buck Brasil y Don Mario Lenox tuvieron una mayor severidad con el aislado 1 en Los Hornos mientras que los primeros dos obtuvieron valores similares en Pergamino. Klein Castor evidenció una mayor severidad con el aislado 2 en Los Hornos y presentó un valor similar en Pergamino. Klein León mostró una mayor severidad con el aislado 2 en Pergamino y obtuvo el valor más alto, con el mismo aislado, en Los Hornos. Buck AGP Fast presentó la severidad más alta con el aislado 2 en ambos ambientes. Baguette Premium 11, ProInta Puntal, Klein Volcán, Klein Dragón, BioInta 2004 y Don Mario Cronox tuvieron una mayor severidad con el aislado 3 en Los Hornos. Entre estos cultivares Klein Volcán, Klein Dragón, BioInta 2004 y Don Mario Cronox mostraron los valores más altos de severidad en Pergamino para el mismo aislado. Por su parte Baguette Premium 11 evidenció valores similares en ambos ambientes. Baguette 9 tuvo un comportamiento similar a lo evidenciado en la anterior evaluación aunque sin diferencias significativas entre los aislados.

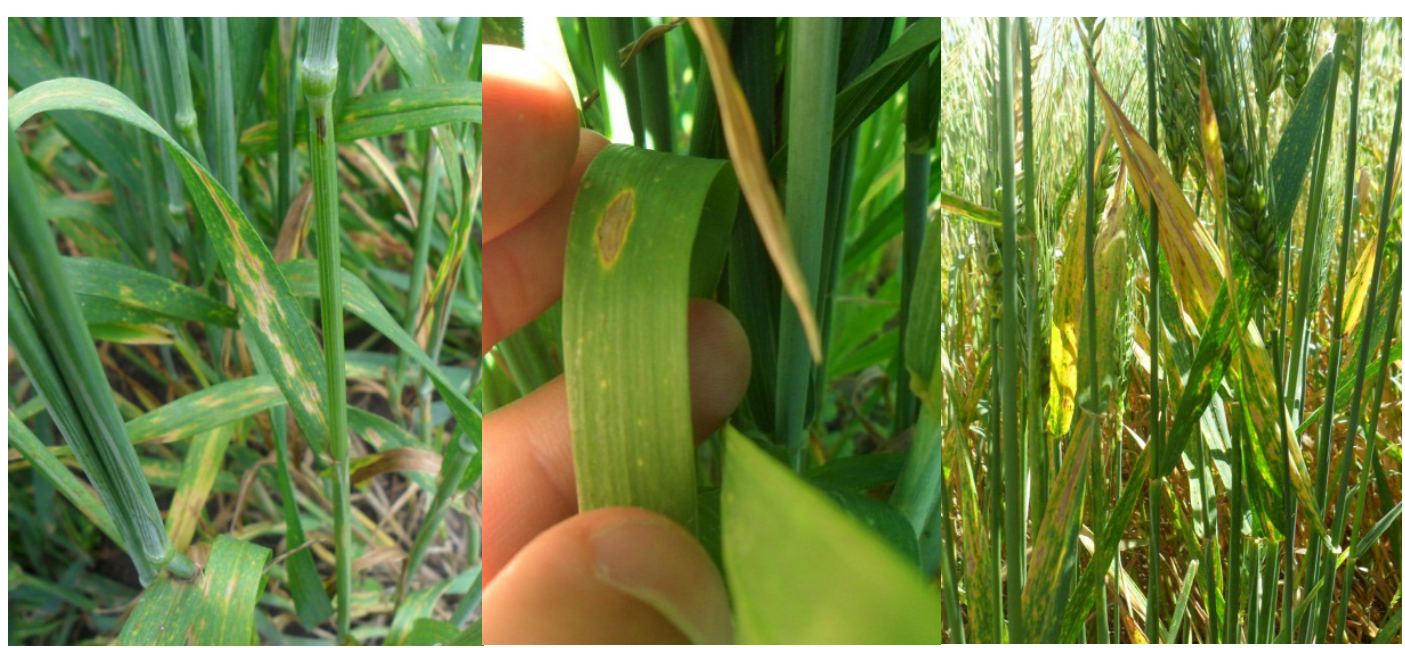

Figura 3.4.1. Síntomas observados en un ensayo de trigo inoculado individualmente con aislados seleccionados de $D$. tritici-repentis, en dos localidades y 31 cultivares de trigo. 
En la Tabla 3.4.5 se muestran los cuadrados medios y sus correspondientes probabilidades para el tipo de reacción en tres momentos de evaluación (EC 37, EC 75 y EC 82).

Tabla 3.4.5. Cuadrados medios del tipo de reacción en tres momentos de evaluación (EC 37, EC 75 y EC 82) en un ensayo de trigo inoculado individualmente con tres aislados de $D$. tritici-repentis, en dos localidades y en 31 cultivares de trigo.

\begin{tabular}{|c|c|c|c|c|}
\hline $\begin{array}{c}\text { Fuente de } \\
\text { Variación }\end{array}$ & G.L. & $\begin{array}{c}\text { Estadio EC 37 } \\
\text { Promedio de las 4 } \\
\text { hojas superiores- }\end{array}$ & $\begin{array}{c}\text { Estadio EC 75 } \\
\text { - Promedio de las } 4 \\
\text { hojas superiores- }\end{array}$ & $\begin{array}{c}\text { Estadio EC 82 } \\
\text { - Promedio de las 3 } \\
\text { hojas superiores- }\end{array}$ \\
\hline Localidad & 1 & $4,379(0,023)^{*}$ & $34,877(0,071)$ & $44,981(0,047)$ \\
\hline Error a & 1 & 0,006 & 0,432 & 0,243 \\
\hline Aislado & 2 & $0,356(0,071)$ & $0,514(0,345)$ & $0,439(0,135)$ \\
\hline $\mathbf{L} \times \mathbf{A}$ & 2 & $0,003(0,949)$ & $0,365(0,445)$ & $0,100(0,515)$ \\
\hline Error b & 4 & 0,065 & 0,365 & 0,127 \\
\hline Cultivar & 30 & $0,758(<0,001)$ & $3,549(<0,001)$ & $1,351(<0,001)$ \\
\hline $\mathbf{L} \times \mathbf{C}$ & 30 & $0,385(<0,001)$ & $1,215(<0,001)$ & $0,565(<0,001)$ \\
\hline $\mathbf{A} \times \mathbf{C}$ & 60 & $0,089(0,205)$ & $0,205(0,010)$ & $0,191(0,003)$ \\
\hline $\mathbf{L} \times \mathbf{A} \times \mathbf{C}$ & 60 & $0,074(0,521)$ & $0,222(0,003)$ & $0,161(0,029)$ \\
\hline $\mathbf{E r r o r} \mathbf{c}$ & 180 & 0,075 & 0,128 & 0,110 \\
\hline
\end{tabular}

* Valor de P de acuerdo al test de F.

Se observaron diferencias significativas entre localidades para EC 37 y EC 82 . No hubo diferencias entre aislados en ninguno de los tres estadios; mientras que entre cultivares si se encontraron diferencias significativas en los tres estadios. La triple interacción fue significativa en EC 75 y EC 82.

En la Tabla 3.4.6 se presentan las medias del tipo de reacción correspondientes al estadio EC 37 para los tres aislados, dos localidades y 31 cultivares de trigo.

Tabla 3.4.6. Medias del tipo de reacción en un ensayo de trigo inoculado individualmente con aislados seleccionados de $D$. tritici-repentis, en dos localidades y 31 cultivares de trigo, evaluadas en el estadio EC 37.

\begin{tabular}{|c|l|c|c|c|c|c|}
\hline Localidad & Aislado & \multicolumn{5}{|c|}{ Cultivar } \\
\hline & & $\begin{array}{c}\text { Sursem } \\
\text { Nogal }\end{array}$ & $\begin{array}{c}\text { Baguette } \\
\text { Premium 11 }\end{array}$ & Buck SY 300 & $\begin{array}{c}\text { Klein } \\
\text { Capricornio }\end{array}$ & $\begin{array}{c}\text { Don Mario } \\
\text { Lenox }\end{array}$ \\
\hline Los Hornos & 1 & $0,44 \mathrm{a}$ & $0,55 \mathrm{a}$ & $0,32 \mathrm{a}$ & $0,98 \mathrm{a}$ & $0,00 \mathrm{a}$ \\
\hline & 2 & $0,26 \mathrm{a}$ & $0,56 \mathrm{a}$ & $0,55 \mathrm{a}$ & $1,09 \mathrm{a}$ & $0,10 \mathrm{ab}$ \\
\hline & 3 & $0,30 \mathrm{a}$ & $0,40 \mathrm{a}$ & $0,25 \mathrm{a}$ & $0,91 \mathrm{a}$ & $0,62 \mathrm{~b}$ \\
\hline & & & & & & \\
\hline Pergamino & 1 & $0,98 \mathrm{~b}$ & $0,61 \mathrm{a}$ & $1,07 \mathrm{~b}$ & $0,78 \mathrm{a}$ & $0,20 \mathrm{ab}$ \\
\hline & 2 & $0,88 \mathrm{~b}$ & $0,66 \mathrm{a}$ & $0,77 \mathrm{ab}$ & $0,78 \mathrm{a}$ & $0,00 \mathrm{a}$ \\
\hline & 3 & $0,23 \mathrm{a}$ & $0,38 \mathrm{a}$ & $0,53 \mathrm{a}$ & $0,74 \mathrm{a}$ & $0,71 \mathrm{~b}$ \\
\hline Promedio & & 0,52 & 0,53 & 0,58 & 0,88 & 0,27 \\
\hline & & Klein Proteo & Klein Tauro & BioInta 1001 & Klein Castor & $\begin{array}{c}\text { Buck 75 } \\
\text { Aniversario }\end{array}$ \\
\hline
\end{tabular}




\begin{tabular}{|c|c|c|c|c|c|c|}
\hline Los Hornos & 1 & $1,13 \mathrm{a}$ & $0,85 \mathrm{a}$ & $0,45 \mathrm{a}$ & $0,55 \mathrm{a}$ & $0,61 \mathrm{a}$ \\
\hline & 2 & $0,94 \mathrm{a}$ & $0,94 \mathrm{a}$ & $0,46 \mathrm{a}$ & $0,64 \mathrm{a}$ & $0,84 \mathrm{a}$ \\
\hline & 3 & $0,91 \mathrm{a}$ & $0,96 \mathrm{a}$ & $0,18 \mathrm{a}$ & $0,21 \mathrm{a}$ & $0,43 \mathrm{a}$ \\
\hline \multirow[t]{3}{*}{ Pergamino } & 1 & $1,66 \mathrm{a}$ & $1,80 \mathrm{a}$ & $1,01 \mathrm{a}$ & $1,21 \mathrm{a}$ & $1,59 \mathrm{a}$ \\
\hline & 2 & $1,21 \mathrm{a}$ & $1,50 \mathrm{a}$ & $0,68 \mathrm{a}$ & $0,99 \mathrm{a}$ & $1,49 \mathrm{a}$ \\
\hline & 3 & $1,19 \mathrm{a}$ & $1,40 \mathrm{a}$ & $0,61 \mathrm{a}$ & $0,80 \mathrm{a}$ & $1,24 \mathrm{a}$ \\
\hline \multirow[t]{2}{*}{ Promedio } & & 1,17 & 1,24 & 0,57 & 0,73 & 1,03 \\
\hline & & $\begin{array}{c}\text { Buck AGP } \\
\text { Fast }\end{array}$ & Buck SY 110 & $\overline{\text { ACA } 901}$ & Klein León & Klein Rayo \\
\hline \multirow[t]{3}{*}{ Los Hornos } & 1 & $0,48 \mathrm{a}$ & $0,41 \mathrm{a}$ & $0,59 \mathrm{a}$ & $0,45 \mathrm{a}$ & $0,59 \mathrm{a}$ \\
\hline & 2 & $0,30 \mathrm{a}$ & $0,55 \mathrm{a}$ & $0,46 \mathrm{a}$ & $0,43 \mathrm{a}$ & $0,54 \mathrm{a}$ \\
\hline & 3 & $0,27 \mathrm{a}$ & $0,46 \mathrm{a}$ & $0,52 \mathrm{a}$ & $0,41 \mathrm{a}$ & $0,45 \mathrm{a}$ \\
\hline \multirow[t]{3}{*}{ Pergamino } & 1 & $1,21 \mathrm{a}$ & $0,73 \mathrm{a}$ & $0,82 \mathrm{a}$ & $0,89 \mathrm{a}$ & $0,86 \mathrm{a}$ \\
\hline & 2 & $0,73 \mathrm{a}$ & $1,13 \mathrm{a}$ & $0,75 \mathrm{a}$ & $1,01 \mathrm{a}$ & $0,59 \mathrm{a}$ \\
\hline & 3 & $0,81 \mathrm{a}$ & $0,98 \mathrm{a}$ & $0,93 \mathrm{a}$ & $0,77 \mathrm{a}$ & $0,79 \mathrm{a}$ \\
\hline \multirow[t]{2}{*}{ Promedio } & & 0,63 & 0,71 & 0,68 & 0,66 & 0,64 \\
\hline & & $\begin{array}{c}\text { Baguette } \\
\text { Premium } 13\end{array}$ & Baguette 701 & Buck SY 100 & $\overline{A C A 320}$ & Klein Nutria \\
\hline \multirow[t]{3}{*}{ Los Hornos } & 1 & $1,10 \mathrm{a}$ & $0,80 \mathrm{a}$ & $1,11 \mathrm{a}$ & $1,39 \mathrm{~b}$ & $1,18 \mathrm{a}$ \\
\hline & 2 & $0,92 \mathrm{a}$ & $0,80 \mathrm{a}$ & $0,99 \mathrm{a}$ & $1,09 \mathrm{ab}$ & $1,04 \mathrm{a}$ \\
\hline & 3 & $0,75 \mathrm{a}$ & $0,44 \mathrm{a}$ & $1,19 \mathrm{a}$ & $0,74 \mathrm{a}$ & $0,79 \mathrm{a}$ \\
\hline \multirow[t]{3}{*}{ Pergamino } & 1 & $1,11 \mathrm{a}$ & $0,71 \mathrm{a}$ & $0,88 \mathrm{a}$ & $0,73 \mathrm{a}$ & $1,52 \mathrm{a}$ \\
\hline & 2 & $0,86 \mathrm{a}$ & $0,77 \mathrm{a}$ & $1,12 \mathrm{a}$ & $0,84 \mathrm{a}$ & $1,52 \mathrm{a}$ \\
\hline & 3 & $1,04 \mathrm{a}$ & $0,48 \mathrm{a}$ & $0,96 \mathrm{a}$ & $1,06 \mathrm{a}$ & $1,54 \mathrm{a}$ \\
\hline \multirow[t]{2}{*}{ Promedio } & & 0,96 & 0,67 & 1,04 & 0,98 & 1,27 \\
\hline & & $\begin{array}{c}\text { Baguette } \\
601\end{array}$ & Baguette 9 & Baguette 17 & BioInta 3005 & $\begin{array}{c}\text { Don Mario } \\
\text { Cronox } \\
\end{array}$ \\
\hline \multirow[t]{3}{*}{ Los Hornos } & 1 & $0,59 \mathrm{a}$ & $0,41 \mathrm{a}$ & $1,04 \mathrm{a}$ & $0,52 \mathrm{ab}$ & $0,52 \mathrm{a}$ \\
\hline & 2 & $0,23 \mathrm{a}$ & $0,43 \mathrm{a}$ & $0,89 \mathrm{a}$ & $0,43 \mathrm{a}$ & $1,02 \mathrm{a}$ \\
\hline & 3 & $0,45 \mathrm{a}$ & $0,23 \mathrm{a}$ & $1,00 \mathrm{a}$ & $0,98 \mathrm{~b}$ & $0,57 \mathrm{a}$ \\
\hline \multirow[t]{3}{*}{ Pergamino } & 1 & $0,64 \mathrm{a}$ & $1,05 \mathrm{a}$ & $0,66 \mathrm{a}$ & $0,59 \mathrm{a}$ & $1,05 \mathrm{ab}$ \\
\hline & 2 & $0,96 \mathrm{a}$ & $1,09 \mathrm{a}$ & $0,84 \mathrm{a}$ & $0,57 \mathrm{a}$ & $0,66 \mathrm{a}$ \\
\hline & 3 & $0,55 \mathrm{a}$ & $0,88 \mathrm{a}$ & $0,57 \mathrm{a}$ & $0,46 \mathrm{a}$ & $1,34 \mathrm{~b}$ \\
\hline \multirow[t]{2}{*}{ Promedio } & & 0,57 & 0,68 & 0,83 & 0,59 & 0,86 \\
\hline & & $\begin{array}{c}\text { ProInta } \\
\text { Puntal } \\
\end{array}$ & $\begin{array}{c}\text { Klein } \\
\text { Volcán } \\
\end{array}$ & $\begin{array}{c}\text { Klein } \\
\text { Dragón }\end{array}$ & BioInta 2004 & Sursem 2330 \\
\hline \multirow[t]{3}{*}{ Los Hornos } & 1 & $0,43 \mathrm{a}$ & $0,37 \mathrm{a}$ & $0,71 \mathrm{a}$ & $0,34 \mathrm{a}$ & $1,02 \mathrm{a}$ \\
\hline & 2 & $0,55 \mathrm{a}$ & $0,37 \mathrm{a}$ & $0,43 \mathrm{a}$ & $0,04 \mathrm{a}$ & $1,49 \mathrm{a}$ \\
\hline & 3 & $0,38 \mathrm{a}$ & $0,88 \mathrm{a}$ & $0,66 \mathrm{a}$ & $0,54 \mathrm{a}$ & $1,35 \mathrm{a}$ \\
\hline & & & & & & \\
\hline
\end{tabular}




\begin{tabular}{|l|l|c|c|c|c|c|}
\hline Pergamino & 1 & $0,64 \mathrm{a}$ & $0,39 \mathrm{a}$ & $1,39 \mathrm{a}$ & $0,50 \mathrm{a}$ & $0,48 \mathrm{a}$ \\
\hline & 2 & $0,32 \mathrm{a}$ & $0,62 \mathrm{a}$ & $1,48 \mathrm{a}$ & $0,84 \mathrm{a}$ & $0,68 \mathrm{a}$ \\
\hline & 3 & $0,27 \mathrm{a}$ & $0,80 \mathrm{a}$ & $1,36 \mathrm{a}$ & $0,46 \mathrm{a}$ & $0,45 \mathrm{a}$ \\
\hline Promedio & & 0,43 & 0,57 & 1,01 & 0,45 & 0,91 \\
\hline & & Buck Brasil & & & & \\
\hline Los Hornos & 1 & $1,81 \mathrm{c}$ & & & & \\
\hline & 2 & $1,20 \mathrm{~b}$ & & & & \\
\hline & 3 & $0,55 \mathrm{a}$ & & & & \\
\hline & & & & & & \\
\hline Pergamino & 1 & $0,98 \mathrm{a}$ & & & & \\
\hline & 2 & $1,08 \mathrm{a}$ & & & & \\
\hline & 3 & $0,82 \mathrm{a}$ & & & & \\
\hline Promedio & & 0,82 & & & & \\
\hline
\end{tabular}

Referencias: Aislado 1 = cepa LH; Aislado 2 = cepa 25M035; Aislado 3 = cepa G327. Medias seguidas por la misma letra no difieren estadísticamente ( $\mathrm{P}=0,05$, LSD test). LSD cultivar $=0,22$

En EC 37 hubo diferencias significativas entre los cultivares. Los que tuvieron mejor comportamiento, en cuanto a tipo de reacción, fueron Don Mario Lenox, ProInta Puntal, BioInta 2004, Sursem Nogal, Baguette Premium 11, BioInta 1001, Baguette 601, Klein Volcán, Buck SY 300, BioInta 3005 y Buck AGP Fast coincidiendo, en líneas generales, con el comportamiento observado en cuando a la severidad indicado en la Tabla 3.4.2. No hubo diferencias significativas entre aislados (Tabla 6.1.9 del apéndice). Se encontraron diferencias significativas entre localidades siendo Pergamino la que presenta el mayor valor (Tabla 6.1.10 del apéndice). Si bien la triple interacción no fue significativa para este estadio el aislado 1 presentó un aumento significativo para la variedad Sursem Nogal y Buck SY 300 en Pergamino, y para Buck Brasil y ACA 320, en Los Hornos. El aislado 3 mostró los mayores valores para Don Mario Lenox en Pergamino y Los Hornos y para Cronox en Pergamino.

En la Tabla 3.4.7 se presentan las medias del tipo de reacción correspondientes al estadio EC 75 para los tres aislados, dos localidades y 31 cultivares de trigo. 
Tabla 3.4.7. Medias del tipo de reacción en un ensayo de trigo inoculado individualmente con aislados seleccionados de $D$. tritici-repentis, en dos localidades y 31 cultivares de trigo, evaluadas el estadio EC 75.

\begin{tabular}{|c|c|c|c|c|c|c|}
\hline \multirow[t]{2}{*}{ Localidad } & \multirow[t]{2}{*}{ Aislado } & \multicolumn{5}{|c|}{ Cultivar } \\
\hline & & $\begin{array}{c}\begin{array}{c}\text { Sursem } \\
\text { Nogal }\end{array} \\
\end{array}$ & $\begin{array}{c}\text { Baguette } \\
\text { Premium } 11 \\
\end{array}$ & Buck SY 300 & $\begin{array}{c}\text { Klein } \\
\text { Capricornio } \\
\end{array}$ & $\begin{array}{c}\text { Don Mario } \\
\text { Lenox } \\
\end{array}$ \\
\hline \multirow[t]{3}{*}{ Los Hornos } & 1 & $3,18 \mathrm{a}$ & $3,78 \mathrm{a}$ & $1,12 \mathrm{a}$ & $3,87 \mathrm{a}$ & $3,35 \mathrm{a}$ \\
\hline & 2 & $3,34 \mathrm{a}$ & $4,07 \mathrm{a}$ & $2,10 \mathrm{~b}$ & $3,78 \mathrm{a}$ & $3,03 \mathrm{a}$ \\
\hline & 3 & $3,27 \mathrm{a}$ & $4,21 \mathrm{a}$ & $1,94 \mathrm{~b}$ & $4,00 \mathrm{a}$ & $3,14 \mathrm{a}$ \\
\hline \multirow[t]{3}{*}{ Pergamino } & 1 & $2,89 \mathrm{a}$ & $4,16 \mathrm{a}$ & $3,07 \mathrm{a}$ & $4,05 \mathrm{a}$ & $3,23 \mathrm{a}$ \\
\hline & 2 & $2,50 \mathrm{a}$ & $4,53 \mathrm{a}$ & $2,87 \mathrm{a}$ & $4,19 \mathrm{a}$ & $3,46 \mathrm{a}$ \\
\hline & 3 & $2,30 \mathrm{a}$ & $4,18 \mathrm{a}$ & $2,85 \mathrm{a}$ & $3,96 \mathrm{a}$ & $3,53 \mathrm{a}$ \\
\hline \multirow[t]{2}{*}{ Promedio } & & 2,91 & 4,16 & 2,33 & 3,98 & 3,29 \\
\hline & & Klein Proteo & Klein Tauro & BioInta 1001 & Klein Castor & $\begin{array}{c}\text { Buck } 75^{\circ} \\
\text { Aniversario } \\
\end{array}$ \\
\hline \multirow[t]{3}{*}{ Los Hornos } & 1 & $2,23 \mathrm{a}$ & $3,68 \mathrm{a}$ & $1,53 \mathrm{a}$ & $2,14 \mathrm{a}$ & $3,37 \mathrm{~b}$ \\
\hline & 2 & $3,23 \mathrm{~b}$ & $3,08 \mathrm{a}$ & $2,55 \mathrm{~b}$ & $3,08 \mathrm{~b}$ & $2,67 \mathrm{ab}$ \\
\hline & 3 & $2,23 \mathrm{a}$ & $3,69 \mathrm{a}$ & $1,44 \mathrm{a}$ & $2,55 \mathrm{ab}$ & $2,34 \mathrm{a}$ \\
\hline \multirow[t]{3}{*}{ Pergamino } & 1 & $3,96 \mathrm{a}$ & $4,16 \mathrm{a}$ & $3,28 \mathrm{ab}$ & $3,96 \mathrm{a}$ & $3,12 \mathrm{a}$ \\
\hline & 2 & $4,01 \mathrm{a}$ & $4,16 \mathrm{a}$ & $3,67 \mathrm{~b}$ & $3,48 \mathrm{a}$ & $3,66 \mathrm{a}$ \\
\hline & 3 & $3,89 \mathrm{a}$ & $4,10 \mathrm{a}$ & $2,80 \mathrm{a}$ & $3,75 \mathrm{a}$ & $3,37 \mathrm{a}$ \\
\hline \multirow[t]{2}{*}{ Promedio } & & 3,26 & 3,81 & 2,55 & 3,16 & 3,09 \\
\hline & & $\begin{array}{c}\text { Buck AGP } \\
\text { Fast }\end{array}$ & Buck SY 110 & $\overline{\text { ACA } 901}$ & Klein León & Klein Rayo \\
\hline \multirow[t]{3}{*}{ Los Hornos } & 1 & $2,57 \mathrm{~b}$ & $1,50 \mathrm{a}$ & $2,76 \mathrm{a}$ & $2,30 \mathrm{a}$ & $3,01 \mathrm{a}$ \\
\hline & 2 & $2,10 \mathrm{ab}$ & $1,96 \mathrm{a}$ & $2,96 \mathrm{a}$ & $2,89 \mathrm{a}$ & $3,25 \mathrm{a}$ \\
\hline & 3 & $1,53 \mathrm{a}$ & $1,80 \mathrm{a}$ & $2,62 \mathrm{a}$ & $2,12 \mathrm{a}$ & $2,71 \mathrm{a}$ \\
\hline \multirow[t]{3}{*}{ Pergamino } & 1 & $3,25 \mathrm{a}$ & $3,17 \mathrm{~b}$ & $3,48 \mathrm{a}$ & $3,03 \mathrm{a}$ & $3,87 \mathrm{a}$ \\
\hline & 2 & $3,17 \mathrm{a}$ & $3,21 \mathrm{~b}$ & $3,50 \mathrm{a}$ & $3,80 \mathrm{~b}$ & $3,82 \mathrm{a}$ \\
\hline & 3 & $3,14 \mathrm{a}$ & $2,41 \mathrm{a}$ & $3,62 \mathrm{a}$ & $3,41 \mathrm{ab}$ & $3,75 \mathrm{a}$ \\
\hline \multirow[t]{2}{*}{ Promedio } & & 2,63 & 2,34 & 3,16 & 2,93 & 3,40 \\
\hline & & $\begin{array}{c}\text { Baguette } \\
\text { Premium } 13\end{array}$ & Baguette 701 & Buck SY 100 & $\overline{A C A 320}$ & Klein Nutria \\
\hline \multirow[t]{3}{*}{ Los Hornos } & 1 & $1,82 \mathrm{a}$ & $4,16 \mathrm{a}$ & $2,48 \mathrm{a}$ & $3,87 \mathrm{a}$ & $3,12 \mathrm{a}$ \\
\hline & 2 & $2,51 \mathrm{a}$ & $4,08 \mathrm{a}$ & $2,42 \mathrm{a}$ & $3,75 \mathrm{a}$ & $2,58 \mathrm{a}$ \\
\hline & 3 & $2,08 \mathrm{a}$ & $4,00 \mathrm{a}$ & $2,42 \mathrm{a}$ & $3,91 \mathrm{a}$ & $2,73 \mathrm{a}$ \\
\hline \multirow[t]{3}{*}{ Pergamino } & 1 & $2,76 \mathrm{a}$ & $2,58 \mathrm{a}$ & $3,21 \mathrm{a}$ & $3,87 \mathrm{a}$ & $3,87 \mathrm{a}$ \\
\hline & 2 & $3,14 \mathrm{a}$ & $2,28 \mathrm{a}$ & $2,82 \mathrm{a}$ & $4,30 \mathrm{a}$ & $3,67 \mathrm{a}$ \\
\hline & 3 & $3,35 \mathrm{a}$ & $2,07 \mathrm{a}$ & $2,85 \mathrm{a}$ & $4,26 \mathrm{a}$ & $3,94 \mathrm{a}$ \\
\hline \multirow[t]{2}{*}{ Promedio } & & 2,61 & 3,20 & 2,70 & 3,99 & 3,32 \\
\hline & & Baguette & Baguette 9 & Baguette 17 & BioInta 3005 & Don Mario \\
\hline
\end{tabular}




\begin{tabular}{|c|c|c|c|c|c|c|}
\hline \multirow{3}{*}{ Los Hornos } & & 601 & & & & Cronox \\
\hline & 1 & $1,30 \mathrm{a}$ & $2,48 \mathrm{a}$ & $1,91 \mathrm{a}$ & $3,73 \mathrm{a}$ & $2,05 \mathrm{a}$ \\
\hline & 2 & $1,51 \mathrm{a}$ & $3,39 \mathrm{~b}$ & $2,03 \mathrm{ab}$ & $3,82 \mathrm{a}$ & $2,73 a b$ \\
\hline & 3 & $2,01 \mathrm{a}$ & $2,01 \mathrm{a}$ & $2,68 \mathrm{~b}$ & $3,67 \mathrm{a}$ & $2,91 \mathrm{~b}$ \\
\hline Pergamino & $\overline{1}$ & $2.53 \mathrm{a}$ & $2,87 \mathrm{a}$ & $2,83 \mathrm{a}$ & $3,80 \mathrm{a}$ & $3,17 \mathrm{a}$ \\
\hline & 2 & $2,58 \mathrm{a}$ & $3,82 \mathrm{~b}$ & $3,00 \mathrm{a}$ & $4,12 \mathrm{a}$ & $3,46 \mathrm{a}$ \\
\hline & 3 & $2,39 \mathrm{a}$ & $3,14 \mathrm{ab}$ & $3,08 \mathrm{a}$ & $4,23 \mathrm{a}$ & $3,62 \mathrm{a}$ \\
\hline Promedio & & 2.05 & 295 & 2.59 & 390 & 299 \\
\hline & & $\begin{array}{c}\text { ProInta } \\
\text { Puntal }\end{array}$ & $\begin{array}{c}\text { Klein } \\
\text { Volcán }\end{array}$ & $\begin{array}{c}\text { Klein } \\
\text { Dragón }\end{array}$ & BioInta 2004 & Sursem 2330 \\
\hline Los Hornos & 1 & $1,75 \mathrm{a}$ & $2,21 \mathrm{a}$ & $2,82 \mathrm{a}$ & $2,07 \mathrm{a}$ & $4,03 \mathrm{a}$ \\
\hline & 2 & $1,62 \mathrm{a}$ & $2,46 \mathrm{ab}$ & $3,01 \mathrm{a}$ & $2,55 \mathrm{ab}$ & $3,92 \mathrm{a}$ \\
\hline & 3 & $3,00 \mathrm{~b}$ & $2,98 \mathrm{~b}$ & $3,80 \mathrm{~b}$ & $2,83 \mathrm{~b}$ & $4,14 \mathrm{a}$ \\
\hline Pergamino & $\overline{1}$ & $3,16 \mathrm{a}$ & $2,87 \mathrm{a}$ & $3,48 \mathrm{a}$ & $3,10 \mathrm{a}$ & $3,94 \mathrm{a}$ \\
\hline & 2 & $3,53 \mathrm{a}$ & $3,35 \mathrm{a}$ & $3,69 \mathrm{a}$ & $3,33 \mathrm{a}$ & $3,96 \mathrm{a}$ \\
\hline & 3 & $3,19 \mathrm{a}$ & $2,91 \mathrm{a}$ & $3,28 \mathrm{a}$ & $3,16 \mathrm{a}$ & $3,75 \mathrm{a}$ \\
\hline Promedio & & 2,71 & 2,80 & 3,35 & 2,84 & 3,96 \\
\hline & & Buck Brasil & & & & \\
\hline Los Hornos & 1 & $3,92 \mathrm{~b}$ & & & & \\
\hline & 2 & $2,51 \mathrm{a}$ & & & & \\
\hline & 3 & $3,03 \mathrm{a}$ & & & & \\
\hline Pergamino & 1 & $3,87 \mathrm{a}$ & & & & \\
\hline & 2 & $3,94 a$ & & & & \\
\hline & 3 & $4,03 \mathrm{a}$ & & & & \\
\hline Promedio & & 3,55 & & & & \\
\hline
\end{tabular}

Referencias: Aislado 1 = cepa LH; Aislado 2 = cepa 25M035; Aislado 3 = cepa G327. Medias seguidas por la misma letra no difieren estadísticamente ( $\mathrm{P}=0,05, \mathrm{LSD}$ test). LSD cultivar $=0,29$

En EC 75 hubo diferencias significativas entre los cultivares, destacándose como de mejor comportamiento a Baguette 601, Buck SY 300, Buck SY 110 , BioInta 1001, Baguette 17, Baguette Premium 13, Buck AGP Fast, Buck SY 100, ProInta Puntal, Klein Volcán, BioInta 2004 y Sursem Nogal mostrando algunas coincidencias con las evaluaciones realizadas en plántula. Los aislados no se diferenciaron significativamente entre sí (Tabla 6.1.11 del apéndice). Si bien no se observaron diferencias significativas entre localidades hubo, en general, un predominio del tipo de reacción 3 para la localidad de Pergamino en comparación con Los Hornos (Tabla 6.1.12 del apéndice). Los cultivares Buck $75^{\circ}$ Aniversario, Buck AGP Fast y Buck Brasil tuvieron un aumento significativo del tipo de reacción con el aislado 1 en Los Hornos y presentaron valores similares en Pergamino. Buck SY 300, Klein Proteo y Klein Castor presentaron 
un aumento significativo con el aislado 2 en Los Hornos y valores similares en Pergamino. Buck SY 110 y Klein León mostraron un aumento significativo con el aislado 2 en Pergamino. Este último también obtuvo el valor más alto del tipo de reacción, con el mismo aislado, en Los Hornos. Los cultivares Baguette 9 y BioInta 1001 presentaron un aumento significativo con el aislado 2 en ambas localidades. Baguette 17, Don Mario Cronox, ProInta Puntal, Klein Volcán, Klein Dragón y BioInta 2004 presentaron un aumento significativo con el aislado 3 en Los Hornos. Entre estas variedades, Baguette 17 y Don Mario Cronox presentaron los valores más elevados del tipo de reacción para el mismo aislado en Pergamino.

En la Tabla 3.4.8 se presentan las medias del tipo de reacción correspondientes al estadio EC 82 para los tres aislados, dos localidades y 31 cultivares de trigo.

Tabla 3.4.8. Medias del tipo de reacción en un ensayo de trigo inoculado individualmente con aislados seleccionados de $D$. tritici-repentis, en dos localidades y 31 cultivares de trigo, evaluadas en el estadio EC 82.

\begin{tabular}{|c|c|c|c|c|c|c|}
\hline Localidad & Aislado & \multicolumn{5}{|c|}{ Cultivar } \\
\hline & & $\begin{array}{c}\text { Sursem } \\
\text { Nogal }\end{array}$ & $\begin{array}{c}\text { Baguette } \\
\text { Premium } 11\end{array}$ & Buck SY 300 & $\begin{array}{c}\text { Klein } \\
\text { Capricornio }\end{array}$ & $\begin{array}{c}\text { Don Mario } \\
\text { Lenox }\end{array}$ \\
\hline \multirow[t]{3}{*}{ Los Hornos } & 1 & $3,64 \mathrm{a}$ & $4,23 \mathrm{a}$ & $2,45 \mathrm{a}$ & $4,19 \mathrm{a}$ & $3,64 \mathrm{a}$ \\
\hline & 2 & $3,54 \mathrm{a}$ & $4,31 \mathrm{a}$ & $3,54 \mathrm{~b}$ & $4,21 \mathrm{a}$ & $3,11 \mathrm{a}$ \\
\hline & 3 & $3,92 \mathrm{a}$ & $4,64 \mathrm{a}$ & $2,83 \mathrm{a}$ & $4,40 \mathrm{a}$ & $3,38 \mathrm{a}$ \\
\hline \multirow[t]{5}{*}{ Pergamino } & 1 & $3,88 \mathrm{a}$ & $4,81 \mathrm{a}$ & $4,07 \mathrm{a}$ & $5,00 \mathrm{a}$ & $3,92 \mathrm{a}$ \\
\hline & 2 & $3,85 \mathrm{a}$ & $4,88 \mathrm{a}$ & $4,19 \mathrm{a}$ & $4,90 \mathrm{a}$ & $4,23 \mathrm{a}$ \\
\hline & 3 & $3,85 \mathrm{a}$ & $4,71 \mathrm{a}$ & $4,07 \mathrm{a}$ & $4,83 \mathrm{a}$ & $4,47 \mathrm{a}$ \\
\hline & & 3,78 & 4,60 & 3,53 & 4,59 & 3,79 \\
\hline & & Klein Proteo & Klein Tauro & BioInta 1001 & Klein Castor & $\begin{array}{c}\text { Buck } 75^{\circ} \\
\text { Aniversario }\end{array}$ \\
\hline \multirow[t]{3}{*}{ Los Hornos } & 1 & $3,54 \mathrm{a}$ & $4,00 \mathrm{a}$ & $3,09 \mathrm{a}$ & $3,45 \mathrm{a}$ & $4,26 \mathrm{~b}$ \\
\hline & 2 & $3,88 \mathrm{a}$ & $3,78 \mathrm{a}$ & $3,38 \mathrm{a}$ & $4,26 \mathrm{~b}$ & $3,47 \mathrm{a}$ \\
\hline & 3 & $3,38 \mathrm{a}$ & $3,83 \mathrm{a}$ & $3,57 \mathrm{a}$ & $3,47 \mathrm{a}$ & $3,50 \mathrm{a}$ \\
\hline \multirow[t]{5}{*}{ Pergamino } & 1 & $4,71 \mathrm{a}$ & $4,85 \mathrm{a}$ & $4,76 \mathrm{a}$ & $4,78 \mathrm{a}$ & $4,24 \mathrm{a}$ \\
\hline & 2 & $4,83 \mathrm{a}$ & $4,73 \mathrm{a}$ & $4,83 \mathrm{a}$ & $4,61 \mathrm{a}$ & $4,23 \mathrm{a}$ \\
\hline & 3 & $4,92 \mathrm{a}$ & $4,89 \mathrm{a}$ & $4,81 \mathrm{a}$ & $4,83 \mathrm{a}$ & $4,31 \mathrm{a}$ \\
\hline & & 4,21 & 4,35 & 4,07 & 4,23 & 4,00 \\
\hline & & $\begin{array}{c}\text { Buck AGP } \\
\text { Fast }\end{array}$ & Buck SY 110 & $\overline{\text { ACA 901 }}$ & Klein León & Klein Rayo \\
\hline \multirow[t]{3}{*}{ Los Hornos } & 1 & $3,02 \mathrm{a}$ & $2,38 \mathrm{a}$ & $4,02 \mathrm{a}$ & $3,61 \mathrm{a}$ & $3,92 \mathrm{a}$ \\
\hline & 2 & $3,92 \mathrm{~b}$ & $2,78 \mathrm{a}$ & $4,16 \mathrm{a}$ & $3,83 \mathrm{a}$ & $4,42 \mathrm{a}$ \\
\hline & 3 & $3,45 \mathrm{ab}$ & $2,71 \mathrm{a}$ & $3,85 \mathrm{a}$ & $3,50 \mathrm{a}$ & $4,16 \mathrm{a}$ \\
\hline \multirow[t]{2}{*}{ Pergamino } & 1 & $4,09 \mathrm{a}$ & $3,92 \mathrm{a}$ & $4,64 \mathrm{a}$ & $4,23 \mathrm{a}$ & $4,83 \mathrm{a}$ \\
\hline & 2 & $4,76 \mathrm{~b}$ & $4,35 \mathrm{a}$ & $4,71 \mathrm{a}$ & $4,50 \mathrm{a}$ & $4,78 \mathrm{a}$ \\
\hline
\end{tabular}




\begin{tabular}{|c|c|c|c|c|c|c|}
\hline & 3 & $4,71 \mathrm{ab}$ & $4,19 \mathrm{a}$ & $4,85 \mathrm{a}$ & $4,83 \mathrm{a}$ & $4,95 \mathrm{a}$ \\
\hline & & 3,99 & 3,39 & 4,37 & 4,08 & 4,51 \\
\hline & & $\begin{array}{c}\text { Baguette } \\
\text { Premium } 13 \\
\end{array}$ & Baguette 701 & Buck SY 100 & $\overline{\text { ACA 320 }}$ & Klein Nutria \\
\hline \multirow[t]{3}{*}{ Los Hornos } & 1 & $3,71 \mathrm{a}$ & $4,52 \mathrm{a}$ & $3,85 \mathrm{~b}$ & $4,38 \mathrm{a}$ & $3,76 \mathrm{a}$ \\
\hline & 2 & $3,66 \mathrm{a}$ & $4,35 \mathrm{a}$ & $3,09 \mathrm{a}$ & $3,97 \mathrm{a}$ & $3,57 \mathrm{a}$ \\
\hline & 3 & $3,76 \mathrm{a}$ & $4,47 \mathrm{a}$ & $3,78 \mathrm{~b}$ & $3,90 \mathrm{a}$ & $3,59 \mathrm{a}$ \\
\hline \multirow[t]{5}{*}{ Pergamino } & 1 & $4,45 \mathrm{a}$ & $3,97 \mathrm{a}$ & $4,23 \mathrm{a}$ & $4,64 \mathrm{a}$ & $4,73 \mathrm{a}$ \\
\hline & 2 & $4,38 \mathrm{a}$ & $3,81 \mathrm{a}$ & $4,06 \mathrm{a}$ & $4,71 \mathrm{a}$ & $4,76 \mathrm{a}$ \\
\hline & 3 & $4,47 \mathrm{a}$ & $3,76 \mathrm{a}$ & $4,19 a$ & $4,92 \mathrm{a}$ & $4,83 \mathrm{a}$ \\
\hline & & 4,07 & 4,15 & 3,87 & 4,42 & 4,21 \\
\hline & & $\begin{array}{c}\text { Baguette } \\
601\end{array}$ & Baguette 9 & Baguette 17 & BioInta 3005 & $\begin{array}{c}\text { Don Mario } \\
\text { Cronox } \\
\end{array}$ \\
\hline \multirow[t]{3}{*}{ Los Hornos } & 1 & $2,83 \mathrm{a}$ & $3,76 \mathrm{a}$ & $3,69 \mathrm{a}$ & $4,28 \mathrm{a}$ & $3,81 \mathrm{a}$ \\
\hline & 2 & $2,92 \mathrm{a}$ & $3,90 \mathrm{a}$ & $3,92 \mathrm{a}$ & $4,26 \mathrm{a}$ & $4,14 \mathrm{a}$ \\
\hline & 3 & $2,90 \mathrm{a}$ & $3,66 \mathrm{a}$ & $4,04 \mathrm{a}$ & $4,09 \mathrm{a}$ & $4,35 \mathrm{a}$ \\
\hline \multirow[t]{5}{*}{ Pergamino } & 1 & $3,45 \mathrm{a}$ & $4,23 \mathrm{a}$ & $3,97 \mathrm{a}$ & $4,59 \mathrm{a}$ & $4,31 \mathrm{a}$ \\
\hline & 2 & $3,81 \mathrm{a}$ & $4,69 \mathrm{a}$ & $4,07 \mathrm{a}$ & $4,81 \mathrm{a}$ & $4,64 \mathrm{a}$ \\
\hline & 3 & $3,64 \mathrm{a}$ & $4,40 \mathrm{a}$ & $4,21 \mathrm{a}$ & $4,81 \mathrm{a}$ & $4,85 \mathrm{a}$ \\
\hline & & 3,26 & 4,11 & 3,98 & 4,47 & 4,35 \\
\hline & & $\begin{array}{c}\text { ProInta } \\
\text { Puntal } \\
\end{array}$ & $\begin{array}{c}\text { Klein } \\
\text { Volcán } \\
\end{array}$ & $\begin{array}{c}\text { Klein } \\
\text { Dragón }\end{array}$ & BioInta 2004 & Sursem 2330 \\
\hline \multirow[t]{3}{*}{ Los Hornos } & 1 & $3,16 \mathrm{a}$ & $3,92 \mathrm{a}$ & $3,95 \mathrm{a}$ & $3,47 \mathrm{a}$ & $4,19 \mathrm{a}$ \\
\hline & 2 & $3,42 \mathrm{a}$ & $3,76 \mathrm{a}$ & $4,26 \mathrm{a}$ & $4,04 \mathrm{a}$ & $4,42 \mathrm{a}$ \\
\hline & 3 & $4,16 b$ & $4,40 \mathrm{a}$ & $4,81 \mathrm{a}$ & $4,09 \mathrm{a}$ & $4,52 \mathrm{a}$ \\
\hline \multirow[t]{5}{*}{ Pergamino } & 1 & $4,09 \mathrm{a}$ & $3,88 \mathrm{a}$ & $4,69 \mathrm{a}$ & $4,35 \mathrm{a}$ & $4,38 \mathrm{a}$ \\
\hline & 2 & $4,31 \mathrm{a}$ & $4,35 \mathrm{a}$ & $4,85 \mathrm{a}$ & $4,38 \mathrm{a}$ & $4,54 \mathrm{a}$ \\
\hline & 3 & $4,19 \mathrm{a}$ & $4,38 \mathrm{a}$ & $4,83 \mathrm{a}$ & $4,52 \mathrm{a}$ & $4,71 \mathrm{a}$ \\
\hline & & 3,89 & 4,12 & 4,57 & 4,14 & 4,46 \\
\hline & & Buck Brasil & & & & \\
\hline \multirow[t]{3}{*}{ Los Hornos } & 1 & $4,75 \mathrm{c}$ & & & & \\
\hline & 2 & $3,52 \mathrm{~b}$ & & & & \\
\hline & 3 & $1,76 \mathrm{a}$ & & & & \\
\hline \multirow[t]{4}{*}{ Pergamino } & 1 & $4,61 \mathrm{a}$ & & & & \\
\hline & 2 & $4,50 \mathrm{a}$ & & & & \\
\hline & 3 & $4,57 \mathrm{a}$ & & & & \\
\hline & & 3,95 & & & & \\
\hline
\end{tabular}

Referencias: Aislado 1 = cepa LH; Aislado 2 = cepa 25M035; Aislado 3 = cepa G327. Medias seguidas por la misma letra no difieren estadísticamente $(\mathrm{P}=0,05, \mathrm{LSD}$ test). LSD cultivar $=0,27$ 
En EC 82 hubo diferencias significativas entre los cultivares destacándose como los de mejor comportamiento a Baguette 601, Buck SY 110, Buck SY 300, Sursem Nogal, Don Mario Lenox, Buck SY 100, ProInta Puntal, Buck Brasil, Baguette 17, Buck AGP Fast, Buck 75 Aniversario, Baguette Premium 13 y BioInta 1001. No hubo diferencias significativas entre aislados (Tabla 6.1.13 del apéndice). La localidad Pergamino se diferenció significativamente de Los Hornos (Tabla 6.1.14 del apéndice). Los cultivares Buck 75 Aniversario, Buck SY 100 y Buck Brasil tuvieron un aumento significativo del tipo de reacción con el aislado 1 en Los Hornos y los dos últimos presentaron el mayor valor para el mismo aislado en Pergamino. Buck SY 300 y Klein Castor presentaron un aumento significativo con el aislado 2 en Los Hornos y este último presentó el mayor valor para Pergamino. Buck AGP Fast evidenció un aumento significativo con el aislado 2 en ambas localidades. ProInta Puntal mostró un aumento significativo con el aislado 3 en Los Hornos y tuvo un valor similar en Pergamino.
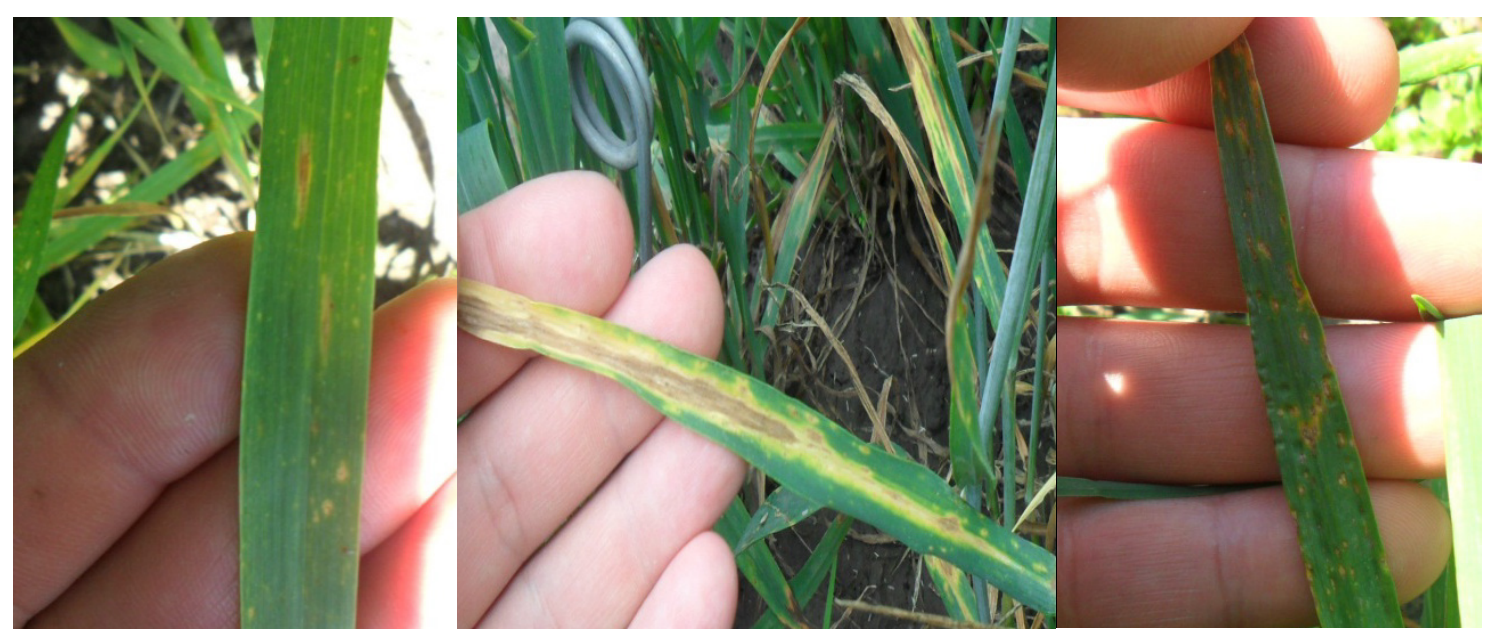

Figura 3.4.2. Tipos de reacción observados en un ensayo de trigo inoculado individualmente con aislados seleccionados de D. tritici-repentis, en dos localidades y en 31 cultivares de trigo.

En la Tabla 3.4.9 se muestran los cuadrados medios y sus correspondientes probabilidades para el área bajo la curva de progreso de la enfermedad (ABCPE). 
Tabla 3.4.9. Cuadrados medios del ABCPE en un ensayo de trigo inoculado individualmente con aislados seleccionados de D. tritici-repentis, en dos localidades y en 31 cultivares de trigo.

\begin{tabular}{|c|c|c|}
\hline Fuente de Variación & G.L. & ABCPE \\
\hline Localidad & 1 & $14830205(0,054)^{*}$ \\
\hline Error a & 1 & 109122 \\
\hline Aislado & 2 & $381145(0,058)$ \\
\hline $\mathbf{L} \times \mathbf{A}$ & 2 & $84131(0,347)$ \\
\hline Error b & 4 & 60280 \\
\hline Cultivar & 30 & $983449(<0,001)$ \\
\hline $\mathbf{L} \times \mathbf{C}$ & 30 & $316423(<0,001)$ \\
\hline $\mathbf{A} \times \mathbf{C}$ & 60 & $38869(0,145)$ \\
\hline $\mathbf{L} \times \mathbf{A} \times \mathbf{C}$ & 60 & $55869(0,002)$ \\
\hline Error c & 180 & 31416 \\
\hline
\end{tabular}

* Valor de $\mathrm{P}$ de acuerdo al test de $\mathrm{F}$.

No se observaron diferencias significativas entre localidades, ni entre aislados si se considera un nivel de $\mathrm{P}<=0,05$, pero fue en ambos casos inferior a $\mathrm{P}<0,06 \mathrm{Se}$ encontraron diferencias significativas entre cultivares y la triple interacción $(\mathrm{L} \times \mathrm{A} \times \mathrm{C})$ fue significativa.

En la Tabla 3.4.10 se presentan las medias del ABCPE para los 31 cultivares de trigo, en las dos localidades y para los tres aislados.

Tabla 3.4.10. Medias del ABCPE en un ensayo de trigo inoculado individualmente con aislados seleccionados de $D$. tritici-repentis, en dos localidades y 31 cultivares de trigo.

\begin{tabular}{|l|l|c|c|c|c|c|}
\hline Localidad & Aislado & \multicolumn{5}{|c|}{ Cultivar } \\
\hline & & Sursem Nogal & $\begin{array}{c}\text { Baguette } \\
\text { Premium 11 }\end{array}$ & Buck SY 300 & $\begin{array}{c}\text { Klein } \\
\text { Capricornio }\end{array}$ & $\begin{array}{c}\text { Don Mario } \\
\text { Lenox }\end{array}$ \\
\hline Los Hornos & 1 & $876,1 \mathrm{a}$ & $1238,6 \mathrm{a}$ & $125,0 \mathrm{a}$ & $1345,2 \mathrm{a}$ & $529,0 \mathrm{a}$ \\
\hline & 2 & $791,9 \mathrm{a}$ & $1318,5 \mathrm{ab}$ & $440,8 \mathrm{a}$ & $1209,2 \mathrm{a}$ & $254,8 \mathrm{a}$ \\
\hline & 3 & $840,7 \mathrm{a}$ & $1638,6 \mathrm{~b}$ & $316,3 \mathrm{a}$ & $1406,4 \mathrm{a}$ & $403,9 \mathrm{a}$ \\
\hline & & & & & & \\
\hline & 1 & $833,2 \mathrm{a}$ & $1680,2 \mathrm{a}$ & $865,4 \mathrm{a}$ & $1748,0 \mathrm{a}$ & $717,3 \mathrm{a}$ \\
\hline & 2 & $681,9 \mathrm{a}$ & $1968,8 \mathrm{a}$ & $941,8 \mathrm{a}$ & $1709,1 \mathrm{a}$ & $911,9 \mathrm{a}$ \\
\hline & 3 & $608,1 \mathrm{a}$ & $1683,0 \mathrm{a}$ & $796,8 \mathrm{a}$ & $1579,3 \mathrm{a}$ & $1011,9 \mathrm{a}$ \\
\hline & & 772,0 & 1588,0 & 581,0 & 1499,5 & 638,1 \\
\hline Promedio & & Klein Proteo & Klein Tauro & BioInta 1001 & Klein Castor & $\begin{array}{c}\text { Buck 75 } \\
\text { Aniversario }\end{array}$ \\
\hline & & $524,4 \mathrm{a}$ & $870,9 \mathrm{a}$ & $224,5 \mathrm{a}$ & $535,2 \mathrm{a}$ & $1091,5 \mathrm{~b}$ \\
\hline & 3 & $881,2 \mathrm{a}$ & $626,2 \mathrm{a}$ & $549,8 \mathrm{a}$ & $962,3 \mathrm{~b}$ & $733,1 \mathrm{a}$ \\
\hline & & $586,3 \mathrm{a}$ & $957,9 \mathrm{a}$ & $382,7 \mathrm{a}$ & $601,6 \mathrm{a}$ & $507,7 \mathrm{a}$ \\
\hline Pergamino Hornos & 1 & & & & & \\
\hline
\end{tabular}




\begin{tabular}{|c|c|c|c|c|c|c|}
\hline & 2 & $1493,3 \mathrm{a}$ & $1596,2 \mathrm{a}$ & $1338,2 \mathrm{~b}$ & $1215,9 \mathrm{a}$ & $1258,6 \mathrm{a}$ \\
\hline & 3 & $1585,8 \mathrm{a}$ & $1587,7 \mathrm{a}$ & $928,4 \mathrm{a}$ & $1454,8 \mathrm{a}$ & $1062,7 \mathrm{a}$ \\
\hline \multirow[t]{2}{*}{ Promedio } & & 1089,5 & 1215,4 & 740,5 & 1045,7 & 938,0 \\
\hline & & $\begin{array}{c}\text { Buck AGP } \\
\text { Fast } \\
\end{array}$ & Buck SY 110 & ACA 901 & Klein León & Klein Rayo \\
\hline \multirow[t]{3}{*}{ Los Hornos } & 1 & $495,9 \mathrm{a}$ & $175,6 \mathrm{a}$ & $716,6 \mathrm{a}$ & $658,3 \mathrm{a}$ & $866,2 \mathrm{a}$ \\
\hline & 2 & $612,8 \mathrm{a}$ & $293,4 \mathrm{a}$ & $928,5 \mathrm{a}$ & $763,8 \mathrm{a}$ & $1079,5 \mathrm{a}$ \\
\hline & 3 & $329,8 \mathrm{a}$ & $255,9 \mathrm{a}$ & $766,5 \mathrm{a}$ & $608,9 \mathrm{a}$ & $945,7 \mathrm{a}$ \\
\hline \multirow[t]{3}{*}{ Pergamino } & 1 & $945,6 \mathrm{a}$ & $819,1 \mathrm{a}$ & $1100,6 \mathrm{a}$ & $986,1 \mathrm{a}$ & $1444,0 \mathrm{a}$ \\
\hline & 2 & $1152,1 \mathrm{a}$ & $916,1 \mathrm{a}$ & $1203,6 \mathrm{a}$ & $1364,7 \mathrm{~b}$ & $1407,4 \mathrm{a}$ \\
\hline & 3 & $1083,0 \mathrm{a}$ & $830,6 \mathrm{a}$ & $1392,5 \mathrm{a}$ & $1244,2 \mathrm{ab}$ & $1451,4 \mathrm{a}$ \\
\hline \multirow[t]{2}{*}{ Promedio } & & 769,9 & 548,5 & 1018,1 & 937,7 & 1199,0 \\
\hline & & $\begin{array}{c}\text { Baguette } \\
\text { Premium 13 } \\
\end{array}$ & Baguette 701 & Buck SY 100 & ACA 320 & Klein Nutria \\
\hline \multirow[t]{3}{*}{ Los Hornos } & 1 & $527,6 \mathrm{a}$ & $1493,9 \mathrm{a}$ & $760,0 \mathrm{a}$ & $1309,2 \mathrm{a}$ & $700,1 \mathrm{a}$ \\
\hline & 2 & $748,9 \mathrm{a}$ & $1494,2 \mathrm{a}$ & $637,4 \mathrm{a}$ & $1058,2 \mathrm{a}$ & $627,4 \mathrm{a}$ \\
\hline & 3 & $694,3 \mathrm{a}$ & $1452,3 \mathrm{a}$ & $813,3 \mathrm{a}$ & $1171,7 \mathrm{a}$ & $676,2 \mathrm{a}$ \\
\hline \multirow[t]{3}{*}{ Pergamino } & 1 & $1039,9 \mathrm{a}$ & $614,2 \mathrm{a}$ & $1086,7 \mathrm{a}$ & $1433,1 \mathrm{a}$ & $1436,1 \mathrm{a}$ \\
\hline & 2 & $1094,4 \mathrm{a}$ & $575,3 \mathrm{a}$ & $952,1 \mathrm{a}$ & $1751,8 \mathrm{ab}$ & $1272,7 \mathrm{a}$ \\
\hline & 3 & $1292,9 \mathrm{a}$ & $613,8 \mathrm{a}$ & $985,5 \mathrm{a}$ & $1907,7 \mathrm{~b}$ & $1472,7 \mathrm{a}$ \\
\hline \multirow[t]{2}{*}{ Promedio } & & 899,7 & 1040,6 & 872,5 & 1438,6 & 1030,9 \\
\hline & & Baguette 601 & Baguette 9 & Baguette 17 & BioInta 3005 & $\begin{array}{c}\text { Don Mario } \\
\text { Cronox } \\
\end{array}$ \\
\hline \multirow[t]{3}{*}{\begin{tabular}{|l|} 
Los Hornos \\
\end{tabular}} & 1 & $164,4 \mathrm{a}$ & $660,8 \mathrm{a}$ & $518,0 \mathrm{a}$ & $1154,6 \mathrm{a}$ & $651,8 \mathrm{a}$ \\
\hline & 2 & $168,7 \mathrm{a}$ & $1113,1 \mathrm{~b}$ & $613,6 \mathrm{ab}$ & $1227,3 \mathrm{a}$ & $942,6 \mathrm{ab}$ \\
\hline & 3 & $287,5 \mathrm{a}$ & $569,6 \mathrm{a}$ & $903,3 \mathrm{~b}$ & $1054,1 \mathrm{a}$ & $1016,4 \mathrm{~b}$ \\
\hline \multirow[t]{3}{*}{ Pergamino } & 1 & $533,3 \mathrm{a}$ & $906,6 \mathrm{a}$ & $724,8 \mathrm{a}$ & $1415,2 \mathrm{a}$ & $998,4 \mathrm{a}$ \\
\hline & 2 & $637,4 \mathrm{a}$ & $1475,3 \mathrm{~b}$ & $864,7 \mathrm{a}$ & $1799,7 \mathrm{~b}$ & $1203,9 \mathrm{ab}$ \\
\hline & 3 & $612,8 \mathrm{a}$ & $1120,4 \mathrm{ab}$ & $940,8 \mathrm{a}$ & $1835,7 \mathrm{~b}$ & $1386,4 \mathrm{~b}$ \\
\hline \multirow[t]{2}{*}{ Promedio } & & 400,7 & 974,3 & 760,9 & 1414,4 & 1033,3 \\
\hline & & $\begin{array}{c}\text { ProInta } \\
\text { Puntal } \\
\end{array}$ & Klein Volcán & Klein Dragón & BioInta 2004 & Sursem 2330 \\
\hline \multirow[t]{3}{*}{ Los Hornos } & 1 & $287,3 \mathrm{a}$ & $647,8 \mathrm{a}$ & $756,4 \mathrm{a}$ & $454,0 \mathrm{a}$ & $1305,2 \mathrm{a}$ \\
\hline & 2 & $330,0 \mathrm{a}$ & $704,9 \mathrm{a}$ & $940,2 \mathrm{a}$ & $662,0 \mathrm{ab}$ & $1384,4 \mathrm{a}$ \\
\hline & 3 & $910,6 \mathrm{~b}$ & $969,8 \mathrm{a}$ & $1474,4 \mathrm{~b}$ & $920,1 \mathrm{~b}$ & $1521,2 \mathrm{a}$ \\
\hline \multirow[t]{3}{*}{ Pergamino } & 1 & $938,9 \mathrm{a}$ & $762,8 \mathrm{a}$ & $1240,3 \mathrm{a}$ & $996,7 \mathrm{a}$ & $1282,0 \mathrm{a}$ \\
\hline & 2 & $1195,8 \mathrm{a}$ & $1161,3 \mathrm{~b}$ & $1304,9 \mathrm{a}$ & $1176,3 \mathrm{a}$ & $1439,1 \mathrm{a}$ \\
\hline & 3 & $1000,5 \mathrm{a}$ & $987,0 \mathrm{ab}$ & $1147,1 \mathrm{a}$ & $1072,6 \mathrm{a}$ & $1326,1 \mathrm{a}$ \\
\hline \multirow[t]{2}{*}{ Promedio } & & 777,2 & 872,3 & 1143,9 & 880,3 & 1376,3 \\
\hline & & Buck Brasil & & & & \\
\hline Los Hornos & 1 & $1214,2 \mathrm{~b}$ & & & & \\
\hline
\end{tabular}




\begin{tabular}{|c|l|c|l|l|l|l|} 
& 2 & $704,5 \mathrm{a}$ & & & & \\
\hline & 3 & $742,9 \mathrm{a}$ & & & & \\
\hline & & & & & & \\
\hline Pergamino & 1 & $1351,5 \mathrm{a}$ & & & & \\
\hline & 2 & $1426,8 \mathrm{a}$ & & & & \\
\hline & 3 & $1535,0 \mathrm{a}$ & & & & \\
\hline Promedio & & 1162,5 & & & & \\
\hline
\end{tabular}

Referencias: Aislado 1 = cepa LH; Aislado 2 = cepa 25M035; Aislado 3 = cepa G327. Medias seguidas por la misma letra no difieren estadísticamente ( $\mathrm{P}=0.05$, LSD test). LSD cultivar $=143$

El aislado 3 se presentó el mayor valor y se diferenció significativamente del 1 pero no del 2 (Tabla 6.1.15 del apéndice). Si bien no existieron diferencias significativas entre localidades, Pergamino presentó un mayor valor con relación a Los Hornos (Tabla 6.1.16 del apéndice). Buck $75^{\circ}$ Aniversario y Buck Brasil tuvieron un aumento significativo con el aislado 1 en Los Hornos. Klein Castor mostró un aumento significativo con el aislado 2 en Los Hornos. BioInta 1001, Klein León y Klein Volcán tuvieron un aumento significativo del ABCPE con el aislado 2 en Pergamino y los primeros dos evidenciaron el mayor nivel con el mismo aislado en Los Hornos. Baguette 9 tuvo un aumento significativo con el aislado 2 en ambos ambientes. Don Mario Cronox mostró un aumento significativo con el aislado 3 en ambos ambientes. Baguette 17 presentó un aumento significativo con el mismo aislado en Los Hornos y obtuvo el mayor valor, para el mismo aislado, en Pergamino. Los cultivares Baguette Premium 11, ProInta Puntal, Klein Dragón y BioInta 2004 tuvieron un aumento significativo del ABCPE con el aislado 3 en Los Hornos. ACA 320 presentó un aumento significativo para el aislado 3 en Pergamino y BioInta 3005 para el aislado 2 y 3 en la misma localidad.

En las Figuras 3.4.3, 3.4.4, 3.4.5, 3.4.6, 3.4.7 y 3.4.8 se presentan las medias del ABCPE para cada una de los cultivares, en cada uno de los ambientes y para cada aislado. 


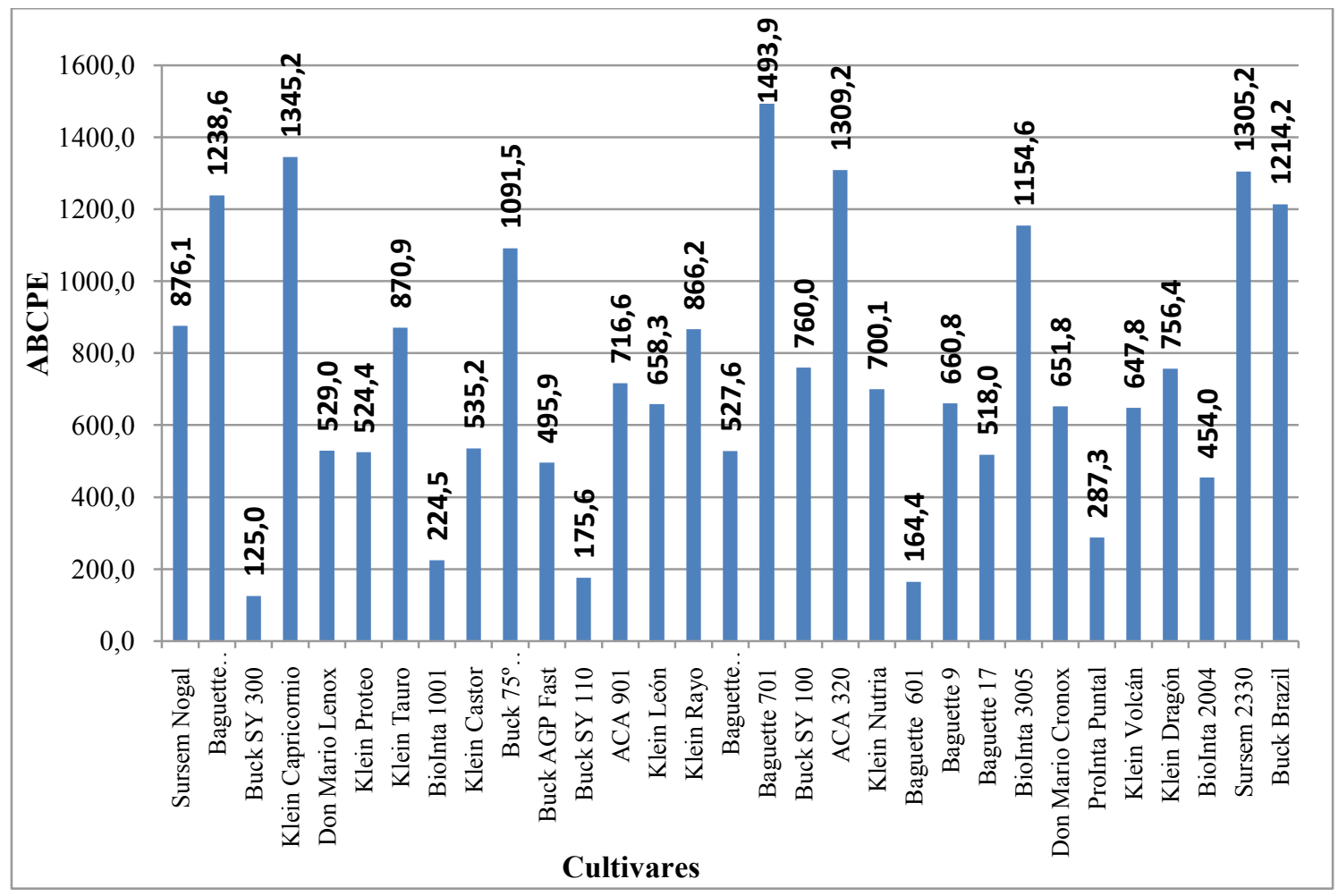

Figura 3.4.3. Medias del ABCPE en un ensayo de trigo inoculado con el aislado 1 de $D$. tritici-repentis, en la localidad de Los Hornos sobre 31 cultivares de trigo. Referencias: Aislado 1 = cepa LH. LSD cultivar (comparando medias en la misma localidad $)=122$

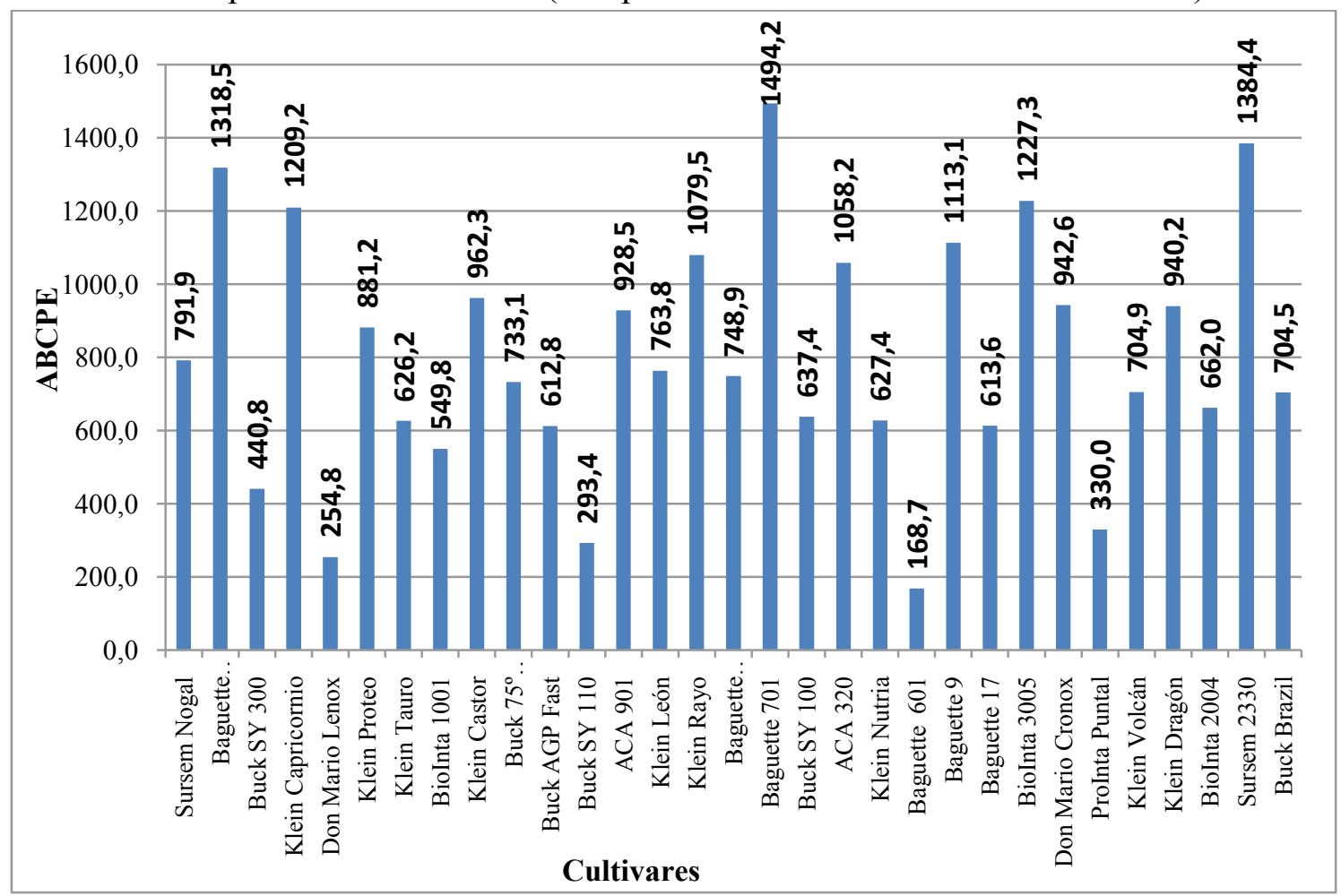

Figura 3.4.4. Medias del ABCPE en un ensayo de trigo inoculado con el aislado 2 de $D$. tritici-repentis, en la localidad de Los Hornos sobre 31 cultivares de trigo. Referencias: Aislado 2 = cepa 25M035. LSD cultivar (comparando medias en la misma localidad) $=$ 122 


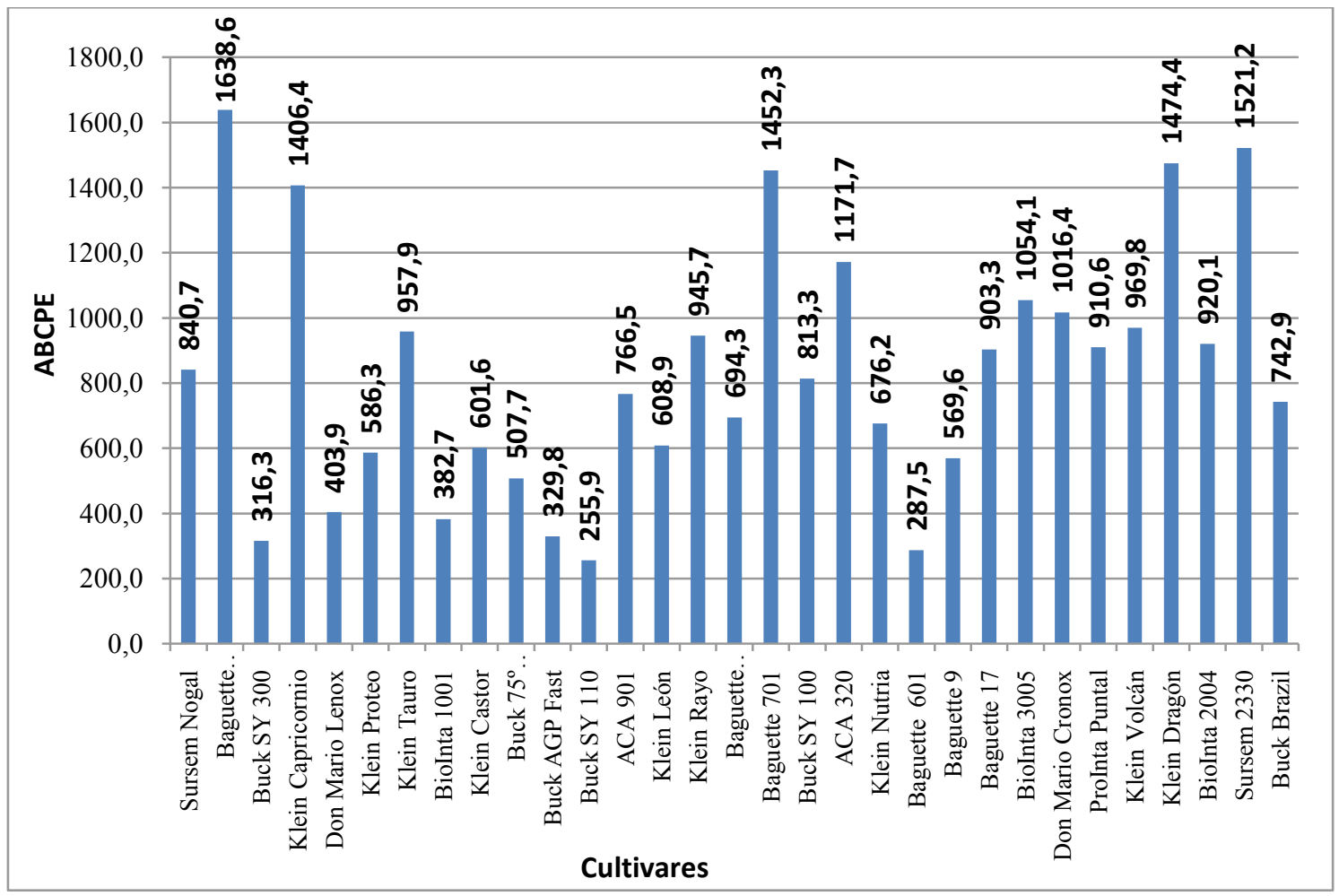

Figura 3.4.5. Medias del ABCPE en un ensayo de trigo inoculado con el aislado 3 de $D$. tritici-repentis, en la localidad de Los Hornos sobre 31 cultivares de trigo. Referencias:

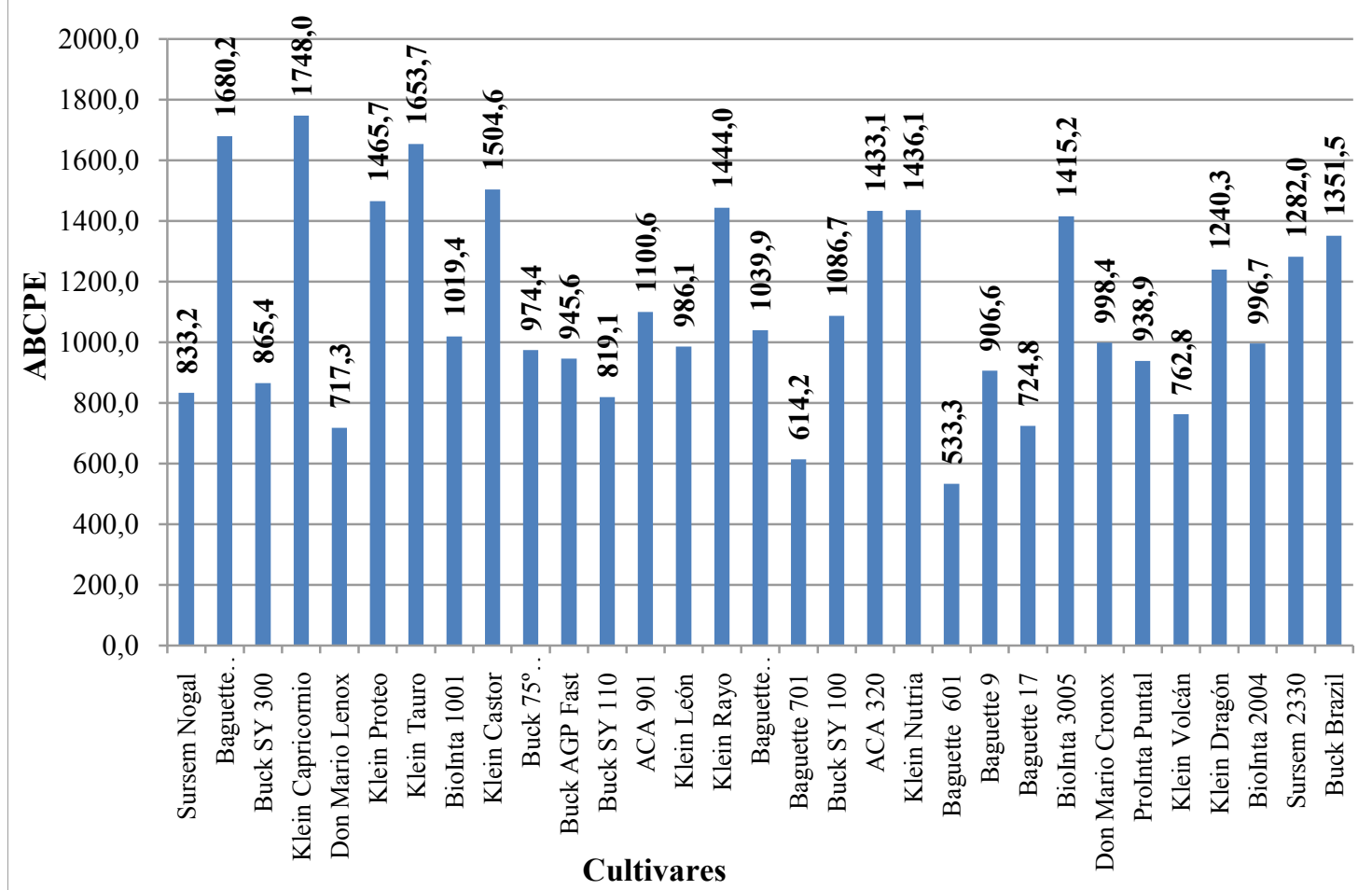

Aislado 3 = cepa G327. LSD cultivar (comparando medias en la misma localidad) $=122$ Figura 3.4.6. Medias del ABCPE en un ensayo de trigo inoculado con el aislado 1 de $D$. tritici-repentis, en la localidad de Pergamino sobre 31 cultivares de trigo. Referencias: Aislado 1 = cepa LH. LSD cultivar $($ comparando medias en la misma localidad $)=122$ 


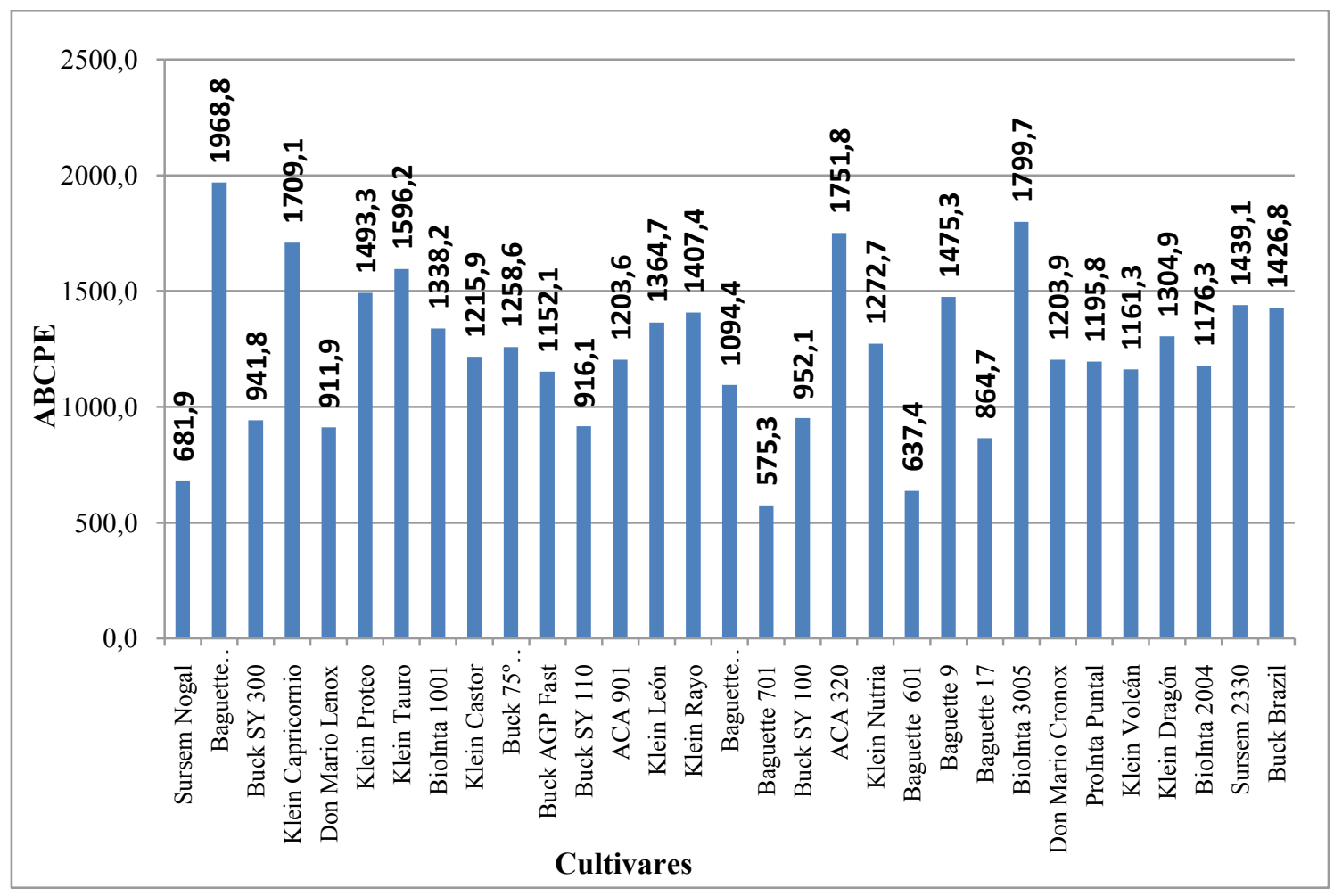

Figura 3.4.7. Medias del ABCPE en un ensayo de trigo inoculado con el aislado 2 de $D$. tritici-repentis, en la localidad de Pergamino sobre 31 cultivares de trigo. Referencias: Aislado 2 = cepa 25M035. LSD cultivar (comparando medias en la misma localidad) $=$ 122

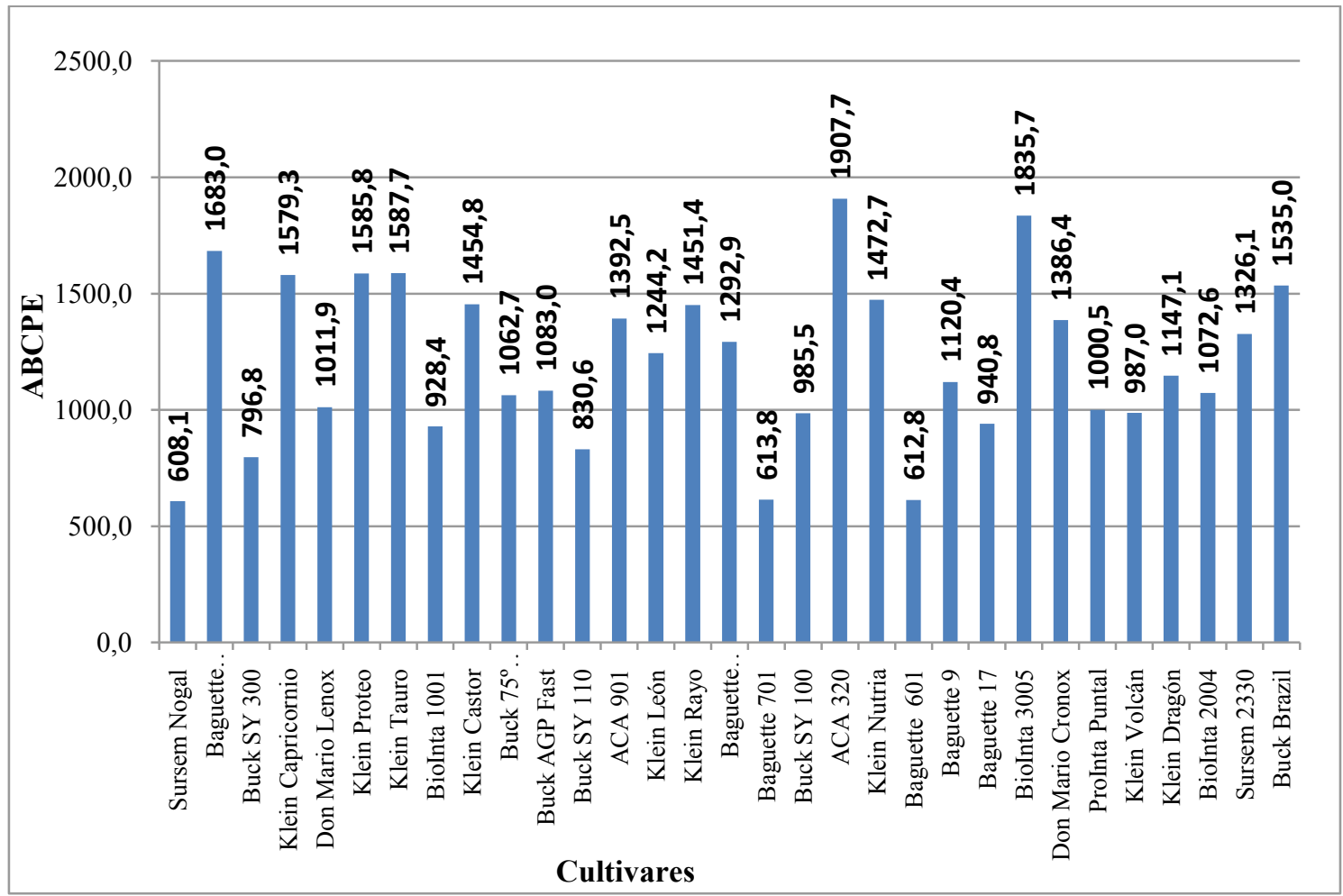

Figura 3.4.8. Medias del ABCPE en un ensayo de trigo inoculado con el aislado 3 de $D$. tritici-repentis, en la localidad de Pergamino sobre 31 cultivares de trigo. Referencias: Aislado 3 = cepa G327. LSD cultivar (comparando medias en la misma localidad) $=122$ 
Los cultivares que presentaron menor $\mathrm{ABCPE}$ promedio fueron Baguette 601, Buck SY 110, Buck SY 300, Don Mario Lenox, BioInta 1001, Baguette 17, Buck AGP Fast, Sursem Nogal, ProInta Puntal y Klein Volcán.

En la Tabla 3.4.11 se presenta la clasificación de los cultivares según valores de ABCPE para cada localidad y aislado.

Tabla 3.4.11. Clasificación de cultivares de trigo según valores de área bajo la curva de progreso de la enfermedad en un ensayo inoculado individualmente con tres aislados de D. tritici-repentis, en dos localidades y en 31 cultivares de trigo.

\begin{tabular}{|c|c|c|c|c|c|c|}
\hline \multirow[t]{2}{*}{ Localidad } & \multirow[t]{2}{*}{ Aislado } & \multicolumn{5}{|c|}{ Cultivar } \\
\hline & & $\begin{array}{c}\text { Sursem } \\
\text { Nogal }\end{array}$ & $\begin{array}{c}\text { Baguette } \\
\text { Premium 11 }\end{array}$ & Buck SY 300 & $\begin{array}{c}\text { Klein } \\
\text { Capricornio }\end{array}$ & $\begin{array}{c}\text { Don Mario } \\
\text { Lenox }\end{array}$ \\
\hline \multirow[t]{3}{*}{ Los Hornos } & 1 & MR & MS & $\mathrm{R}$ & MS & MR \\
\hline & 2 & MR & MS & $\mathrm{R}$ & MS & $\mathrm{R}$ \\
\hline & 3 & MR & $S$ & $\mathrm{R}$ & MS & $\mathrm{R}$ \\
\hline \multirow[t]{4}{*}{ Pergamino } & 1 & MR & $\mathrm{S}$ & MR & $\mathrm{S}$ & MR \\
\hline & 2 & MR & $S$ & MR & $\mathrm{S}$ & MR \\
\hline & 3 & MR & $S$ & MR & MS & MR \\
\hline & & Klein Proteo & Klein Tauro & BioInta 1001 & Klein Castor & $\begin{array}{c}\text { Buck } 75^{\circ} \\
\text { Aniversario } \\
\end{array}$ \\
\hline \multirow[t]{3}{*}{ Los Hornos } & 1 & MR & MR & $\bar{R}$ & $\overline{M R}$ & $\mathrm{MS}$ \\
\hline & 2 & MR & MR & MR & MR & MR \\
\hline & 3 & MR & MR & $\mathrm{R}$ & MR & MR \\
\hline \multirow[t]{4}{*}{ Pergamino } & 1 & MS & $S$ & MR & MS & MR \\
\hline & 2 & MS & MS & MS & MS & MS \\
\hline & 3 & MS & MS & MR & $\mathrm{MS}$ & $\mathrm{MS}$ \\
\hline & & $\begin{array}{c}\text { Buck AGP } \\
\text { Fast } \\
\end{array}$ & Buck SY 110 & $\overline{\text { ACA } 901}$ & Klein León & Klein Rayo \\
\hline \multirow[t]{3}{*}{ Los Hornos } & 1 & MR & $\mathrm{R}$ & MR & MR & MR \\
\hline & 2 & MR & $\mathrm{R}$ & MR & MR & MS \\
\hline & 3 & $\mathrm{R}$ & $\mathrm{R}$ & MR & MR & MR \\
\hline \multirow[t]{4}{*}{ Pergamino } & 1 & MR & MR & MS & MR & MS \\
\hline & 2 & MS & MR & MS & MS & $\mathrm{MS}$ \\
\hline & 3 & MS & MR & MS & MS & MS \\
\hline & & $\begin{array}{c}\text { Baguette } \\
\text { Premium } 13\end{array}$ & Baguette 701 & Buck SY 100 & $\overline{\text { ACA } 320}$ & Klein Nutria \\
\hline \multirow[t]{3}{*}{ Los Hornos } & 1 & MR & MS & MR & MS & MR \\
\hline & 2 & MR & MS & MR & $\mathrm{MS}$ & MR \\
\hline & 3 & MR & MS & MR & MS & MR \\
\hline \multirow[t]{4}{*}{ Pergamino } & 1 & MR & MR & MS & MS & MS \\
\hline & 2 & MS & MR & MR & $\mathrm{S}$ & MS \\
\hline & 3 & MS & MR & MR & $\mathrm{S}$ & MS \\
\hline & & $\begin{array}{c}\text { Baguette } \\
601\end{array}$ & Baguette 9 & Baguette 17 & BioInta 3005 & $\begin{array}{c}\text { Don Mario } \\
\text { Cronox } \\
\end{array}$ \\
\hline Los Hornos & 1 & $\mathrm{R}$ & MR & MR & $\mathrm{MS}$ & MR \\
\hline
\end{tabular}




\begin{tabular}{|c|c|c|c|c|c|c|}
\hline & 2 & $\mathrm{R}$ & MS & MR & MS & MR \\
\hline & 3 & $\mathrm{R}$ & MR & MR & MS & MR \\
\hline \multirow{4}{*}{ Pergamino } & 1 & MR & MR & MR & MS & MR \\
\hline & 2 & MR & MS & MR & $\mathrm{S}$ & MS \\
\hline & 3 & MR & MS & MR & $\mathrm{S}$ & MS \\
\hline & & $\begin{array}{c}\text { ProInta } \\
\text { Puntal } \\
\end{array}$ & $\begin{array}{c}\text { Klein } \\
\text { Volcán } \\
\end{array}$ & $\begin{array}{c}\text { Klein } \\
\text { Dragón } \\
\end{array}$ & BioInta 2004 & Sursem 2330 \\
\hline \multirow[t]{3}{*}{ Los Hornos } & 1 & $\mathrm{R}$ & MR & MR & $\mathrm{R}$ & MS \\
\hline & 2 & $\mathrm{R}$ & MR & MR & MR & MS \\
\hline & 3 & MR & MR & MS & MR & MS \\
\hline \multirow[t]{4}{*}{ Pergamino } & 1 & MR & MR & MS & MR & MS \\
\hline & 2 & MS & MS & MS & MS & MS \\
\hline & 3 & MR & MR & MS & $\mathrm{MS}$ & MS \\
\hline & & Buck Brasil & & & & \\
\hline \multirow[t]{3}{*}{ Los Hornos } & 1 & MS & & & & \\
\hline & 2 & MR & & & & \\
\hline & 3 & MR & & & & \\
\hline \multirow[t]{3}{*}{ Pergamino } & 1 & MS & & & & \\
\hline & 2 & MS & & & & \\
\hline & 3 & $\mathrm{MS}$ & & & & \\
\hline
\end{tabular}

Referencias: Resistente (R) = 0 - 483; Moderadamente Resistente (MR) = 483 - 1046; Moderadamente Susceptible (MS) $=1046$ - 1610; Susceptible (S) $>1610$. Aislado $1=$ cepa LH; Aislado 2 = cepa 25M035; Aislado $3=$ cepa G327. LSD (localidad $\times$ aislado $\times$ cultivar $)=358$.

El análisis de correlación entre ABCPE para cada localidad y el promedio de severidad al estado de plántula muestra un valor de $r=0,75$ para Los Hornos y $r=0,31$ para Pergamino. 


\section{CAPITULO 4:}

\section{DISCUSIÓN}

\subsection{Caracterización del tipo de reacción en líneas diferenciales de trigo.}

Los aislados seleccionados fueron diferentes entre sí en base a los patrones fenotípicos sobre líneas diferenciales de trigo. El aislado 1 se diferenció del 2 por mostrar una reacción de Necrosis y Clorosis en las líneas Glenlea y Coulter; mientras que el 3 se diferenció de éstos por presentar una reacción de Necrosis y Clorosis en Katepwa y 4B-160, de clorosis en 6B662 y de necrosis en Glenlea y Salamouni.

Ninguno de los tres aislados seleccionados compartieron los patrones fenotípicos de las razas conocidas internacionalmente. Similares resultados fueron hallados por Moreno et al. (2014) quienes caracterizaron fenotípica y genéticamente 65 aislados provenientes de diferentes localidades del país. En base a la caracterización fenotípica solo 32 aislados se pudieron asignar a una raza en particular mientras que el resto no pudieron ser asignados a ninguna de las razas conocidas. Entre los primeros se encontró la siguiente proporción: raza 1 (un aislado), raza 2 (cuatro aislados), raza 3 (un aislado), raza 4 (11 aislados), raza 5 (un aislado), raza 6 (un aislado) y raza 8 (13 aislados). Los restantes 33 aislados no tuvieron el mismo patrón que ninguna de las razas conocidas. Benslimane et al. (2011) caracterizaron 55 aislados provenientes de Algeria y encontraron que 5 de ellos no poseían los patrones fenotípicos de las razas actualmente conocidas y que probablemente éstos podían tener nuevas toxinas. En el presente trabajo se observó que los tres aislados producen necrosis y algunos clorosis en Salamouni que es resistente a las razas conocidas (Strelkov \& Lamari, 2003); similares observaciones fueron realizadas por Moreno et al. (2014) quienes encontraron tres aislados (CH009, H001 and H003) que producen necrosis en la misma línea. El cultivar Glenlea es considerado resistente a clorosis (Lamari et al., 2003), a pesar de ello en el presente trabajo el aislado 1 causó una reacción de clorosis en esta línea. Moreno et al. (2008) y Moreno et al. (2014) también han detectado clorosis en esta línea.

\subsection{Análisis molecular de genes que codifican toxinas en los aislados estudiados.}

Los aislados seleccionados fueron también diferentes entre sí por el análisis molecular de los genes que codifican la producción de toxinas específicas. El aislado 1 se caracterizó por la presencia del gen $T o x B$; el 2 por la presencia de los genes homólogos Tox B, Tox B1 y Tox $b$ y el aislado 3 por poseer el gen Tox $A$ y Tox B1.

No hubo coincidencias entre la caracterización fenotípica y genotípica. El aislado 1 al poseer un gen que codifica para la producción de la ToxB debería producir clorosis en las líneas Katepwa y 6B662, al igual que el aislado 2 que posee tres genes que codifican para la producción de esta toxina y, a pesar de ello, no causa clorosis en estas líneas. Varios autores han encontrado aislados que poseían el gen Tox $B$ y sus homólogos aunque sin la producción de su toxina asociada o aislados que causaban clorosis en líneas sensibles a ToxB y que no amplificaban para este gen. Strelkov et al. (2006) han encontrado aislados provenientes de Canadá que poseían genes homólogos 
Tox $B$ con una producción reducida o nula de ToxB. Moreno et al. (2014) han encontrado 13 aislados que se correspondían fenotípicamente con raza 8 , uno con raza 6 y uno con raza 5 que no amplificaban para el gen Tox $B$ ni sus homólogos. Andrie et al. (2007) identificaron un aislado (PT82) que posee los patrones de virulencia de la raza 8 aunque no amplificaba para el gen Tox $B$.

El aislado 3 es el que más correspondencia tuvo entre ambos tipos de caracterizaciones. Causó necrosis en Glenlea y Katepwa lo que concuerda con la presencia del gen Tox $A$ y clorosis en Katepwa y 6B662 debido, probablemente, al gen Tox $B 1$. Este aislado podría haberse designado como raza 8 pero expreso síntomas de necrosis en Salamouni.

Varios trabajos encuentran discrepancias entre los patrones fenotípicos y el análisis genético de aislados de D. tritici-repentis. Andrie et al. (2007) encontraron dos aislados (SO3 and PT82) que en base a la caracterización fenotípica corresponden a la raza 2 y 8 respectivamente; sin embargo $\mathrm{SO} 3$ carecía del gen Tox $A$ y su correspondiente toxina y PT82 carecía del gen Tox $B$ y su correspondiente toxina. Similares resultados fueron hallados por Ali et al. (2010) quienes determinaron la presencia o ausencia de los genes Tox $A$ y Tox $B$ en 42 aislados de $D$. tritici-repentis obtenidos de Arkansas, USA. Hallaron que entre 19 aislados que producían necrosis en Glenlea sólo 6 tenían el gen Tox A. Ambos autores sugirieron que aquéllos aislados deficientes en genes Tox $A$ y Tox $B$, y que producían necrosis y/o clorosis, deberían estar produciendo una nueva toxina y serían nuevas razas de este patógeno. Pandelova \& Ciuffetti (2005) han propuesto la presencia de una nueva toxina, llamada ToxD, producida por el aislado SO3, a partir de una proteína desconocida que produce síntomas de necrosis. Lepoint et al. (2010) a partir de 88 aislados procedentes de diversas partes del mundo encontraron algunos aislados que no pudieron asignarse a una raza particular, discrepancias entre la caracterización fenotípica y genotípica y amplificaciones de fragmentos muy grandes del gen Tox $A$ para tres aislados designados como raza 1. Este autor sugiere que nuevas toxinas y razas deben estar presentes, que el número de líneas diferenciales de trigo usadas limitaría el número posible de razas a identificar y que falta mejorar la caracterización genotípica debido a que nuevos genes esperan ser descubiertos o caracterizados.

En nuestro país, Moreno et al. (2014) han evaluado los patrones fenotípicos y genéticos de 65 aislados provenientes de diferentes partes del país y han encontrado que la mayoría de los aislados que producían clorosis en 6B662 y Katepwa no amplificaban para el gen Tox $B$ ni sus homólogos y muchos aislados que amplificaban para el gen Tox $A$ no producían necrosis en Glenlea o Katepwa. Estos autores sugieren que son necesarios más estudios para investigar la presencia de nuevas toxinas. A partir de estos datos podría decirse que la estructura del patógeno no está bien determinada, tampoco en Argentina, y que nuevas toxinas y razas esperan ser identificadas. 
4.3 Caracterización de cultivares argentinos de trigo al estado de plántula frente a la presencia/actividad de los aislados seleccionados de $D$. tritici-repentis en invernáculo.

Se observaron diferencias significativas entre aislados para la severidad y tipo de reacción. El aislado 3 presentó el mayor valor para ambos parámetros seguidos por el 2 y luego por el 1.

La interacción aislado $\times$ cultivar fue significativa para la severidad y tipo de reacción. Para severidad se puede destacar que Buck $75^{\circ}$ Aniversario tuvo un aumento significativo con el aislado 1; Klein Proteo, Klein Castor y Baguette 9 con el aislado 2 y Baguette Premium 11, Klein Tauro, Klein León, ACA 320, Baguette 17, Klein Dragón y BioInta 2004 con el aislado 3. Para el tipo de reacción Klein Proteo y Baguette 9 tuvieron un aumento significativo del tipo de reacción con el aislado 2; mientras que Sursem Nogal, Baguette Premium 11, Buck SY 300, Klein Tauro, Buck AGP Fast, Baguette 17, Cronox, ProInta Puntal, Klein Dragón y Sursem 2330 lo expresaron con el 3.

Los cultivares que presentaron mejor comportamiento para severidad fueron Baguette 601, Buck SY 300, Buck SY 110, Don Mario Lenox, Baguette 17, Buck AGP Fast, Sursem Nogal, BioInta 1001, ProInta Puntal y SY100. De estas Baguette 601, Buck SY 300, Buck SY 110, Don Mario Lenox, Buck AGP Fast, Sursem Nogal, BioInta 1001, ProInta Puntal y SY100 mostraron buenos niveles de resistencia frente a los tres aislados; mientras que Baguette 17 fue susceptible al 3. Para el tipo de reacción los que mejor se comportaron fueron Baguette 601, Buck SY 300, Klein Tauro, Buck SY 110, Buck SY 100, BioInta 1001, Klein Proteo, Klein Volcán, Don Mario Lenox y ACA 320. Todas estos cultivares evidenciaron buenos niveles de resistencia para los tres aislados excepto por Buck SY 300 y Klein Tauro que fueron susceptibles al $3 \mathrm{y}$ Klein Proteo al 2.

4.4 Caracterización de cultivares argentinos de trigo al estado de planta adulta frente a la presencia/actividad de los aislados seleccionados de $D$. tritici-repentis bajo condiciones a campo.

En líneas generales se puede decir que la localidad de Pergamino presentó un mayor nivel de severidad y tipo de reacción en relación a Los Hornos. Si bien no se observaron diferencias significativas entre localidades para la severidad en el estadio EC 37 y EC 75, en Pergamino se registraron mayores niveles con respecto a Los Hornos; mientras que en EC 82 si existieron mostrando Pergamino el mayor valor. Para el tipo de reacción se observó un comportamiento similar con un aumento significativo en EC 37 y EC 82 para Pergamino y un mayor nivel para EC 75. El ABCPE también fue mayor para Pergamino.

Los aislados se diferenciaron significativamente entre sí, en cuanto a la severidad, en EC 37 y EC 82 pero no en EC 75. En EC 82 el aislado 3 presentó el mayor valor, seguido por el 2 y luego por el 1 (62.43\%, $60.49 \%$ y $57.56 \%$ respectivamente), 
con resultados similares en EC 75 (36.32\%, $35.95 \%$ y $32.00 \%$ respectivamente). Estos resultados coinciden con los hallados en plántula. En EC 37 se observó un comportamiento diferente siendo el aislado 1 el que originó la mayor severidad, seguido por el 2 y luego por el $3(1.66 \%, 1.54 \%$ y $1.39 \%$ respectivamente) debido, posiblemente, a los bajos valores de severidad registrados en esta evaluación. Podría decirse que el aislado 3 tendría un comportamiento más agresivo que el 2 y este que el 1. No se encontraron diferencias significativas entre aislados para el tipo de reacción en ninguna de los tres estadios. El aislado 3 se diferenció significativamente del 1 pero no del 2 para el ABCPE y mostró una tendencia similar a la registrada para la severidad en el estadio EC 75 y EC 82 donde el primero obtuvo el mayor valor seguido por el 2 y luego el 1.

Se registraron interacciones especificas significativas localidad $\times$ aislado $\times$ cultivar para la evaluación de severidad y tipo de reacción en EC 75 y EC 82 pero no en EC 37. Se observaron algunas diferencias en las interacciones aislado $\times$ cultivar para cada una de las localidades debido, probablemente, a la presencia de mayor inóculo natural en Pergamino en comparación con Los Hornos.

En EC 75 los cultivares Buck $75^{\circ}$ Aniversario y Buck Brasil tuvieron un aumento significativo de la severidad y el tipo de reacción con el aislado 1 en Los Hornos, Klein Proteo y Klein Castor mostraron el mismo resultado con el aislado 2 en Los Hornos y Baguette 9 para ambas localidades. BioInta 1001, Klein León y Klein Volcán tuvieron una mayor severidad con el aislado 2 en Pergamino; de éstos BioInta 1001 tuvo un aumento significativo del tipo de reacción para el mismo aislado en ambas localidades y Klein León lo tuvo para Pergamino, además ambos evidenciaron el mayor nivel de severidad para este aislado en la otra localidad. Los cultivares, ProInta Puntal, Klein Dragón, Baguette 17 y BioInta 2004 tuvieron un aumento significativo de la severidad y el tipo de reacción con el aislado 3 en Los Hornos; Baguette Premium 11 y Klein Tauro lo mostraron para la severidad y Don Mario Cronox para el tipo de reacción. ACA 320 y BioInta 3005 tuvieron una mayor severidad con el aislado 3 en Pergamino.

Similares resultados se obtuvieron en EC 82. Buck $75^{\circ}$ Aniversario y Buck Brasil tuvieron un aumento significativo de la severidad y el tipo de reacción con el aislado 1 en Los Hornos y valores similares en Pergamino; Klein Castor presentó la misma tendencia para el aislado 2 en la misma localidad. Klein León evidenció un aumento significativo de la severidad con el aislado 2 en Pergamino y Buck AGP Fast obtuvo el mismo resultado para el tipo de reacción en ambas localidades y para el mismo aislado. Baguette 9 tuvo un comportamiento similar a lo evidenciado en la anterior evaluación aunque sin diferencias significativas entre los aislados. Baguette Premium 11, ProInta Puntal, Klein Volcán, Klein Dragón, BioInta 2004 y Don Mario Cronox tuvieron una mayor severidad con el aislado 3 en Los Hornos. De estos cultivares Klein Volcán, Klein Dragón, BioInta 2004 y Don Mario Cronox mostraron los valores más altos en Pergamino para el mismo aislado. Ambas evaluaciones (EC 75 y EC 82) muestran algunas coincidencias con los resultados hallados en plántula. 
La triple interacción también fue significativa para el ABCPE con resultados similares a ambas estadios. Buck $75^{\circ}$ Aniversario y Buck Brasil tuvieron un aumento significativo con el aislado 1 en Los Hornos. Castor mostró el mismo resultado con el aislado 2 en la misma localidad y BioInta 1001, Klein León y Klein Volcán para el aislado 2 en Pergamino. Baguette 9 tuvo un aumento significativo con el aislado 2 en ambos ambientes y Don Mario Cronox para el aislado 3. Los cultivares Baguette Premium 11, Baguette 17, ProInta Puntal, Klein Dragón y BioInta 2004 tuvieron un aumento significativo del ABCPE con el aislado 3 en Los Hornos y ACA 320 con el mismo aislado en Pergamino.

Investigaciones anteriores también han reportado diferencias en la virulencia de aislados de D. tritici-repentis (Ali \& Francl, 2001b; 2003; Gamba \& Lamari, 1998; Gamba et al., 1998; Gilchrist et al., 1984; Lamari \& Gilbert, 1998; Lamari et al., 1995; 1998; Luz \& Hosford, 1980; Hunger \& Brown, 1987; Misra \& Singh, 1972; Schilder \& Bergstrom, 1990). Basado en el tipo de reacción producido por 92 aislados obtenidos de 11 cultivares sembrados en Canadá, Lamari \& Bernier (1989a) reportaron interacciones específicas entre cultivares y aislados indicando que los mismos diferían en su grado de virulencia. En este trabajo dichos investigadores propusieron la existencia de tres patotipos. Schilder \& Bergstrom (1990) evaluaron 70 aislados obtenidos de Canadá sobre 12 cultivares de trigo y encontraron diferencias en las interacciones aislado $\mathrm{x}$ cultivar. Similares resultados fueron reportados por Sah \& Fehrmann (1992) desde aislados obtenidos de Brasil, Germania, India, Nepal y Estados Unidos de Norte América. Sin embargo Ali \& Buchenau (1992) observaron especialización fisiológica basado en el tipo de reacción desde aislados obtenidos de Estados Unidos de Norte América. Mehta et al. (2004) evaluaron 40 aislados obtenidos de Paraná (Brasil) en 6 cultivares de trigo y hallaron baja interacción aislado $\times$ cultivar. En nuestro país, Moreno (2007) detectó interacciones significativas aislado $\times$ cultivar para aislados de este patógeno obtenidos de diversas áreas productoras de trigo. Las interacciones específicas, encontradas en este trabajo, entre los aislados del patógeno y los cultivares argentinos de trigo serían indicativas de especialización fisiológica. Estudios moleculares recientes (Friesen et al., 2005; Singh \& Hughes, 2006) han hallado alta variación genética entre aislados de este hongo y la presencia de frecuente reproducción sexual aumenta aún más las posibilidades de recombinación y aparición de nuevas razas.

En general, los cultivares que presentaron mejor comportamiento en cuanto al nivel de severidad en la segunda evaluación también lo tuvieron para el ABCPE; estas fueron fueron Baguette 601, Buck SY 110, Buck SY 300, Don Mario Lenox, BioInta 1001, Baguette 17, Buck AGP Fast, Sursem Nogal y ProInta Puntal. De estas Baguette 601, Buck SY 110, Buck SY 300, Buck AGP Fast, Don Mario Lenox y Sursem Nogal mostraron un buen comportamiento a los tres aislados evaluados; mientras que BioInta 1001 fue más susceptible al aislado 2 y Baguette 17 junto con ProInta Puntal al 3. Estos resultados coinciden, en líneas generales, con la evaluación de severidad en plántula. Los cultivares con mejor comportamiento para tipo de reacción, en la segunda evaluación, fueron Baguette 601, Buck SY 110, Buck SY 300, Don Mario Lenox, 
BioInta 1001, Buck AGP Fast, Baguette 17, Baguette P. 13 y ProInta Puntal observándose similares resultados que para severidad y ABCPE. De estas Baguette 601, Don Mario Lenox y Baguette Premium 13 presentaron buen comportamiento frente a los tres aislados; Baguette 17 y ProInta Puntal fueron más susceptibles al 3; Buck AGP Fast al 1; BioInta 1001 al 2; Buck SY 110 al 1 y 2 y Buck SY 300 al 2 y 3. Para este parámetro hubo menos coincidencias entre los resultados hallados en planta adulta a campo y en plántula. Los cultivares que presentaron mejor comportamiento a los 3 aislados deberían seguir siendo evaluadas frente a varios más para valorar la posibilidad de resistencia parcial no específica a la raza. La descripción de la estructura de la población en razas es de utilidad para la identificación de genes de resistencia, cuando se identifican nuevas razas de $D$. tritici-repentis, se hace necesaria la identificación e incorporación de nuevos genes de resistencia al germoplasma existente (Gamba et al., 1998). Stakman (1938) manifestó que si bien en la pérdida de la resistencia de un cultivo a un patógeno intervienen numerosos factores, la existencia de razas en diferentes regiones es uno de los principales problemas. En particular todas las líneas de trigo deberían ser evaluadas frente a las razas predominantes de una región previas a ser comercializadas.

Se encontró una alta correlación entre el ABCPE para la localidad de Los Hornos y la severidad al estado de plántula $(\mathrm{r}=0.75)$ y moderada para Pergamino $(\mathrm{r}=$ 0.31) debido, probablemente, a la presencia de inóculo natural en esta zona. Buenos niveles de correlación entre estadio de plántula y adulta fueron también hallados por otros investigadores (Cox \& Hosford, 1987; Rees et al., 1988). Evans et al. (1999) inocularon 10 cultivares al estado de plántula en invernáculo y en planta adulta en condiciones de campo, en dos localidades, y encontraron una alta correlación $(r=0.75 \mathrm{a}$ 0.93 ) entre tamaño de lesión, en plántula, y ABCPE al estado adulto. Tadesse et al. (2010) también encontraron una alta correlación $(\mathrm{r}=0.72)$ entre resistencia en plántula (en invernáculo) y planta adulta a campo para 12 cultivares de trigo inoculados con $D$. tritici-repentis. Lamari \& Bernier (1989a) también hallaron una alta correlación ( $\mathrm{r}=$ 0.63 ) entre el nivel de resistencia al estado de plántula, en invernáculo, y planta adulta a campo para 55 líneas evaluadas. Estos autores sugieren que la evaluación en plántula, para esta enfermedad, permite evaluar mayor cantidad de germoplasma en menor espacio y tiempo que el que requiere la evaluación a campo y además posibilita hacer una pre-selección de materiales para descartar los más susceptibles frente a la enfermedad en un corto periodo de tiempo. 


\section{CAPITULO 5:}

\section{CONCLUSIONES GENERALES}

- Existen diferencias entre aislados seleccionados de D. tritici-repentis en base a caracteres fenotípicos y genotípicos.

- Existen interacciones específicas entre los aislados del patógeno y los cultivares argentinos de trigo.

- Existe resistencia frente a varios aislados seleccionados del patógeno en cultivares argentinos de trigo.

- El nivel de resistencia en cultivares seleccionados de trigo a aislamientos específicos de $D$. tritici-repentis es dependiente del estado fenológico de la planta y del germoplasma estudiado. 


\section{BIBLIOGRAFIA}

Alam K.B. \& J.P. Gustafson. 1988. Tan-spot resistance screening of Aegilops species. Plant Breeding 100: 112-118.

Alberione, E., C.T. Bainotti, J.A. Fraschina, J.H. Salines, G.M. Donaire \& M.B. Formica. 2011a. Información sanitaria de ECR en campo de productores. Disponible en: http://inta.gob.ar/documentos/informacion-sanitaria-de-ecr-en-campo-deproductores (Verificado 10 de Enero de 2014).

Alberione, E., C.T. Bainotti, J.A. Fraschina, J.H. Salines, G.M. Donaire \& M.B. Formica. 2011b. Evaluación sanitaria de cultivares de trigo en la subregión triguera II Norte - Campaña 2010/11. Disponible en: http://inta.gob.ar/documentos/evaluacion-sanitaria-de-cultivares-detrigo-en-la-subregion-triguera-ii-norte-campana-2010-11 (Verificado 10 de Enero de 2014).

Alberione, E., C.T. Bainotti, J.A. Fraschina, J.H. Salines, G.M. Donaire, M.B. Formica \& D.T. Gomez. 2012. Evaluación sanitaria de cultivares de trigo en la subregión triguera II Norte - Campaña 2011/12. Disponible en: http://inta.gob.ar/documentos/evaluacion-sanitaria-decultivares-de-trigo-en-la-subregion-triguera-ii-norte-2013-campana2011-12 (Verificado 10 de Enero de 2014).

Ali, S. \& G. W. Buchenau. 1992. Incidence of toxin-producing pathotypes of Pyrenophora tritici-repentis in South Dakota. Phytopathology 82: 1159 (Abst).

Ali S. \& L.J. Francl. 2001a. First report of tan spot on wheat in Pakistan. Plant Disease 85: 1031.

Ali S. \& L.J. Francl. 2001b. Recovery of Pyrenophora triticirepentis from barley and reaction of 12 cultivars to five races and two host-selective toxins. Plant Disease 85: 580-584.

Ali S. \& L.J. Francl. 2002a. A new race of Pyrenophora triticirepentis from Brazil. Plant Disease 86: 9.

Ali S. \& L.J. Francl. 2002b. Race structure of Pyrenophora triticirepentis isolates obtained from wheat in South America. Plant Protection Science 38 (Special Issue 2): 302-304.

Ali S. \& L.J. Francl. 2003. Population race structure of Pyrenophora tritici-repentis prevalent of wheat and non-cereal grasses in the Great Plains. Plant Disease 87: 418-422.

Ali, S., L.J. Francl \& E.D. de Wolf. 1990. First report of Pyrenophora tritici-repentis race 5 from North America. Plant Disease 83: 591 . 
Ali, S., H. Ling, S. Meinhardt \& L. Francl. 2002. A new race of Pyrenopho ratritici-repentis that produces a putative host-selective toxin. Phytopathology 92: S3.

Ali, S., S. Gurung \& T.B. Adhikari. 2010. Identification and characterization of novel isolates of Pyrenophora tritici-repentis from Arkansas. Plant Disease 94: 229-235.

Andrie, R.M., I. Pandelova \& L.M. Ciuffetti. 2007. A combination of phenotipic and genotypic characterization Pyrenophora triticirepentis race identification. Phytopathology 97: 694-701.

Annone, J.G. 1985. Presencia de la "mancha tostada" del trigo (Helminthosporium tritici-repentis). Carpeta de Producción Vegetal. Trigo. Tomo VII. INTA, EEA Pergamino. Informe $\mathrm{N}^{\circ} 88$.

Annone, J.G. 1995. La mancha amarilla o bronceada del trigo. Eds: Kohli, M.M., J.G. Annone y R. Gracía 1996. Las enfermedades de trigo en el Cono Sur. Curso de manejo de enfermedades del trigo. Pergamino, Argentina, 29-31 de Agosto de 1995.

Annone, J.G. 1998. Tan Spot of wheat in Argentina: Importance and disease managment practices. En: Helminthosporium Blights of Wheat: Spot Blotch and Tan Spot. Eds. E. Duveiller, H.J. Dubin, J. Reeves, and A. McNab. Mexico, D.F. CIMMYT. pp 339-345.

Annone, J.G. 2004. Las principales enfermedades del trigo en Argentina: Su importancia relativa en las regiones productoras Norte y Sur. En: A Todo Trigo. Actas del congreso 13 y 14 de Mayo 2004. Mar del Plata. Argentina. p. 53-58.

Annone, J.G. 2006. Las principales enfermedades del trigo en Argentina: Su importancia relativa en las regiones productoras Norte y Sur. Actas del Congreso A Todo Trigo 2006. Nuevos conocimientos aplicados a la producción. Federación de Centros y Entidades Gremiales de Acopiadores de Cereales. Mar del Plata, Buenos Aires. pp. 53-58.

Annone, J.G. 2006b. Roya de la hoja en trigo. Importancia económica y estrategias para reducir los efectos sobre la producción. Trigo. EEA INTA Marcos Juárez. Informe de Actualización Técnica $\mathrm{N}^{\mathrm{o}}$ 1. $3 \mathrm{pp}$.

Annone, J.G. \& E. Frutos. 1988. Estimación del efecto del "Golpe Blanco" del trigo (Fusarium graminearum) sobre la producción de granos de un grupo de variedades comerciales. INTA Pergamino. Informe Técnico $\mathrm{N}^{\mathrm{o}} 218.22 \mathrm{p}$.

Annone, J.G. \& R. García. 2005. Status of resistance of Argentinean wheat cultivars to the causal agent of tan spot. En: Session on Breeding for resistance to biotic stresses. Abstracts of the $7^{\text {th }}$ 
International Wheat Conference. Noviembre 27 al 2 de diciembre de 2005. Mar del Plata, Buenos Aires, Argentina.p. 126.

Annone, J.G., A. Calzolari, O. Polidoro, \& H. Conta. 1991. Efecto de la mancha de la hoja causada por Septoria tritici sobre el rendimiento. EEA Pergamino. INTA Pergamino. Informe Técnico N ${ }^{0} 122$. $26 \mathrm{pp}$.

Annone, J.G., G. Botta \& A. Ivancovich. 1994. Ocurrencia de la mancha bronceada del trigo en el área norte de la provincia de Buenos Aires. III Congreso Nacional de Trigo y I Simposio Nacional de cereales de Siembra otoño-invernal. Depto. De Agronomía, Universidad Nacional del Sur - Asociación de Ingenieros Agrónomos del Norte de la Provincia de Buenos Aires. Bahía Blanca, Buenos Aires. pp 205-207.

Annone, J.G., R. García, G. Botta \& A. Ivancovich. 2001. Pérdidas de rendimiento ocasionadas por la "roya de la hoja" y la "mancha amarilla" del trigo: estimaciones en el norte de la provincia de Buenos Aires. Revista de tecnología Agropecuaria $\mathrm{N}^{0}$ 16. Vol. VI. EEA Pergamino. INTA Pergamino. $32 \mathrm{pp}$

Araya C.M. \& C. Cárdenas. 1999. Variabilidad patogénica y fuentes de resistencia a poblaciones de Colletotrichum lindemuthianum en Costa Rica. Actas de Congreso XXXIX Reunión Anual APS-CD. Puerto Rico. pp. 72.

Ballance, G.M., L. Lamari \& C.C. Bernier. 1989. Purification and characterization of a host selective necrosis toxin from Pyrenophora tritici-repentis. Physiological and Molecular Plant Pathology35: 203213.

Benslimane, H., L. Lamari, A. Benbelkacem, R. Sayoud \& Z Bouznad. 2011. Distribution of races of Pyrenophora tritici-repentis in Algeria and identification of a new virulence type. Phytopathol. Mediterr. (2011) 50:203-211.

Carmona, M., E.M. Reis \& P. Cortese. 1999. Manchas foliares del trigo: diagnóstico, epidemiología y nuevos criterios para el manejo. Eds. Carmona M., Reis E.M. y P. Cortese. pp 32.

Carmona, M. 2003. Manejo Integrado de las Enfermedades del trigo. Nuestra oportunidad para asegurar la sustentabilidad del cultivo. En:www.acopiadores.com/publico/atodotrigo/Manejointegradodelasenfer medadesdeltrigo.pdf.

Castro, M., M. Díaz, S. Germán \& D. Vázquez. 2010. Resultados Experimentales de la Evaluación de Cultivares de Trigo de ciclo intermedio Período 2007-2008.2009. Disponible en: 
http://www.inia.org.uy/convenio_inase_inia/resultados/trigoci09.htm (Verificado 10 de Enero de 2014).

Catalogo Semillas Buck Trigo. 2012. Disponible en: http://www.bucksemillas.com.ar/admin/uploads/originals/Catalogo\%20Buck\%20Trigo \%202012.pdf(Verificado 10 de Enero de 2014).

Ciuffetti, L.M., R.P. Tuori \& J.M. Gaventa. 1997. A single gene encodes a selective toxin causal to the development of tan spot of wheat. Plant Cel19: 135-144.

Ciuffetti, L.M., L.J. Francl, G.M. Balance, W.W. Bockus, L. Lamari, S.W. Meinhardt \& J.B. Rasmussen. 1998. Standarization of toxin nomenclature in the Pyrenophora tritici-repentis/wheat interaction. Canadian Journal of Plant Pathology20: 421-424.

Ciuffetti, L.M., V. A. Manning, J. P. Martinez, I. Pandelova \& R. M. Andrie. 2003. Proteinaceous toxins of Pyrenophora tritici-repentis and investigation of the site-of-action of Ptr Tox A. Proceedings of the Fourth International Wheat Tan Spot and Spot Blotch Workshop. North Dakota Agricultural Experiment Station. pp 96-102.

Cox, D.J. \& R.M. Hosford. 1987. Resistant winter wheats compared at differing growth stages and leaf positions for tan spot severity. Plant Disease 71: 883-886.

Dalcero, A., A. Torres, M. Etcheverry, S. Chulze \& E. Varsavsky. 1997. Occurrence of deoxynivalenol and Fusarium graminearum in Argentinian wheat. Food Additives and Contaminants 14: 11-14.

Day, P.R. 1960. Variation in phytopathogenic fungi. Annual Review of Microbiology 14: 1-16.

de Wolf, E.D., R.J. Effertz, S. Ali \& L.J. Francl. 1998. Vistas of tan spot research. Canadian Journal of Plant Pathology 20: 349-370.

Diaz de Ackermann, M. 1987. Resistance among winter wheat to Pyrenophora tritici-repentis isolates and variability in fungal growth, color, sporulation and pathogenicity. M. Sc. Tesis. North Dakota State University. Fargo. 49 pp.

Diaz de Ackermann, M. 2010. Mancha Parda o Amarilla del Trigo. En: Seminario de Actualización. Manejo de Enfermedades de Trigo y Cebada. Serie Actividades de Difusión N618. INIA. pp 81-93.

Dirección de Mercados Agrícolas. 2014. Disponible en: http://www.minagri.gob.ar/dimeagro/indec/tn_trigo.php (Verificado 10 de Octubre de 2014).

División estadística de la FAO. 2014. Perspectivas AgropecuariasResúmenes de mercado-FAO. Disponible en 
http://faostat3.fao.org/faostat-gateway/go/to/download/Q/QC/E (Verificado 10 de Octubre de 2014).

Evans, C.K., R.M. Huger \& W.C. Siegerist. 1993. Enhaced production of Pyrenophora tritici-repentis conidial suspensions. Plant Disease 77: 981-984.

Evans, C.K., R.M. Huger \& W.C. Siegerist. 1999. Comparison of greenhouse and field testing to identify wheat resistant to tan spot. Plant Disease 83:269-273.

Fernández, P.J. \& Corró Molas A. 2001. El Pietín del Trigo Revista Forrajes \& Granos. Artículo de Divulgación.

Friesen, T.L., S. Ali, K.K. Kleim \& J.B. Rasmussen. 2005. Population genetic analysis of a global collection of Pyrenophora triticirepentis, causal agent of tan spot of wheat. Phytopathology 95: 11441150 .

Galich, M.T.V. de. 2002. Fusariosis de la espiga de Trigo. Trigo: Actualización 2002. EEA Marcos Juárez. INTA Marcos Juárez. Información para extensión $\mathrm{N}^{0} 71.6 \mathrm{pp}$.

Galich, M.T.V. de \& A. Galich. 1994. Enfermedades del trigo en el área sur de Santa Fe y Córdoba correspondientes a la subregión II Norte, Año 1993/94. EEA Marcos Juárez. INTA Marcos Juárez. Información para extensión $\mathrm{N}^{\circ} 5.7 \mathrm{pp}$.

Galich, A.N., M.T.V. de Galich, A. Legasa \& G. Musso. 1986. Estimación de pérdidas por enfermedades foliares en cultivares de trigo. Capitulo IV. Congreso Nacional de trigo. AIANBA. Pergamino, Bs. As. pp. $41-50$.

Gamba, F. M. \& L. Lamari. 1998. Mendelian inheritance of resistance to tan spot (Pyrenophora tritici-repentis) in selected genotypes of durum wheat (Triticum turgidum). Canadian Journal of Plant Pathology 20: 408-414.

Gamba, F.M., L. Lamari \& A. Brûlé- Babel. 1998. Inheritance of race-specific necrotic and chlorotic reactions induce by Pyrenophora tritici-repentis in hexaploid wheats. Canadian Journal of Plant Pathology 20: $401-407$.

Gilchrist, S.L. 1992. Resistance to Pyrenophora tritici-repentis in CIMMYT bread wheat germplasm. Proceedings of the 2 nd international tan spot workshop. Advances in tan spot research. North Dakota State University, Fargo. pp. 44-49.

Gilchrist, S.L., S. Fuentes \& M. de la Isla de Bauer. 1984. Identificación de Helminthosporium tritici-repentis (=Pyrenophora trichostoma) agente causal de un tizón de la hoja de trigo en México. Agrociencia 56: 151-162. 
Hosford, R.M. Jr. 1971. A form of Pyrenophora trichostoma pathogenic to wheat and other grasses.Phytopathology61:28-32.

Hosford, R.M. Jr. 1981. Tan Spot. En: Tan Spot of Wheat and Related Diseases. Work-shop. Ed. Hosford, R.M. Jr. North Dakota State University, Fargo. pp. 1-24.

Hosford, R.M. Jr \& R.H. Busch. 1974. Losses in wheat caused by Pyrenophora trichostoma and leptosphaeria avenaria f. $\mathrm{sp}$. triticea. Phytopathology 64: 184-187.

Hunger, R.M. \& D.A. Brown. 1987. Colony color, growth, sporulation, fungicide sensitive and pathogenicity of Pyrenophora tritici-repentis. Plant Disease 71: 907-910.

Kohli, M., Y.R. Mehta \& M. Ackermann. 1992. Spread of Tan Spot in the Southern Cone region of South America. Proceedings of the 2nd international tan spot workshop. Advances in tan spot research. North Dakota State University, Fargo. pp. 86-90.

Kohli, M., J.G. Annone \& M. T. V. Galich. 1996. Fusariosis de la espiga y su manejo. En: Las enfermedades del trigo en el Cono Sur. Curso de manejo de enfermedades de trigo. Eds. Kohli, M., Annone, J. y R. García. Buenos Aires, Pergamino.pp. 164-189.

Krupinsky, J.M. 1987. Pathogenicity on wheat of Pyrenophora tritici-repentis isolated from Bromus inermis. Phytopathology 77: 760765 .

Krupinsky, J.M. 1992. Grass host of Pyrenophora tritici-repentis. Plant Disease 76: 92-95.

Lamari L. \& C.C. Bernier. 1989a. Evaluation of wheat lines and cultivars to tan spot (Pyrenophora tritici-repentis) based on type lesions. Canadian Journal of Plant Pathology 11: 49-56.

Lamari L. \& C.C. Bernier.1989b. Virulence of isolates of Pyrenophora tritici-repentis on 11 wheat cultivars and cytology of the differential host reactions. Canadian Journal of Plant Pathology 11: 284290 .

Lamari L. \& C.C. Bernier. 1991. Genetics of tan necrosis and extensive chlorosis in tan spot of wheat caused by Pyrenophora triticirepentis. Phytopathology 81: 1092-1095.

Lamari L. \& J. Gilbert. 1998. Toward a coherent model of hostpathogen interactions in tan spot of wheat: An epilogue to the Third International Workshop on Tan Spot of wheat. Canadian Journal of Plant Pathology 20: 440-443. 
Lamari, L., R. Sayoud, M. Boulif \& C.C. Bernier. 1995. Identification a new race in Pyrenophora tritici-repentis: implications for the current pathotype classification system. Canadian Journal of Plant Pathology17: 312-318.

Lamari, L., J. Gilbert \& A. Tekauz. 1998. Race differentiation in Pyrenophora tritici-repentis and survey of physiologic variation in western Canada. Canadian Journal of Plant Pathology 20: 396-400.

Lamari, L., S.E. Strelkov, A. Yahyaoui, J. Orabi \& R.B. Smith. 2003. The identification of two new races of Pyrenophora triticirepentisfrom the host center of diversity confirms a one-to-one relationship in tan spot of wheat. Phytopathology 93: 391-396.

Lamari, L., B.D. Mc Callum \& R.M. de Pauw. 2005. Forensic pathology of Canadian bread wheat: The case of Tan Spot. Phytopathology 95: 144-152.

Leisová, L., A. Hanzalová \& L. Kucera. 2008. Genetic diversity of Pyrenophora triticirepentis isolates as revealed by AFLP analysis. Journal of Plant Pathology 90: 223-245.

Lepoint, P., M.E. Renard, A. Legrève, E. Duveiller \& H. Maraite. 2010. Genetic diversity of the mating type and toxin production genes in Pyrenophora tritici-repentis. Phytopathology 100: 474-483.

Luz da W.C. \& R.M. Jr. Hosford. 1980. Twelve Pyrenophora trichostoma races for virulence to wheat in the central plains of North America. Phytopathology 70: 1193-1196.

Manning, V. A., I. Pandelova, \& L. M. Ciuffetti. 2002. A race for a novel host-selective toxin. (Abstr.) Phytopathology 92: S51.

Martínez, J.P., S.A. Ottum, S. Ali, L.J. Francl \& L.M. Ciuffetti. 2001. Characterization of the ToxB gene from Pyrenophora triticirepentis. Molecular Plant Microbe Interactions 14: 675-677.

Martínez, J.P., N.W. Oesch \& L.M. Ciuffetti. 2004. Characterization of the multiple- copy host-selective toxin gene, ToxB, in pathogenic and nonpathogenic isolates of Pyrenophora triticirepentis. Molecular Plant Microbe Interactions 17: 467-474.

Mehta Y.R. \& C.A Gaudencio. 1991. The effects of tillage practices and crop rotation on the epidemiology of some major wheat diseases. En: Wheat for the Nontraditional Warm Areas. Ed. D.E Saunders. Mexico. pp. 266-283.

Mehta, Y.R., A. Mehta \& C.R. Riede. 2004. Molecular and pathogenic variability of Pyrenophora tritici-repentis isolates causing tan spot of wheat in the state of Paraná, Brazil. Summa Phytopathologica 30: $436-444$. 
Meinhardt, S., S. Ali, H. Ling \& L. Francl. 2003. A new race of Pyrenophora tritici-repentis that produces a putative host-selective toxin. Proceedings of the Fourth International Wheat Tan Spot and Spot Blotch Workshop. North Dakota Agricultural Experiment Station. pp 117-121.

Mihtra, M.A. 1934. Leaf spot disease of wheat caused by Helminthosporium tritici-repentis Died. Indian Journal of Agricultural Scince 4: 692-700.

Misra A.P. \& R.A. Singh. 1972. Pathogenic differences among three isolates of Helminthosporium tritici-repentis and the performance of wheat varieties against them. Indian Phytopathology 25: 350-353.

Moreno, M.V. 2007. Caracterización cultural, patogénica, genética y bioquímico-molecular de Pyrenophora tritici-repentis en Argentina. Doctoral Thesis. Facultad de Ciencias Naturales y Museo, Universidad Nacional de La Plata, La Plata, Argentina. 188 pp.

Moreno M.V. \& A.E. Perelló. 2010. Occurrence of Pyrenophora tritici-repentis causing tan spot in Argentina. En: Management of Fungal Pathogens: Current Trends and Progress. Eds A. Arya \& A. Perelló. Buenos Aires, La Plata. pp. 275-290.

Moreno, M.V., S.A. Stenglein, A.E. Perelló \& Balatti P.A. 2008. Pathogenic and genetic diversity of isolates of Pyrenophora triticirepentis causing tan spot of wheat in Argentina. European Journal of Plant Pathology 122: 239-252.

Moreno, M.V., A.M. Arambarri \& A. Perelló. 2011. Diversity of Pyrenophora tritici-repentis isolates from the Argentinian wheat growing area: morphocultural and pathogenic analysis. International Research Journal of Agricultural Science and Soil Science.1: 365-382.

Moreno, M.V., S.A. Stenglein \& A.E. Perelló. 2012. Pyrenophora tritici-repentis, the causal agent of tan spot: a review of intraspecific genetic diversity. En: Genetic Diversity / Book 2. Ed. Maahmut Caliskan (INTECH publisher). pp 297-330.

Moreno, M.V., S.A. Stenglein \& A.E. Perelló. 2014. Distribution of races and Tox genes in Pyrenophora tritici-repentis isolates from wheat in Argentina. Tropical Plant Pathology: En prensa

Murray, M.G. \& W.F. Thompson. 1980. Rapid isolation of high molecular weight plant DNA. Nucleic Acids Research 8: 4321-4325.

Oliver, R.E., X. Cai, R.C. Wang, S.S. Xu, T.L. Friesen. 2008. Resistance to tan spot and Stagonospora nodorum blotch in wheat-alien species derivatives. Plant Disease 92:150-157. 
Pandelova, I. \& Ciuffetti, L.M. 2005. A proteomics-based approach for identification of the Tox D gen. Fungal Genet. Newsl. 52 (Suppl.): 133.

Perelló, A. 2007. Enfermedades nuevas y emergentes en trigo. Manejo de bajo impacto ambiental con microorganismos antagonistas. Jornada de actualización en enfermedades de trigo. Libro de Resúmenes. Buenos Aires, Lavallol. pp 30-34.

Perelló, A.E., M. Yannicari, A.M. Castro \& M.V. Moreno. 2012. Genetic analysis and comparative virulence of isolates of Pyrenophora tritici-repentis from wheat in Argentina. African Journal of Microbiology Research 6: 5558-5567.

Pereyra, S. \& M. Díaz. 2011. Herramientas para el Manejo de Enfermedades en Trigo. En: Jornada de Divulgación. Aportes a la zafra de cultivos de invierno. La Estanzuela, INIA. Serie Actividades de Difusión no. 646. Pp. 23-31.

Pereyra, S. \& S. Germán. 2012. Manejo de enfermedades en trigo y cebada en un contexto de márgenes reducidos. En: Jornada Cultivos de Invierno. La Estanzuela, INIA. Serie Actividades de Difusión no. 677. pp $15-25$.

Perspectivas alimentarias FAO 2014. Informe "Perspectivas alimentarias" (Resúmenes de mercado) Mayo 2014 FAO. Disponible en http://www.fao.org/3/a-i3915s.pdf. (Verificado 10 de Octubre de 2014).

Pujol Vieira dos Santos, A.M., A.T. Santos Matsumura \& S.T. Van der Sand. 2002. Intraspecific genetic diversity of Drechslera triticirepentis as detected by a random amplified polymorphic DNA analysis. Genetic and Molecular Biology 25: 243-250.

Proyecto Regional Trigo: principales logros y avances / IICA PROCISUR. 2010. Montevideo, Uruguay. Disponible en: http://www.procisur.org.uy. (Verificado 15 de Enero de 2014).

Rajaram, S. 2001. Mejoramiento Internacional de Trigo. Palabras de apertura. En: Estrategias y Metodologías utilizadas en el mejoramiento de trigo. Seminario Internacional. Eds. Kohli, M. M., Diaz, M. y Castro, M. Uruguay, La Estanzuela. pp XI-XII.

Raymond P.J. \& W.W. Bockus. 1982. An in-vitro technique for profuse sporulation of Drechslera tritici-repentis. Phytopathology 72: S934.

Red de Ensayos Comparativos de Variedades de Trigo. Campaña 2012/13. Localidades: Marcos Juárez, Pergamino y Pla. Fuente: INASE. Disponible en: http://www.inase.gov.ar/index.php?option=com_content\&view=article\&i 
$\mathrm{d}=340 \% 3$ Acampana $-20122013 \&$ catid $=45 \% 3$ Aensayos - detrigo\&Itemid=91 (Verificado 10 de Enero de 2014).

Rees L. G. \& G. J. Platz. 1979. The occurrence and control of yellow spot of wheat in North-Eastern Australia. Australian Journal of Agricultural Research 19: 369-372.

Rees L. G. \& G. J. Platz. 1980. The epidemiology of yellow leaf spot of wheat in Southern Queensland. Australian Journal of Agricultural Research 31: 259-267.

Rees L. G. \& G. J. Platz. 1983. Effect of yellow spot on wheat: comparison of epidemics at different stages of crop development. Australian Journal of Agricultural Research 34: 39-46.

Rees L. G. \& G. J. Platz. 1990. Sources of resistance to Pyrenophora tritici-repentis in bread wheats. Euphytica 45: 59-69.

Rees L. G. \& G. J. Platz. 1992. Tan Spot and its control-Some Australian experiences. Proceedings of the 2nd international tan spot workshop. Advances in tan spot research. North Dakota State University, Fargo. pp. 1-9.

Rees, L.G., R.J. Mayer \& G.J. Platz. 1981. Yield losses in wheat from yellow spot: A disease-loss relationship derived from single tillers. Australian Journal of Agricultural Research 32: 851-859.

Rees, L.G., G.J. Platz \& R.J. Mayer. 1982. Yield losses in wheat from yellow spot: comparison of estimates derived from single tillers an plots. Australian Journal of Agricultural Research 33: 899-908.

Rees, L.G., G.J. Platz \& R.J. Mayer. 1988. Susceptibility of Australian wheats to Pyrenophora tritici-repentis. Australian Journal of Agricultural Research 39:141-151.

Reis, E.M. \& M.A. Carmona. 1996. Mancha Amarilla de la hoja de trigo. Ed. Bayer. 14 pp.

Resultados Experimentales de la Evaluación de Cultivares de Trigo, Cebada, Colza, Triticale y Trigo doble propósito de los tres últimos años. Período 2008-2009-2010. Covenio INIA-INASE. Disponible en: http://www.inia.org.uy/convenio_inase_inia/resultados/index_00.htm (Verificado 10 de Enero de 2014).

Riede, C.R., L.J. Francl, J.G. Jordahl \& S.W. Meinhardt. 1996. Additional sources of resistance to tan spot of wheat. Crop Science 36: 771-777.

Sah, D.N. \& H. Ferhmann. (1992). Virulence patterns of geographically differing isolates of Pyrenophora tritici-repentis and sources of resistance in wheat. Plant Disease 76: 712-716. 
Schilder, A.M.C. \& G.C. Bergstrom.1990. Variation in virulence within the population of Pyrenophora tritici-repentis in New York. Phytopathology 80: 84-90.

Schilder, A.M.C. \& G.C. Bergstrom. 1994. Infection of wheat seed by Pyrenophora tritici-repentis. Canadian Journal of Botany 72: 510519.

Sharp, E.L., B.K. Sally \& F.H. Mc Neal. 1976. Effect of Pyrenophora wheat leaf blight on the thousand kernel weight of 30 spring wheat cultivars. Plant Disease 60: 135-138.

Simón, M.R., A.E. Perelló, C.A. Cordo, \& P.C. Struik. 2002. Influence of Septoria tritici on Yield, Yield Components, and Test Weight of Wheat under Two Nitrogen Fertilization Conditions. Crop Science 42: 1974-1981.

Singh. P.K. \& G.R. Hughes. 2006. Genetic similarity among isolates of Pyrenophora tritici-repentis, causal agent of tan spot of wheat. Journal of Phytopathology 154:178-184.

Singh, P.K., M. Mergoum, S. Ali, T.B. Adhikari, E.M. Elias, J.A. Anderson, K.D. Glover \& W.A. Berzonsky. 2006. Evaluation of elite wheat germplasm for resistance to tan spot. Plant Disease 90: 13201325 .

Singh, P.K., R. P. Singh, E. Duveiller, M. Mergoum, T.B. Adhikari \& E.M. Elias. 2010. Genetics of wheat-Pyrenophora tritici-repentis interactions. Euphytica 171:1-13.

Sistema Integrado de Información Agropecuaria. 2014. Disponible en: http://dev.siia.gov.ar/series. (Verificado 10 de Octubre de 2014).

Stakman, E.C. 1938. The problem of specialization and variation in pathogenic fungi. Genetic 18: 372-389.

Strelkov, S.E. \& L. Lamari. 2003. Host-parasite interaction in tan spot Pyrenophora tritici-repentis of wheat.Canadian Journal of Plant Pathology 25: 339-349.

Strelkov, S.E., L. Lamari \& G.M. Balance. 1999. Characterization of a host-specific protein toxin (PtrTox B) from Pyrenohora triticirepentis. Molecular Plant-Microbe Interactions 12: 728-732.

Strelkov, S.E., L. Lamari, R. Sayoud \& R.B. Smith. 2002. Comparative virulence of chlorosis-inducing races of Pyrenophora tritici-repentis. Canadian Journal of PlantPathology 24: 29-35.

Strelkov, S.E., R.F. Kowatsch, G.M. Balance \& L. Lamari. 2006. Characterization of the Tox B gene from North America and Canadian isolates of Pyrenophora tritici-repentis. Physiological and Molecular Plant Pathology67: 164-170. 
Tadesse, W., S.L.K. Hsam, G. Wenzel \& F.J. Zeller. 2006a. Identification and monosomic analysis of tan spot resistance genes in synthetic wheat lines (Triticum turgidum L. x Aegilops tauschii Coss.). Crop Science 46: 1212-1217.

Tadesse, W., S.L.K. Hsam \& F.J. Zeller 2006b. Evaluation of common wheat (Triticum aestivum L.) cultivars for tan spot resistance and chromosomal location of a resistance gene in cultivar 'Salamouni'. Plant Breeding 125:318-322.

Tadesse, W., H. J. Reents, S. L. K. Hsam \& F. J. Zeller. 2010. Relationship of seedling and adult plant resistance and evaluation of wheat germplasm against tan spot (Pyrenophora tritici-repentis). Genet. Resour. Crop. Evol. (2011) 58:339-346.

Tombetta, E.E., M.B. Cuniberti \& J.A. Viale. 1994. Influencia de Fusarium Graminearum sobre la calidad comercial e industrial del trigo pan. Actas del III Congreso Nacional de trigo y Primer Simposio Nacional de Cereales de siembra otoño-invernal. Buenos Aires, Bahía Blanca. pp. 235-236.

Vanderplank, J.E. 1963. Disease resistance in plants. Ed. Academic Press. Inc. Orlando, Florida. 206 pp.

Vanderplank, J.E. 1978. Genetic and molecular basis of plant pathogenesis. Ed. Springer-Verlag. Berlin, Germany. 167 pp.

Wagner, D.B., G.R Furnier, M.A. Saghay-Maroof, S.M. Williams, B.P. Dancik \& R.W. Allard. 1987. Chloroplast DNA polymorphisms in lodgepole and jack pines and their hybrids. Proceedings of the National Academy of Science USA 84: 2097-2100

Wiese, M.V. 1987. Compendium of wheat diseases. Ed. The American phytopatological Society. St. Paul. 106 pp.

Wright, K.H. \& J.C. Sutton. 1990. Inoculum of Pyrenophora tritici-repentis in relations to epidemics of tan spot of winter wheat in Ontario. Canadian Journal of Plant Pathology 12: 149-157.

Young, R.A. \& J.D. Kelly. 1997. RAPD markers linked to three major anthracnose resistance genes in common bean. Crop Science 37: 940-946.

Zadoks, J.C., Chang T.T. \& Konzak C.F. 1974. "A Decimal Code for the Growth Stages of Cereals". Weed Research 14: 415-421.

Zhang X. \& Y. Jin. 1998. Sensitivity of Ptr ToxA and tan spot infection responses in Aegilops/Triticum complex. Canadian Journal of Plant Pathology 20: 415-418.

Zhang, H., L.J. Francl, J.G. Jordahl \& S.W. Meinhardt. 1997. Structural and physical properties of a necrosis-inducing toxin from Pyrenophora tritici-repentis. Phytopathology 87: 154-160. 
Zillinsky, F.J. 1984. Guía para la identificación de enfermedades de cereales de grano pequeño. Ed. Centro Internacional de Mejoramiento de Maíz y Trigo, CIMMYT. El Batán, México. 142 pp. 


\section{APENDICE}

Tabla 6.1.1. Medias de severidad de tres aislados de $D$. tritici-repentis en un ensayo de trigo, en 31 cultivares al estado de plántula.

\begin{tabular}{|c|c|}
\hline Aislado & Severidad promedio \\
\hline 1 & $17,25 \mathrm{a}$ \\
\hline 2 & $18,63 \mathrm{~b}$ \\
\hline 3 & $20,60 \mathrm{c}$ \\
\hline
\end{tabular}

Referencias: Aislado 1 = cepa LH; Aislado 2 = cepa 25M035; Aislado 3 = cepa G327. Medias seguidas por la misma letra no difieren estadísticamente $(\mathrm{P}=0,05$, LSD test). LSD aislado $=0,90$

Tabla 6.1.2. Medias del tipo de reacción de tres aislados de $D$. tritici-repentis en un ensayo de trigo, en 31 cultivares al estado de plántula.

\begin{tabular}{|c|c|}
\hline Aislado & Tipo de reacción \\
\hline 1 & $1,26 \mathrm{a}$ \\
\hline 2 & $1,37 \mathrm{~b}$ \\
\hline 3 & $1,72 \mathrm{c}$ \\
\hline
\end{tabular}

Referencias: Aislado 1 = cepa LH; Aislado 2 = cepa 25M035; Aislado 3 = cepa G327. Medias seguidas por la misma letra no difieren estadísticamente $(\mathrm{P}=0,05$, LSD test). LSD aislado $=0,09$

Tabla 6.1.3. Medias de severidad de tres aislados de $D$. tritici-repentis en un ensayo de trigo en dos localidades y 31 cultivares de trigo, evaluadas en el estadio EC 37.

\begin{tabular}{|c|c|}
\hline Aislado & Severidad promedio \\
\hline 1 & $1,66 \mathrm{a}$ \\
\hline 2 & $1,54 \mathrm{ab}$ \\
\hline 3 & $1,39 \mathrm{bc}$ \\
\hline
\end{tabular}

Referencias: Aislado 1 = cepa LH; Aislado 2 = cepa 25M035; Aislado 3 = cepa G327. Medias seguidas por la misma letra no difieren estadísticamente $(\mathrm{P}=0,05$, LSD test). $\mathrm{LSD}$ aislado $=0,22$ 
Tabla 6.1.4. Medias de severidad de dos localidades en un ensayo de trigo inoculado con tres aislados de $D$. tritici-repentis, en 31 cultivares, evaluadas en el estadio EC 37.

\begin{tabular}{|l|c|}
\hline \multicolumn{1}{|c|}{ Localidad } & Severidad promedio \\
\hline Los Hornos & $1,38 \mathrm{a}$ \\
\hline Pergamino & $1,68 \mathrm{a}$ \\
\hline
\end{tabular}

Medias seguidas por la misma letra no difieren estadísticamente $(\mathrm{P}=0,05, \mathrm{LSD}$ test $)$. LSD localidad $=$ 2,88

Tabla 6.1.5. Medias de severidad de tres aislados de $D$. tritici-repentis en un ensayo de trigo en dos localidades y 31 cultivares de trigo, evaluadas en el estadio EC 75.

\begin{tabular}{|c|c|}
\hline Aislado & Severidad promedio \\
\hline 1 & $32,00 \mathrm{a}$ \\
\hline 2 & $35,95 \mathrm{a}$ \\
\hline 3 & $36,32 \mathrm{a}$ \\
\hline
\end{tabular}

Referencias: Aislado 1 = cepa LH; Aislado 2 = cepa 25M035; Aislado 3 = cepa G327. Medias seguidas por la misma letra no difieren estadísticamente $(\mathrm{P}=0,05$, LSD test). $\mathrm{LSD}$ aislado $=4,96$

Tabla 6.1.6. Medias de severidad de dos localidades en un ensayo de trigo inoculado con tres aislados de $D$. tritici-repentis, en 31 cultivares, evaluadas en el estadio EC 75.

\begin{tabular}{|l|c|}
\hline \multicolumn{1}{|c|}{ Localidad } & Severidad promedio \\
\hline Los Hornos & $30,18 \mathrm{a}$ \\
\hline Pergamino & $39,30 \mathrm{a}$ \\
\hline
\end{tabular}

Medias seguidas por la misma letra no difieren estadísticamente $(\mathrm{P}=0,05, \mathrm{LSD}$ test $)$. LSD localidad $=$ 16,6 
Tabla 6.1.7. Medias de severidad de tres aislados de $D$. tritici-repentis en un ensayo de trigo en dos localidades y 31 cultivares de trigo, evaluadas en el estadio EC 82.

\begin{tabular}{|c|c|}
\hline Aislado & Severidad promedio \\
\hline 1 & $57,56 \mathrm{a}$ \\
\hline 2 & $60,49 \mathrm{~b}$ \\
\hline 3 & $62,43 \mathrm{c}$ \\
\hline
\end{tabular}

Referencias: Aislado 1 = cepa LH; Aislado 2 = cepa 25M035; Aislado 3 = cepa G327. Medias seguidas por la misma letra no difieren estadísticamente $(\mathrm{P}=0,05$, LSD test). $\mathrm{LSD}$ aislado $=1,84$

Tabla 6.1.8. Medias de severidad de dos localidades en un ensayo de trigo inoculado con tres aislados de D. tritici-repentis, en 31 cultivares, evaluadas en el estadio EC 82.

\begin{tabular}{|l|c|}
\hline \multicolumn{1}{|c|}{ Localidad } & Severidad promedio \\
\hline Los Hornos & $46,95 \mathrm{a}$ \\
\hline Pergamino & $73,36 \mathrm{~b}$ \\
\hline
\end{tabular}

Medias seguidas por la misma letra no difieren estadísticamente $(\mathrm{P}=0,05, \mathrm{LSD}$ test $)$. LSD localidad $=$ 13,1

Tabla 6.1.9. Medias del tipo de reacción de tres aislados de $D$. tritici-repentis en un ensayo de trigo en dos localidades y 31 cultivares de trigo, evaluadas en el estadio EC 37.

\begin{tabular}{|c|c|}
\hline Aislado & Tipo de reacción \\
\hline 1 & $0,81 \mathrm{a}$ \\
\hline 2 & $0,77 \mathrm{a}$ \\
\hline 3 & $0,71 \mathrm{a}$ \\
\hline
\end{tabular}

Referencias: Aislado 1 = cepa LH; Aislado 2 = cepa 25M035; Aislado 3 = cepa G327. Medias seguidas por la misma letra no difieren estadísticamente $(\mathrm{P}=0,05$, LSD test). LSD aislado $=0,09$ 
Tabla 6.1.10. Medias del tipo de reacción de dos localidades en un ensayo de trigo inoculado con tres aislados de $D$. tritici-repentis, en 31 cultivares, evaluadas en el estadio EC 37.

\begin{tabular}{|l|c|}
\hline \multicolumn{1}{|c|}{ Localidad } & Tipo de reacción \\
\hline Los Hornos & $0,66 \mathrm{a}$ \\
\hline Pergamino & $0,87 \mathrm{~b}$ \\
\hline
\end{tabular}

Medias seguidas por la misma letra no difieren estadísticamente $(\mathrm{P}=0,05, \mathrm{LSD}$ test $)$. LSD localidad $=$ 0,10

Tabla 6.1.11. Medias del tipo de reacción de tres aislados de $D$. tritici-repentis en un ensayo de trigo en dos localidades y 31 cultivares de trigo, evaluadas en el estadio EC 75.

\begin{tabular}{|c|c|}
\hline Aislado & Tipo de reacción \\
\hline 1 & $3,04 \mathrm{a}$ \\
\hline 2 & $3,17 \mathrm{a}$ \\
\hline 3 & $3,12 \mathrm{a}$ \\
\hline
\end{tabular}

Referencias: Aislado 1 = cepa LH; Aislado 2 = cepa 25M035; Aislado 3 = cepa G327. Medias seguidas por la misma letra no difieren estadísticamente $(\mathrm{P}=0,05$, LSD test). $\mathrm{LSD}$ aislado $=0,21$

Tabla 6.1.12. Medias del tipo de reacción de dos localidades en un ensayo de trigo inoculado con tres aislados de D. tritici-repentis, en 31 cultivares, evaluadas en el estadio EC 75.

\begin{tabular}{|l|c|}
\hline \multicolumn{1}{|c|}{ Localidad } & Tipo de reacción \\
\hline Los Hornos & $2,81 \mathrm{a}$ \\
\hline Pergamino & $3,42 \mathrm{a}$ \\
\hline
\end{tabular}

Medias seguidas por la misma letra no difieren estadísticamente $(\mathrm{P}=0,05, \mathrm{LSD}$ test $) . \mathrm{LSD}$ localidad $=$ 0,86 
Tabla 6.1.13. Medias del tipo de reacción de tres aislados de $D$. tritici-repentis en un ensayo de trigo en dos localidades y 31 cultivares de trigo, evaluadas en el estadio EC 82.

\begin{tabular}{|c|c|}
\hline Aislado & Tipo de reacción \\
\hline 1 & $4,04 \mathrm{a}$ \\
\hline 2 & $4,14 \mathrm{a}$ \\
\hline 3 & $4,15 \mathrm{a}$ \\
\hline
\end{tabular}

Referencias: Aislado 1 = cepa LH; Aislado 2 = cepa 25M035; Aislado 3 = cepa G327. Medias seguidas por la misma letra no difieren estadísticamente $(\mathrm{P}=0,05$, LSD test). LSD aislado $=0,12$

Tabla 6.1.14. Medias del tipo de reacción de dos localidades en un ensayo de trigo inoculado con tres aislados de $D$. tritici-repentis, en 31 cultivares, evaluadas en el estadio EC 82.

\begin{tabular}{|l|c|}
\hline \multicolumn{1}{|c|}{ Localidad } & Tipo de reacción \\
\hline Los Hornos & $3,77 \mathrm{a}$ \\
\hline Pergamino & $4,46 \mathrm{~b}$ \\
\hline
\end{tabular}

Medias seguidas por la misma letra no difieren estadísticamente $(\mathrm{P}=0,05, \mathrm{LSD}$ test $)$. LSD localidad $=$ 0,65

Tabla 6.1.15. Medias del ABCPE de tres aislados de $D$. tritici-repentis en un ensayo de trigo en dos localidades y 31 cultivares de trigo

\begin{tabular}{|c|c|}
\hline Aislado & Tipo de reacción \\
\hline 1 & $925,7 \mathrm{a}$ \\
\hline 2 & $1012,1 \mathrm{ab}$ \\
\hline 3 & $1029,2 \mathrm{bc}$ \\
\hline
\end{tabular}

Referencias: Aislado 1 = cepa LH; Aislado 2 = cepa 25M035; Aislado 3 = cepa G327. Medias seguidas por la misma letra no difieren estadísticamente $(\mathrm{P}=0,05$, LSD test). $\mathrm{LSD}$ aislado $=86,6$ 
Tabla 6.1.16. Medias del ABCPE de dos localidades en un ensayo de trigo inoculado con tres aislados de D. tritici-repentis, en 31 cultivares.

\begin{tabular}{|l|c|}
\hline Localidad & Tipo de reacción \\
\hline Los Hornos & $789,3 \mathrm{a}$ \\
\hline Pergamino & $1188,7 \mathrm{a}$ \\
\hline
\end{tabular}

Medias seguidas por la misma letra no difieren estadísticamente $(\mathrm{P}=0,05, \mathrm{LSD}$ test $) . \mathrm{LSD}$ localidad $=$ 435,2 